\title{
Nondestructive evaluation of FRP composite members using infrared thermography
}

\author{
Gurudutt Sundara Ram Bangalore \\ West Virginia University
}

Follow this and additional works at: https://researchrepository.wvu.edu/etd

\section{Recommended Citation}

Bangalore, Gurudutt Sundara Ram, "Nondestructive evaluation of FRP composite members using infrared thermography" (2002). Graduate Theses, Dissertations, and Problem Reports. 1218.

https://researchrepository.wvu.edu/etd/1218

This Thesis is protected by copyright and/or related rights. It has been brought to you by the The Research Repository @ WVU with permission from the rights-holder(s). You are free to use this Thesis in any way that is permitted by the copyright and related rights legislation that applies to your use. For other uses you must obtain permission from the rights-holder(s) directly, unless additional rights are indicated by a Creative Commons license in the record and/ or on the work itself. This Thesis has been accepted for inclusion in WVU Graduate Theses, Dissertations, and Problem Reports collection by an authorized administrator of The Research Repository @ WVU. For more information, please contact researchrepository@mail.wvu.edu. 


\title{
NONDESTRUCTIVE EVALUATION OF FRP COMPOSITE MEMBERS USING INFRARED THERMOGRAPHY
}

\author{
By \\ Gurudutt S. Bangalore
}

\begin{abstract}
A THESIS
Submitted to

the College of Engineering and Mineral Resources

West Virginia University
\end{abstract}

In partial fulfillment of the requirements for the degree of

Master of Science in Civil Engineering
Udaya B. Halabe, Ph.D., P.E., Chair
Hota V. S. GangaRao, Ph.D., P.E.
Powsiri Klinkhachorn, Ph.D.
P. V. Vijay, Ph.D.

Department of Civil and Environmental Engineering

Morgantown, West Virginia

2002

Keywords: 2D FFT, Composite, Defects, Delaminations, FRP, Image processing, Image subtraction, Infrared thermography, Wrap 


\section{ABSTRACT \\ NONDESTRUCTIVE EVALUATION OF FRP COMPOSITE MEMBERS USING INFRARED THERMOGRAPHY \\ Gurudutt S. Bangalore}

The objective of this research is to establish infrared thermography as an effective tool for nondestructive evaluation of structural members made of fiber reinforced polymer (FRP) composite materials. The applicability of this method for the detection of subsurface anomalies such as voids, cracks, debonding, and delaminations in concrete bridge decks and pavements and in some configurations of FRP decks has been studied earlier by other researchers. These earlier studies have yielded reasonably satisfactory results though further refinement of the methodology and improvements in the image processing techniques were recommended.

To enhance the effectiveness of the infrared thermography technique, it is important to improve and quantify the contrast in the thermal images. This enables the thermographer to arrive at better conclusions including quantitative estimation of the defect depth. Different methods for analysis of digital infrared images suggested by various researchers were reviewed in this study and recommendations were made for evaluating their applicability for mass-produced FRP composite structural components.

Infrared thermography tests were conducted in the laboratory on various FRP specimens with built-in delaminations. The results showed that the infrared technique can be developed for long term monitoring of FRP structural components. As a part of this research, a field trip was also conducted for detecting the presence of delaminations/debondings in FRP wrapped reinforced concrete bridge columns using infrared thermography. In the field tests, it was possible to detect the locations of delaminations/debondings. These results were in agreement with the tapping test results. 


\section{ACKNOWLEDGEMENTS}

I would like to express my deep sense of gratitude to my adviser Dr. Udaya B. Halabe for all the help that I received from him during my Master of Science in Civil Engineering (M.S.C.E.) degree program at West Virginia University, Morgantown, WV. I also would like

to thank Dr. Hota V. S. GangaRao for his kind support and guidance during my research and studies. I extend my thanks to Dr. Powsiri Klinkhachorn and Dr. P. V. Vijay for serving on my thesis committee and providing valuable help in the completion of this research.

I am also grateful to all the staff members of the Constructed Facilities Center (CFC) at West Virginia University for providing timely help during the research. I would also like to thank CFC for funding this research as a part of a research grant from the Federal Highway Administration (FHWA). I also would like to express my appreciation for the help received from Bedford Reinforced Plastics, Inc., PA and Poly-Carb, Inc., OH in the preparation of specimens that were required for the research.

I would like to thank my parents and all my family members for their constant encouragement and support. Last, but not the least, I would like to thank all my friends for their help directly or indirectly in my research and during the last two years of my stay at Morgantown. 


\section{TABLE OF CONTENTS}

$\underline{\text { Description }}$

Page No.

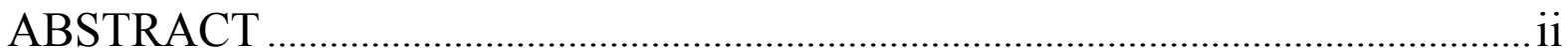

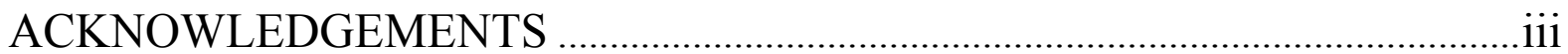

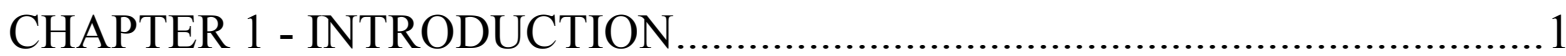

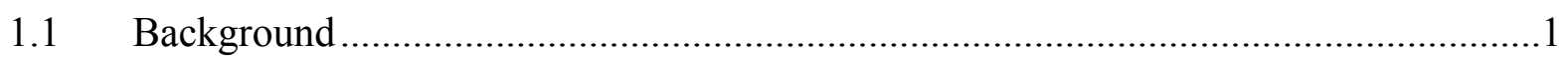

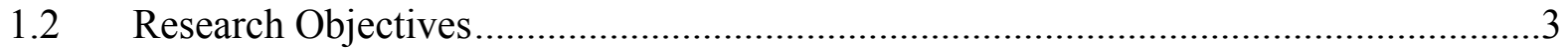

$1.3 \quad$ Scope

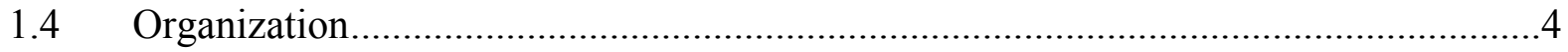

CHAPTER 2 - INFRARED THERMOGRAPHY BASICS .............................5

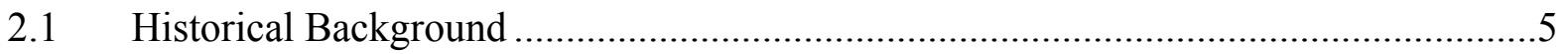

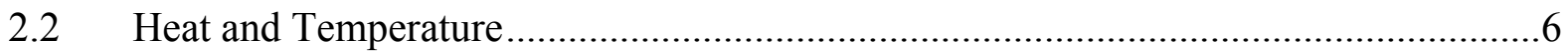

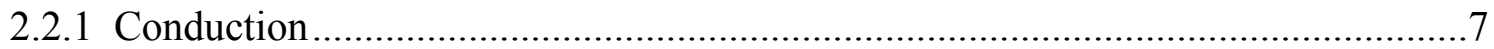

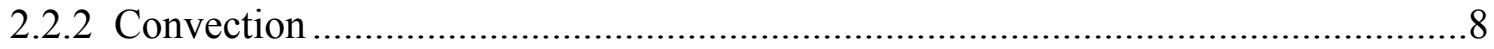

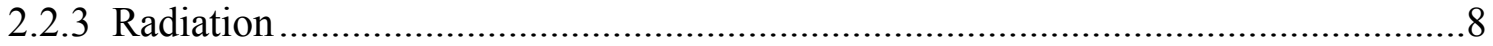

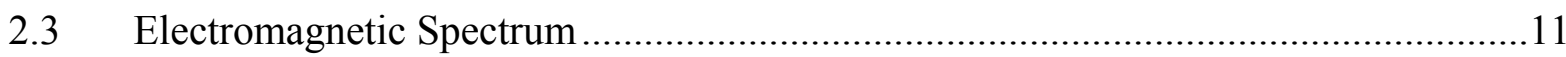

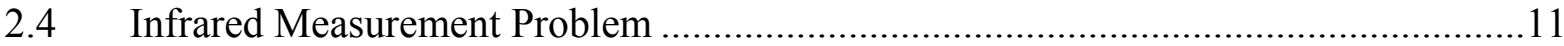

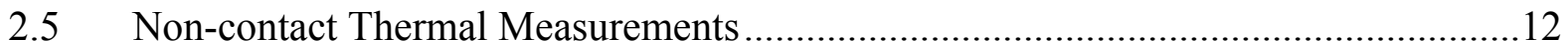

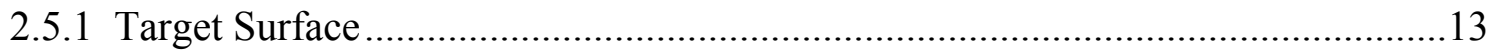

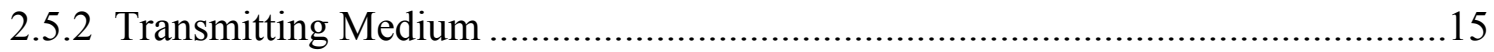

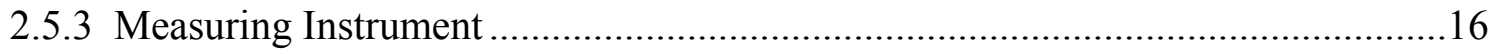

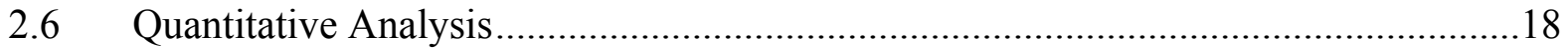


2.7 Infrared Non-Destructive Testing (IRNDT) (Maldague 2000) …………...................19

2.7.1 Passive Thermography ...............................................................................19

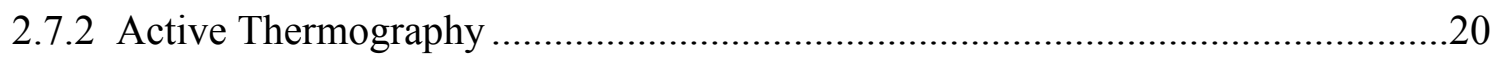

2.7.2.1 Pulsed Thermography …………………………..........................................20

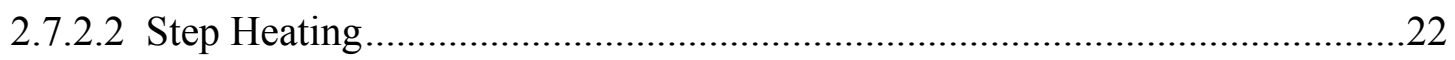

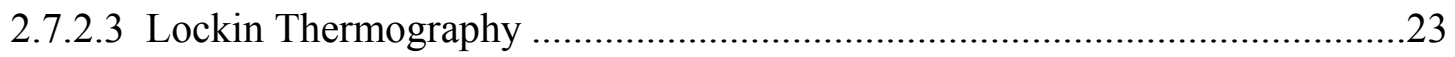

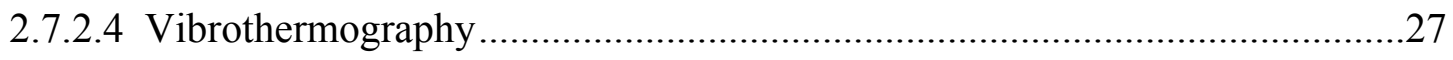

\section{CHAPTER 3 - LITERATURE REVIEW ON INFRARED}

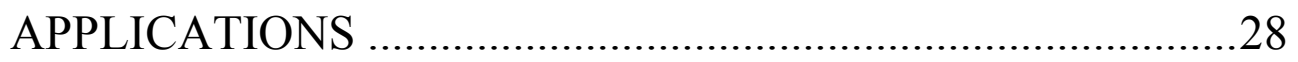

3.1 Detection of Subsurface Anomalies in Composite Bridge Decks

Using Infrared Thermography (Alqennah 2000) .....................................................28

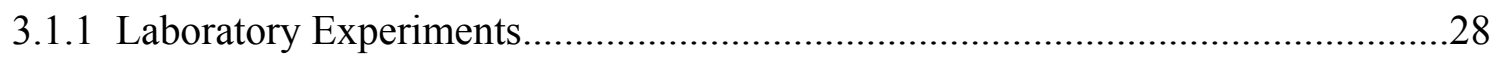

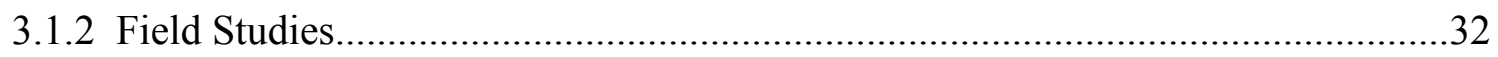

3.2 NDE of Composite Seismic Retrofits to Bridges (Johnson et al. 1999) ........................34

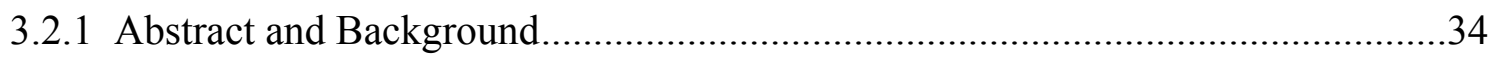

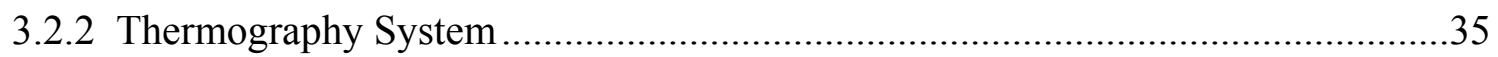

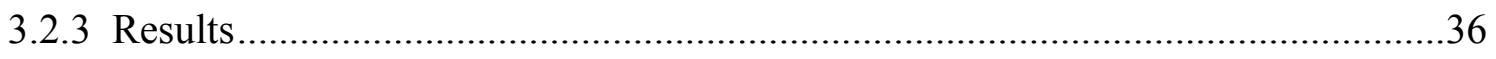

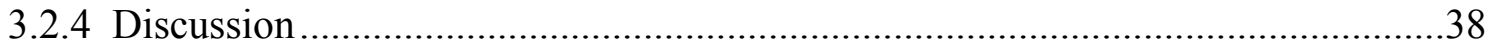

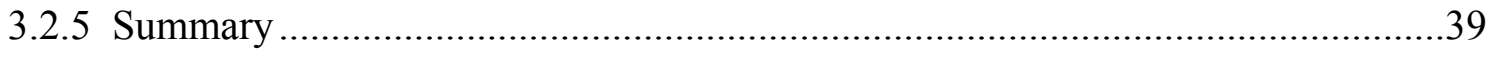

3.3 Automated Thermographic Defect Recognition and Measurement (Shepard et al. $1999)$

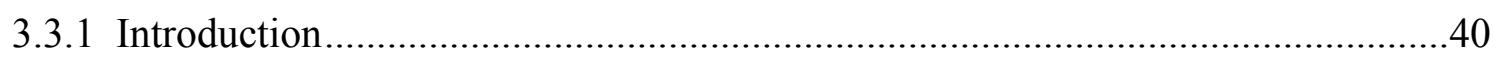

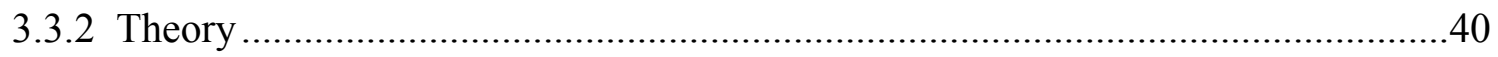

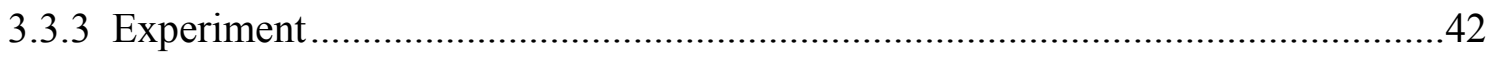


3.3.4 Discussion

3.3.5 Conclusion

3.4 Temporal Treatment of a Thermal Response for Defect Depth Estimation

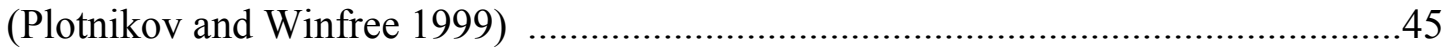

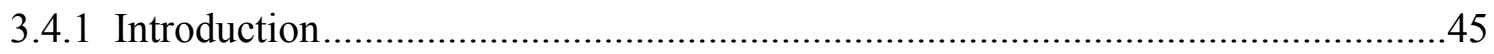

3.4.2 Processing of the Thermal Response in Time Domain.......................................45

3.4.3 Comparison of Algorithms (Computational Approach) .................................46

3.4.4 Comparison of Algorithms (Experimental Approach) ....................................51

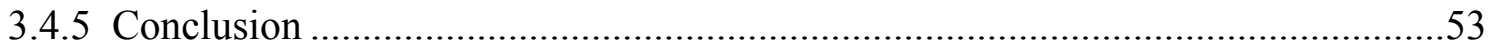

3.5 Enhanced Spatial and Depth Resolution of Pulsed Thermographic Images

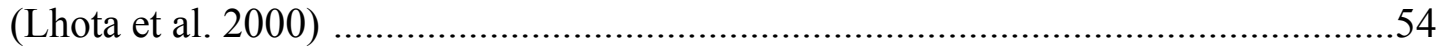

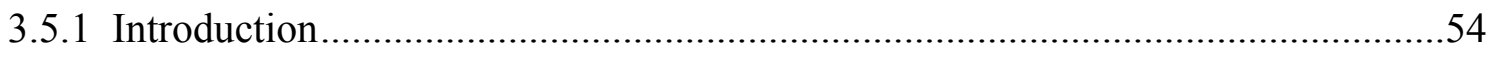

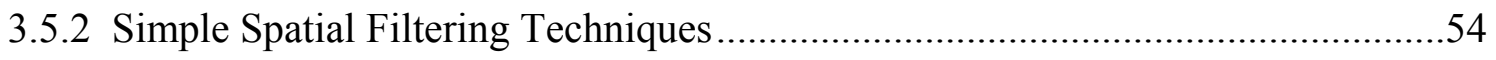

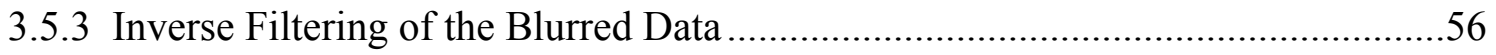

3.5.4 Inversion of Lateral Diffusion Effects ......................................................60

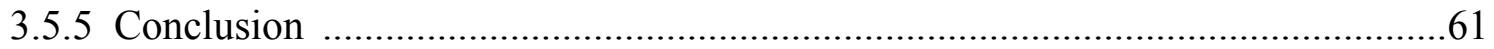

3.6 Health Monitoring of FRP Bridge Decks (Miceli et al. 2001) ................................62

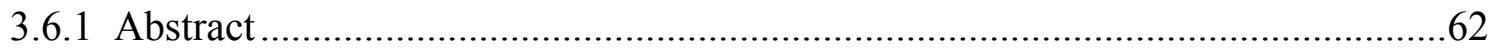

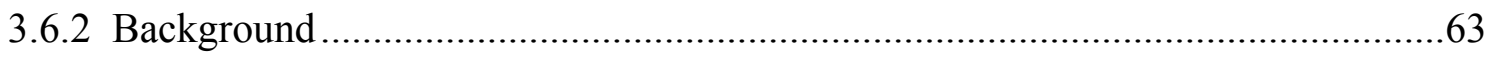

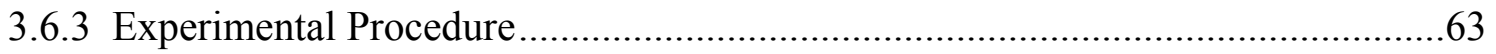

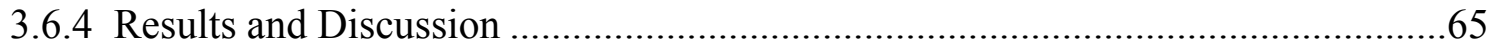

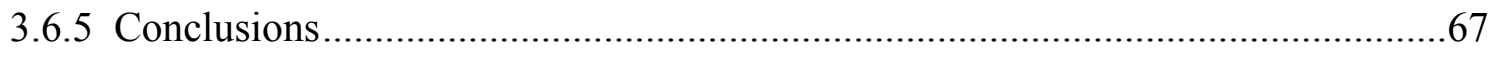

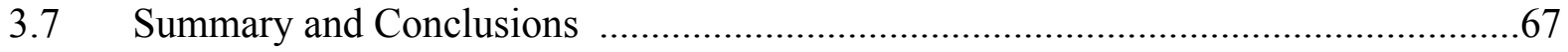


CHAPTER 4 - LABORATORY EXPERIMENTS ..........................................68

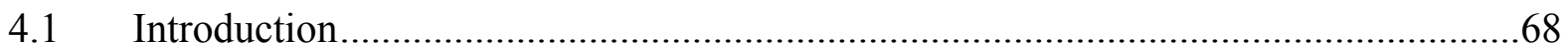

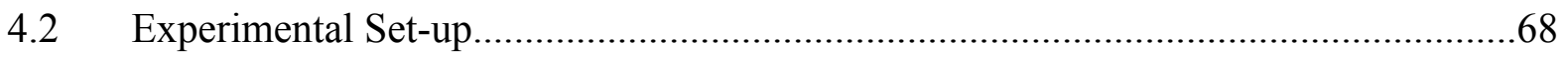

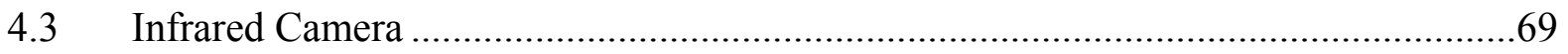

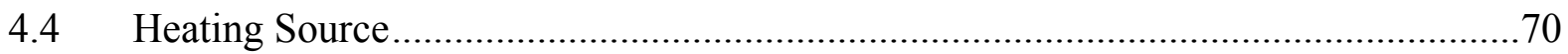

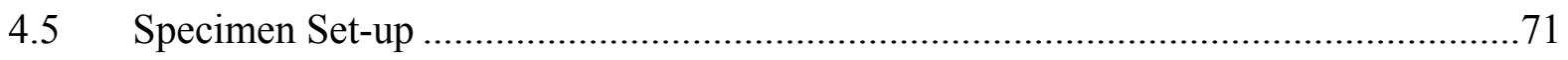

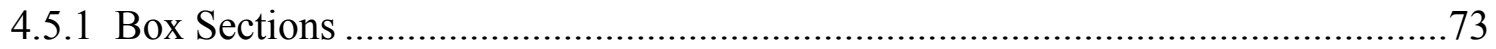

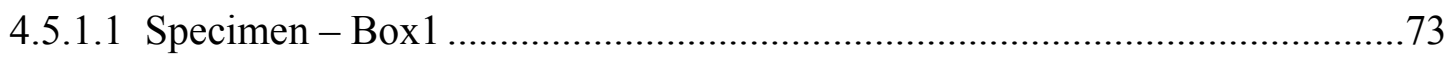

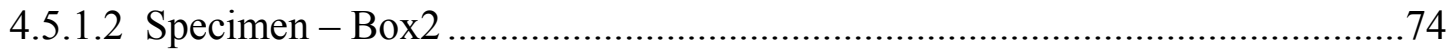

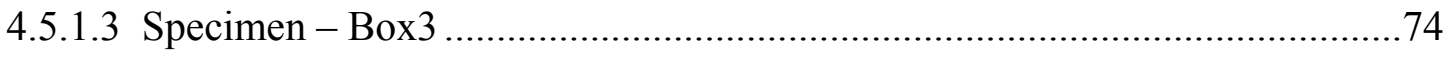

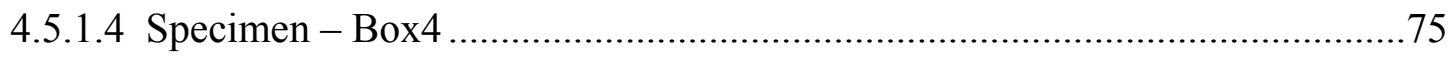

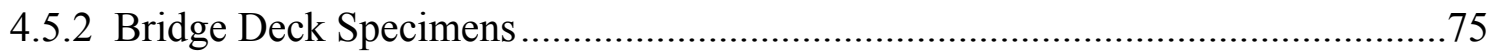

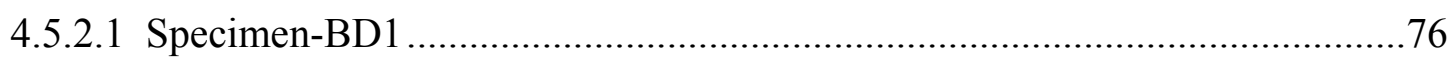

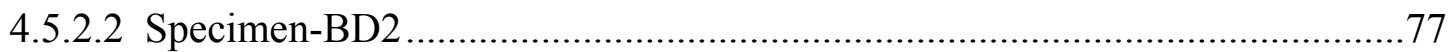

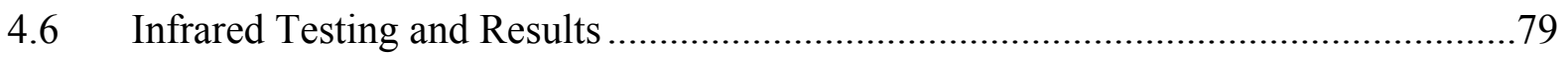

4.6.1 Results for the Box Sections ...........................................................................

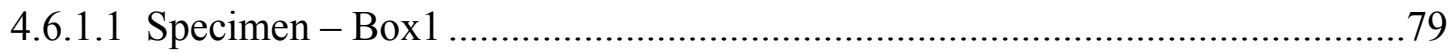

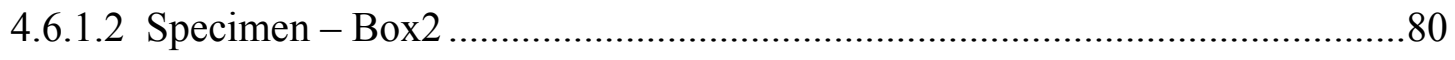

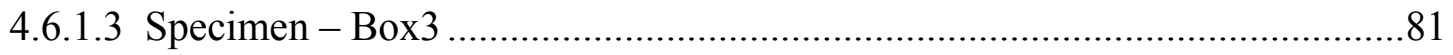

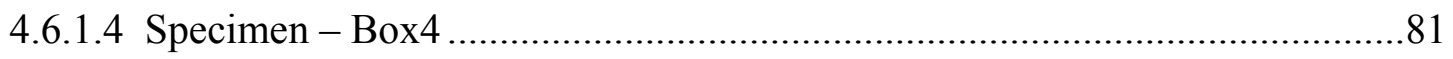

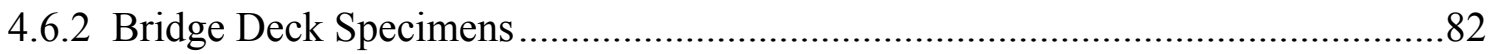

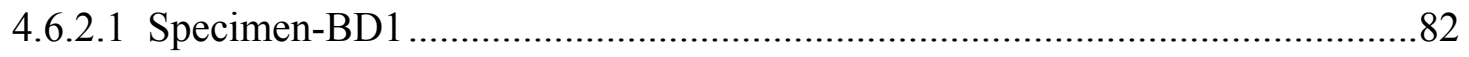

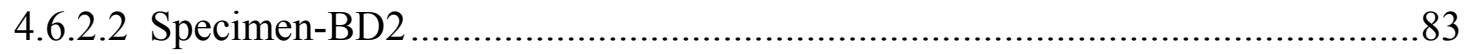




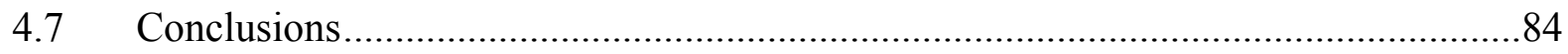

CHAPTER 5 - FIELD TESTS .......................................................... 85

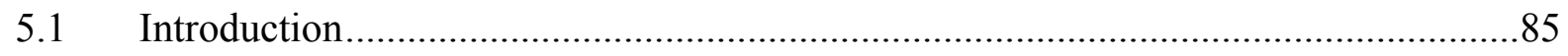

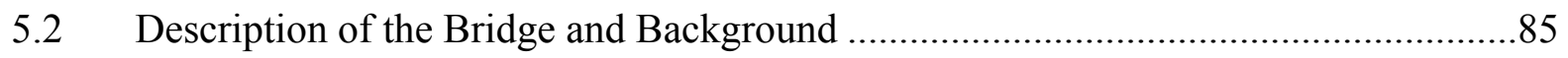

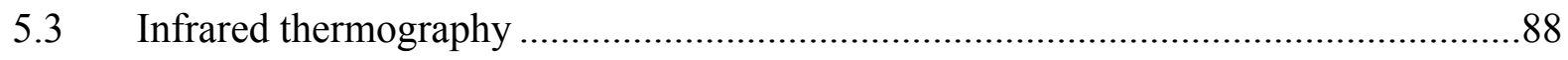

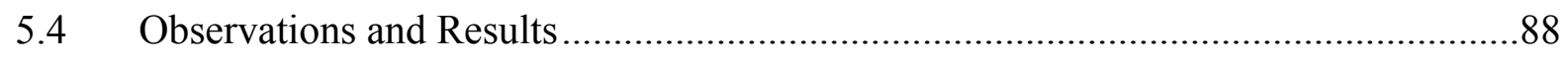

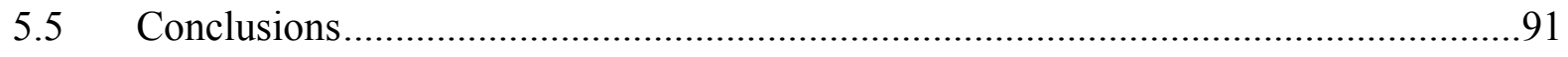

CHAPTER 6 - CONCLUSIONS AND RECOMMENDATIONS ...................92

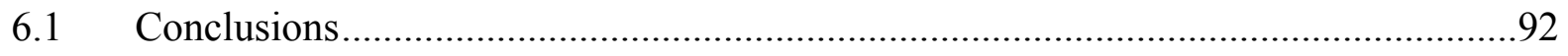

6.2 Advantages and Disadvantages of Using Infrared Thermography ..........................95

6.3 Recommendations for Future Research ............................................................96

REFERENCES ......................................................................98 


\section{CHAPTER 1}

\section{INTRODUCTION}

\subsection{Background}

Nondestructive testing and evaluation (NDT\&E) refers to the condition assessment (in terms of material property evaluation and defect detection) of structural components such as beams, columns, slabs etc. without causing any damage or impairing their future usefulness. The commonly used structural materials are concrete, asphalt and steel. Over many years, several NDT\&E techniques, such as infrared thermography, ground penetrating radar, wave propagation (ultrasonic, acoustic and microwave), fiber optics etc. have been developed and adopted for the condition assessment of structures. The choice of a particular technique depends mainly on the material type apart from various other factors such as the type of structural element, location, weather conditions, accessibility, etc.

As per the National Bridge Inventory (2002) report (collection of about 600,000 Nation's Interstate Highways, U.S. Highways, State and County Roads, and other routes of national significance), as of December 2001 about $28 \%$ of the nation's bridges are structurally deficient or functionally obsolete.

Table 1.1 All Bridges - structurally deficient or functionally obsolete (National Bridge Inventory 2002)

\begin{tabular}{|c|c|c|c|c|c|c|}
\hline $\begin{array}{c}\text { Month- } \\
\text { Year }\end{array}$ & $\begin{array}{c}\# \\
\text { Bridges }\end{array}$ & $\begin{array}{c}\# \text { Not } \\
\text { Deficient. }\end{array}$ & $\begin{array}{c}\# \\
\text { Structurally } \\
\text { Deficient. }\end{array}$ & $\begin{array}{c}\# \\
\text { Functionally } \\
\text { Obsolete. }\end{array}$ & $\begin{array}{c}\text { Total } \\
\text { Deficient. }\end{array}$ & $\begin{array}{c}\% \\
\text { Deficient. }\end{array}$ \\
\hline Dec-96 & 581,862 & 399,136 & 101,518 & 81,208 & 182,726 & 31.4 \\
\hline Dec-97 & 582,751 & 406,866 & 98,475 & 77,410 & 175,885 & 30.2 \\
\hline Dec-98 & 582,984 & 410,387 & 93,076 & 79,506 & 172,582 & 29.6 \\
\hline Dec-99 & 585,542 & 415,492 & 88,150 & 81,900 & 170,050 & 29.0 \\
\hline Dec-00 & 587,458 & 419,877 & 86,692 & 80,889 & 167,581 & 28.5 \\
\hline Dec-01 & 590,066 & 424,967 & 83,630 & 81,469 & 165,099 & 28.0 \\
\hline
\end{tabular}


Though the percentage of structurally deficient or functionally obsolete bridges is slowly and steadily reducing over the years (as indicated by the Table 1.1), much needs to be done in the coming years to bring all the bridges to optimum working standards. This is mainly because most of the existing bridges are constructed of concrete and are in 25-50 year age range. Deterioration rate studies suggest that structures in this category deteriorate slowly during the first few decades of their design life (typically 50 years), followed by a rapid deterioration during the last decade. If these predictions are correct, there are enormous rehabilitation and reconstruction expenses to be incurred over the next two decades. Compounding this problem is the dramatic increase in both the weight and number of heavy commercial vehicles, which impose an exponential increase in damage. To address such problems, new innovative materials are sought for use in bridge repair and replacement. New materials such as Fiber Reinforced Polymers (FRP) have gained prominence in recent years. These lightweight and high strength materials, which were used extensively in the aerospace industry, have shown promising results for their application in the infrastructure industry.

FRP is used in different shapes such as box sections, tubes, pipes, I-sections etc. for different components of the bridges such as beams, stringers, decks, guardrails etc. Further, for bridge decking system, various innovative configurations are being developed in order to achieve high stiffness to weight ratio. However, two important factors that are to be addressed while using these materials are the costs and durability aspects. Over the last decade, the cost of FRP has come down drastically. With the recent developments in the technology, resulting in better and efficient sections, the costs could come down further and could be comparable to that of the conventional building materials such as steel and concrete. With respect to durability, it is essential to develop effective nondestructive tool(s) for 
periodic in-situ assessment of FRP composite structural components. Infrared thermography is fast emerging as a prominent NDT\&E technique for field monitoring of such structures.

Infrared thermography makes use of the variations in the surface temperature profiles of the structure to detect hidden subsurface defects such as debondings, delaminations and cracks. Using an infrared camera, the surface temperature profiles are recorded in the form of color or gray scale images called thermographs, which are analyzed by a thermographer. Infrared thermography is already being used for the condition assessment of bridge decks, detection of roof leaks and a wide range of other industrial applications. However further improvements are required in the techniques so that a standardized, custom made, system is developed for regular monitoring of structures built with FRP materials.

\section{$1.2 \quad$ Research Objectives}

The objectives of this research are to:

- Critically review the recent developments in the processing and analysis of digital infrared images available from the NDT\&E research on aerospace components with emphasis on:

- Automated thermographic defect recognition and measurement.

- Temporal treatment of a thermal response for defect depth estimation.

- Enhanced spatial and depth resolution of infrared images acquired using pulsed thermography.

- Make recommendations for using the above-mentioned techniques for defect detection in mass-produced structural FRP components.

- Create delaminations of different lateral dimensions and particular thickness (1/16") at different locations in FRP composite members during pultrusion process (the process by 
which these members are manufactured) and to use active infrared thermography technique for detection of these delaminations.

\subsection{Scope}

A detailed literature review on the basics of infrared thermography has been carried out. Recent developments in the field of infrared thermography in the aerospace industry, published in prominent journals, are reviewed in detail and recommendations are made for using these advanced techniques for defect detection in mass-produced structural FRP components. Active thermography is conducted to detect delaminations of different sizes that were inserted in FRP composite structural components during pultrusion. Tests were performed on two types of FRP specimens - box sections and bridge deck sections. A field trip was undertaken for the condition assessment of FRP wrapped reinforced concrete columns using infrared thermography. Conclusions and recommendations for further development of infrared thermography as a defect detection tool are provided at the end.

\subsection{Organization}

This thesis is organized into six chapters. The background, objective and scope of the research are presented in Chapter 1 - Introduction. The basics of infrared thermography, its origin, instrumentation and applications are discussed in Chapter 2. Recent research developments in the field of infrared thermography are reviewed in Chapter 3. The laboratory tests on various types of FRP specimens and the results are presented in Chapter 4. The details of the field tests conducted for the condition assessment of wrapped reinforced concrete columns of a bridge and the corresponding results are presented in Chapter 5. The conclusions of this research and the recommendations for further development are presented in Chapter 6 followed by the complete listing of references cited in this thesis. 


\section{CHAPTER 2}

\section{INFRARED THERMOGRAPHY BASICS}

\subsection{Historical Background}

When materials get hot, they radiate energy in the visible as well as in the infrared spectrum. The color of a hot glowing metal is a fair indication of its temperature (the higher the temperature, the whiter the color). This method is used in many of the industries to evaluate the product output standard. This is done by making a differential measurement between the actual brightness of the product and what it should be (the set point) and the differential signal is injected into the process and used to drive the product temperature to the set point.

With the advent of modern infrared detectors, the precision measurement of the thermal energy radiating from the surfaces that "do not glow" became possible.

A formal discovery (Kaplan 1999) of infrared energy beyond the visible light portion of the spectrum is credited to William Herschel (1738-1822). Around the year 1800, he set up an experiment to examine if different colored rays from the beam of sunlight dispersed by a prism might differ in their power to heat a surface. After placing the thermometers under the red, green and violet light, he came up with "heating effects" roughly proportional to 55 for red, 24 for green and 16 for violet (with no reference to units). Suspecting that the heating effect might continue beyond the visible spectrum, he repeated the experiment using ruled paper, and found that the maximum heating occurred some distance (about $1 / 2$ inch) beyond the red light. He went on further to establish that the radiant heat, beyond the visible spectrum, have reflection and refraction properties similar to that of visible light. 


\subsection{Heat and Temperature}

Heat can be defined as the thermal energy in transition. It flows from one place or an object to another because of temperature difference, and the flow of heat changes the energy levels in the object.

Temperature is a property of matter and not the complete measurement of internal energy. It defines the direction of the heat flow when another temperature is known. Temperatures are measured in either relative or absolute terms. Relative temperatures are expressed in "degrees Celsius" or "degrees Fahrenheit" (in FPS units). Absolute temperature is expressed in Kelvin (in SI units). The conversions between the units are as follows:

$$
\begin{aligned}
& \mathrm{T}_{\mathrm{f}}=\frac{9}{5} \mathrm{~T}_{\mathrm{c}}+32 \\
& \mathrm{~T}_{\mathrm{k}}=\mathrm{T}_{\mathrm{c}}+273.16
\end{aligned}
$$

where,

$$
\begin{aligned}
& \mathrm{T}_{\mathrm{c}} \quad=\text { Temperature in degrees Celsius } \\
& \mathrm{T}_{\mathrm{k}} \quad=\text { Temperature in Kelvin } \\
& \mathrm{T}_{\mathrm{f}} \quad=\text { Temperature in degrees Fahrenheit }
\end{aligned}
$$

\section{Heat always flows from the object at higher temperature to that at lower}

temperature. Because of the heat transfer, hotter objects tend to become cooler and colder objects become hotter. This continues until the equilibrium is achieved i.e., until both the objects attain the same temperature.

There are three modes of heat transfer:

- Conduction

- Convection

- Radiation 
The discussions of the above three modes of heat transfer deal with steady-state heat exchange for reasons of simplicity and better understanding. Two points with different temperatures are assumed for the heat flow to occur between them. In many applications, these temperatures are in transition and hence the values shown for the energy emitted from the target surface are the instantaneous values.

\subsubsection{Conduction}

Conduction is the transfer of heat in stationary media. It is the only mode of heat flow in solids but can take place in liquids and gases. It occurs because of molecular collisions (in fluids) and atomic vibrations (in solids) whereby energy is moved, one molecule at a time, from higher temperature sites to lower temperature sites. Thermal conductivity is defined as the ratio of the heat flux to the temperature gradient and is measured in heat flow per unit area for a unit temperature difference across a unit thickness (Neville 1973). The heat flow through a thermally conductive medium is directly proportional to the temperature difference across the medium and the thermal conductivity of the medium in accordance with the Fourier's law (Threlkeld 1970). The heat transfer equation for the one dimensional heat flow is given by:

$$
\mathrm{q}_{\mathrm{net}}=\frac{\mathrm{k}}{\mathrm{d}}\left(\mathrm{T}_{\mathrm{h}}-\mathrm{T}_{\mathrm{c}}\right)
$$

where,

$$
\begin{aligned}
& \mathrm{q}_{\text {net }}=\text { net heat flow through a unit area of the surface per unit time }\left(\mathrm{W} / \mathrm{m}^{2}\right) \\
& \mathrm{k} \quad=\text { thermal conductivity of the medium }\left(\mathrm{J} / \mathrm{m} / \mathrm{s} /{ }^{\circ} \mathrm{C} \text { or W/m} /{ }^{\circ} \mathrm{C}\right) \\
& \mathrm{T}_{\mathrm{h}} \quad=\text { temperature of the hotter side }\left({ }^{\circ} \mathrm{C}\right) \\
& \mathrm{T}_{\mathrm{c}} \quad=\text { temperature of the colder side }\left({ }^{\circ} \mathrm{C}\right) \\
& \mathrm{d} \quad=\text { thickness of the layer or the medium }(\mathrm{m})
\end{aligned}
$$




\subsubsection{Convection}

Convective heat transfer takes place in a moving medium and is usually associated with heat transfer between a solid and a moving fluid (such as air). In convective heat flow, the heat transfer takes place by two mechanisms, the direct conduction through the fluid and the motion of the fluid itself. Forced convection takes place when an external driving force such as wind or an air pump, moves the fluid. Free convection takes place when the temperature differences necessary for heat transfer result in density changes in the fluid and the warmer fluid rises because of increased buoyancy. Convective heat flow is determined by the temperature at the surface, the surrounding temperature, and the speed of the fluid motion. The convective heat transfer between the deck surface and the surrounding air can be obtained by using Langmuir's equation, which is expressed as follows (Malloy 1969):

$$
\mathrm{q}_{\mathrm{c}}=1.947\left(\mathrm{~T}_{\mathrm{o}}-\mathrm{T}_{\mathrm{a}}\right)^{5 / 4} \sqrt{\frac{(\mathrm{v}+0.35)}{0.35}}
$$

where,

$$
\begin{aligned}
& \mathrm{q}_{\mathrm{c}} \quad=\text { convective heat transfer from the surface }\left(\mathrm{W} / \mathrm{m}^{2}\right) \\
& \mathrm{v} \quad=\text { wind velocity }(\mathrm{m} / \mathrm{sec}) \\
& \mathrm{T}_{\mathrm{o}} \quad=\text { surface temperature of the } \operatorname{deck}\left({ }^{\circ} \mathrm{C}\right) \\
& \mathrm{T}_{\mathrm{a}} \quad=\text { ambient air temperature }\left({ }^{\circ} \mathrm{C}\right)
\end{aligned}
$$

\subsubsection{Radiation}

Radiative heat transfer is unlike the other two modes in several respects.

1. It can take place across a vacuum.

2. It occurs by electromagnetic emission and absorption.

3. The radiated energy travels at the speed of light. 
4. The energy transferred is proportional to the fourth power of the temperature difference between the objects.

The behavior of radiant emission is described by the Stefan-Boltzmann law, which states that the heat radiated by a body is directly proportional to the fourth power of its absolute temperature (Vanzetti 1972).

$$
\mathrm{q}_{\mathrm{e}}=\sigma \varepsilon \mathrm{T}^{4}
$$

where,

$\mathrm{q}_{\mathrm{e}}=$ total radiant emission from the radiating surface $\left(\mathrm{W} / \mathrm{m}^{2}\right)$

$\sigma \quad=$ Stefan-Boltzmann constant $=5.673 \times 10^{-8} \mathrm{~W} / \mathrm{m}^{2} / \mathrm{K}^{4}$

$\varepsilon \quad=$ emissivity factor of the object

( 0 for a perfect reflector, 0.9 for asphalt, 0.92 for concrete and 1.0 for a perfect black body)

$\mathrm{T}=$ absolute temperature of the object $(\mathrm{K})$

Any surface not only radiates heat to the atmosphere but also simultaneously receives radiation back from the atmosphere. The net radiation from any surface, in accordance with Stefan-Boltzmann law, is given by the following equation (Halabe and Maser 1986):

$$
\mathrm{q}_{\mathrm{r}}=\sigma \varepsilon\left[\left(\mathrm{T}_{\mathrm{o}}+273\right)^{4}-\left(\mathrm{T}_{\mathrm{a}}+273\right)^{4}\right]
$$

where,

$\mathrm{q}_{\mathrm{r}}=$ net radiation from the radiating surface $\left(\mathrm{W} / \mathrm{m}^{2}\right)$

$\mathrm{T}_{\mathrm{o}}=$ temperature of the radiating surface $\left({ }^{\circ} \mathrm{C}\right)$

$\mathrm{T}_{\mathrm{a}}=$ ambient air temperature $\left({ }^{\circ} \mathrm{C}\right)$ 
It is important to note that the heat transfer also depends on the thermal properties of the materials. Table 2.1 lists the thermal properties of some of the commonly used materials.

Table 2.1. Thermal properties of some materials (Maldague 1993)

\begin{tabular}{|c|c|c|c|c|c|}
\hline Material & $\begin{array}{l}\text { Specific heat } \\
\left(\mathrm{J} \mathrm{Kg}^{-1}{ }^{\circ} \mathrm{C}\right)^{-1}\end{array}$ & $\begin{array}{l}\text { Density } \\
\left(\mathrm{kg} \mathrm{m}^{-3}\right)\end{array}$ & $\begin{array}{l}\text { Heat capacity } \\
\left(\mathrm{J} \mathrm{cm}^{-3}{ }^{\circ} \mathrm{C}^{-1}\right)\end{array}$ & $\begin{array}{l}\text { Thermal } \\
\text { conductivity } \\
\left(\mathrm{W} \mathrm{m}^{-1}{ }^{\circ} \mathrm{C}^{-1}\right)\end{array}$ & $\begin{array}{c}\text { Thermal } \\
\text { diffusivity } \\
\delta \times 10^{-6} \\
\left(\mathrm{~m}^{2} \mathrm{~s}^{-1}\right)\end{array}$ \\
\hline Air (as defect) & 700 & 1.2 & $0.8 \times 10^{-3}$ & 0.024 & 33 \\
\hline Aluminium & 880 & 2700 & 2.4 & 230 & 95 \\
\hline $\begin{array}{l}\text { Brass }(65 \% \quad \mathrm{Cu}, \\
35 \% \mathrm{Zn})\end{array}$ & 380 & 8400 & 3.2 & 130 & 32 \\
\hline $\mathrm{CFRP}^{\mathrm{b}}$ ( $\_\_$fibers) & 1200 & 1600 & 1.9 & 0.8 & 0.42 \\
\hline $\mathrm{CFRP}^{\mathrm{b}}$ (\| fibers) & 1200 & 1600 & 1.9 & 7 & 3.7 \\
\hline Concrete & 800 & 2400 & 1.9 & 1 & 0.53 \\
\hline Copper & 380 & 8900 & 3.4 & 380 & 110 \\
\hline Epoxy resin & 1700 & 1300 & 2.2 & 0.2 & 0.09 \\
\hline Glass & 670 & 2600 & 1.7 & 0.7 & 0.41 \\
\hline $\mathrm{GFRP}^{\mathrm{c}}$ (_L fibers) & 1200 & 1900 & 2.3 & 0.3 & 0.13 \\
\hline GFRP $^{\mathrm{c}}$ (\| fibers) & 1200 & 1900 & 2.3 & 0.38 & 0.17 \\
\hline Lead & 130 & 11300 & 1.5 & 35 & 23 \\
\hline Nickel & 440 & 8900 & 3.9 & 91 & 23 \\
\hline Plexiglass ${ }^{\mathrm{TM}}$ & - & 1200 & - & 0.2 & 0.25 \\
\hline Porcelain & 1100 & 2300 & 2.5 & 1.1 & 0.43 \\
\hline Steel (mild) & 440 & 7900 & 3.5 & 46 & 13 \\
\hline Steel (stainless) & 440 & 7900 & 3.5 & 25 & 7.1 \\
\hline Teflon $^{\mathrm{TM}}$ & - & - & - & 0.42 & 1.59 \\
\hline Titanium & 470 & 4500 & 2.1 & 16 & 7.6 \\
\hline Uranium & 120 & 18700 & 2.2 & 27 & 12 \\
\hline Water & 4180 & 1000 & 4.2 & 0.6 & 0.14 \\
\hline Zircaloy 2 & 280 & 6600 & 1.8 & 13 & 11 \\
\hline
\end{tabular}

(Vavilov 1980, p 182; Reynolds and Wells 1984, p 43; Tretout 1987, p 49; Touloukian and DeWitt 1970)

${ }^{a}$ Defined as $\delta=\mathrm{K} / \rho \mathrm{C}$, where $\mathrm{K}$ is the thermal conductivity, $\rho$ is mass density and $\mathrm{C}$ is the specific heat.

${ }^{\mathrm{b}}$ Carbon fiber reinforced polymer.

${ }^{\mathrm{c}}$ Glass fiber reinforced polymer. 


\subsection{Electromagnetic Spectrum}

The electromagnetic spectrum is illustrated in the Figure 2.3.1. Radiative heat transfer takes place in the infrared portion of the spectrum, from $0.75 \mu$ to about $100 \mu$, although most practical measurements can be made to about $20 \mu$ (Kaplan 1999).

The measurement of thermal infrared radiation is the basis for non-contact temperature measurement and thermography. Thermal infrared radiation leaving a surface is called exitance or radiosity. It is emitted from the surface, reflected off the surface or transmitted through the surface. The total radiosity is equal to the sum of the emitted component (E), the reflected component $(\mathrm{R})$ and the transmitted component $(\mathrm{T})$. The surface temperature is related to $E$, the emitted component only (Kaplan 1999).

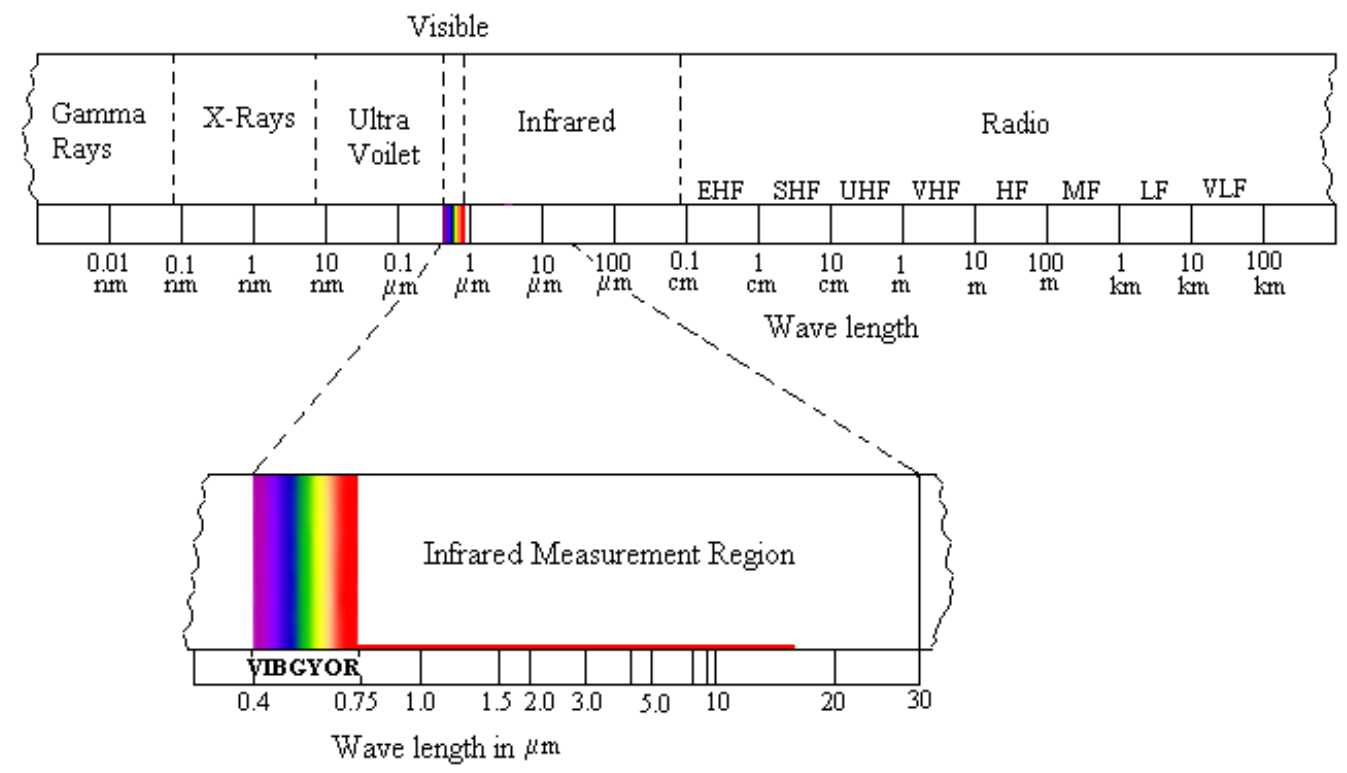

Figure 2.3.1 Infrared regions in the electromagnetic spectrum (Kaplan 1999).

\subsection{Infrared Measurement Problem}

All objects above absolute temperature $\left(0 \mathrm{~K}\right.$ or $\left.-273{ }^{\circ} \mathrm{C}\right)$ radiate energy in the infrared region of the spectrum. The hotter the object, more the energy radiated. Very hot objects radiate in the visible region of the spectrum also. The sun at about $6000 \mathrm{~K}$ appears to glow 
white-hot; tungsten filament at about $3000 \mathrm{~K}$ has a yellowish glow and an electric stove at $800 \mathrm{~K}$ glows red. As the stove element cools, it loses its visible glow but it continues to radiate. We can feel it with a hand placed near the surface but can't see the glow as the energy has shifted from red to infrared. Infrared detectors can sense infrared radiant energy and produce useful electrical signals proportional to the temperature of the surface. Instruments using infrared detectors and optics gather and focus energy from the targets onto these detectors, and are capable of measuring target surface temperatures with sensitivities down to $0.1^{\circ} \mathrm{C}$ and response time in microsecond range. Instruments that combine these measurement capabilities are called thermal infrared imagers. They can produce thermal maps or thermographs where the brightness intensity or the color hue of any spot on the map is representative of the object's surface temperature.

\subsection{Non-Contact Thermal Measurements}

American Society of Testing and Measurements (ASTM) classify infrared noncontact thermal sensors as "infrared radiation thermometers" even though they don't always read out the temperature. The laws of physics allow us to convert infrared radiation measurements to temperature measurements. This is done by converting the electromagnetic radiation emitted by the target objects in the infrared region, to electrical signals using infrared sensors. Three important aspects that need to be considered for making effective infrared measurements are:

- Target surface.

- Transmitting medium.

- Measuring instrument. 


\subsubsection{Target Surface}

As shown in the electromagnetic spectrum (Figure 2.3 .1$)$, the infrared region $(0.75 \mu \mathrm{m}$ to $100 \mu \mathrm{m}$ wavelength) lies next to the visible region $(0.40 \mu \mathrm{m}$ to $0.75 \mu \mathrm{m}$ wavelength). However, the infrared measurements can be made only in $0.75 \mu \mathrm{m}$ to $20.0 \mu \mathrm{m}$ wavelength region. Every target surface above absolute zero $\left(0 \mathrm{~K}\right.$ or $\left.-273{ }^{\circ} \mathrm{C}\right)$ radiates energy in the infrared region. The amount emitted and its distribution with wavelength depends on the temperature and emissivity of the body. Fig. 2.5.1 shows the distribution of the emitted energy over the electromagnetic spectrum for targets at various temperatures.

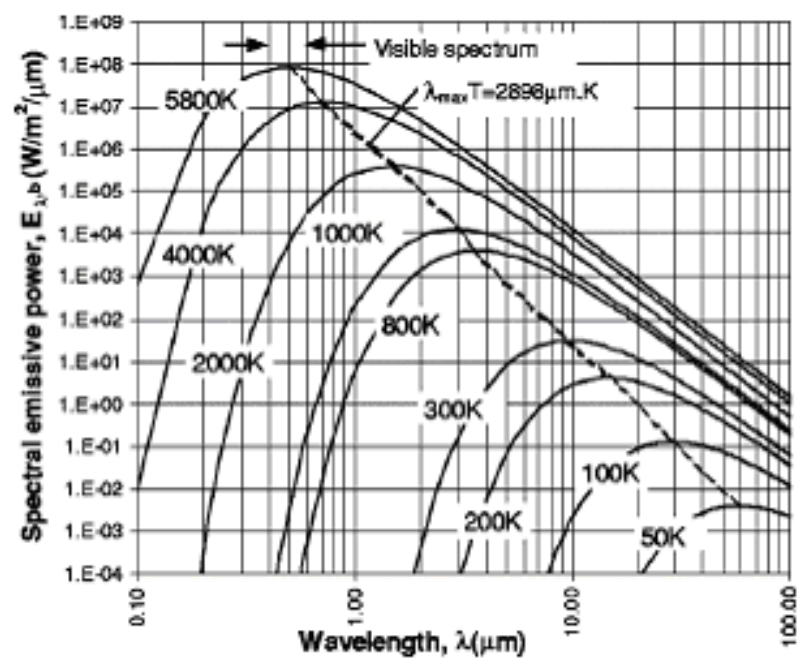

Figure 2.5.1 Blackbody curves at various temperatures (Kreith and Bohn 1993).

The curves shown above in the Figure 2.5.1 are for black bodies. Target surfaces can be classified as blackbodies, graybodies and nongraybodies. A blackbody radiator is a surface having emissivity as unity for all wavelengths and capable of absorbing all the energy available at its surface. This will be an ideal target surface to measure. However, the concept of blackbody is only theoretical as there is nothing such as a perfect blackbody in nature. However, most of the solids are graybodies whose emissivities are high and fairly constant with wavelengths (Kaplan 1999). 
The emissivity of any object is defined as the ratio of the actual emission from the object to that from a blackbody at the same temperature. The emissivity generally varies with wavelength. The property of a blackbody radiator may be calculated theoretically. Three points about the black body are of particular importance:

1. The total energy radiated $\left(\mathrm{W}_{\mathrm{tot}}\right)$ is proportional to the fourth power of the absolute temperature T (Vanzetti 1972):

$$
\mathrm{W}_{\text {tot }}=\sigma \varepsilon \mathrm{T}^{4}
$$

where, $\sigma$ is the Stefan-Boltzmann's constant $=5.673 \times 10^{-8} \mathrm{~W} / \mathrm{m}^{2} / \mathrm{K}^{4}$ and $\varepsilon$ is the emissivity.

2. The curve of variation of energy per interval of wavelength $\left(W_{\lambda} d \lambda\right)$ is always of the same shape, following the Plank's law (Kreith and Bohn 1993):

$$
\mathrm{W}_{\lambda} \mathrm{d} \lambda=\frac{\mathrm{C}_{1} \lambda^{-5} \mathrm{~d} \lambda}{\mathrm{e}^{\left(\frac{\mathrm{C}_{2}}{\lambda \mathrm{T}}\right)}-1}
$$

where, $\mathrm{C}_{1}$ and $\mathrm{C}_{2}$ are the constants given by:

$$
\begin{aligned}
& \mathrm{C}_{1}=3.7415 \times 10^{-16} \mathrm{Wm}^{2} \\
& \mathrm{C}_{2}=1.4388 \times 10^{-16} \mathrm{~K}
\end{aligned}
$$

3. The wavelength of the peak emission is a simple function of the absolute temperature (Wein's displacement law). The peak wavelength in $\mathrm{m}$ is given by (Kreith and Bohn 1993):

$$
\lambda_{\mathrm{pk}}=2.898 \times 10^{-3} / \mathrm{T}
$$




\subsubsection{Transmitting Medium}

The transmission characteristics of the medium in the measurement path between the target and the instrument need to be considered in making non-contact thermal measurements. No loss of energy is encountered when measuring in vacuum. For short distances, very little energy is absorbed by the atmosphere and can be ignored. As the air becomes heavy with water vapor, the energy loss to the atmosphere may be significant and its effects should be considered.

Figure 2.5.2 illustrates the spectral transmission characteristics of $0.3 \mathrm{~km}$ of ground level atmosphere (Kaplan 1999). Two spectral intervals have a very high transmission. These are known as 1-5 $\mu \mathrm{m}$ and the $8-14 \mu \mathrm{m}$ atmospheric "windows" and almost all of the infrared sensing and scanning instruments are designed to operate in one of these windows.

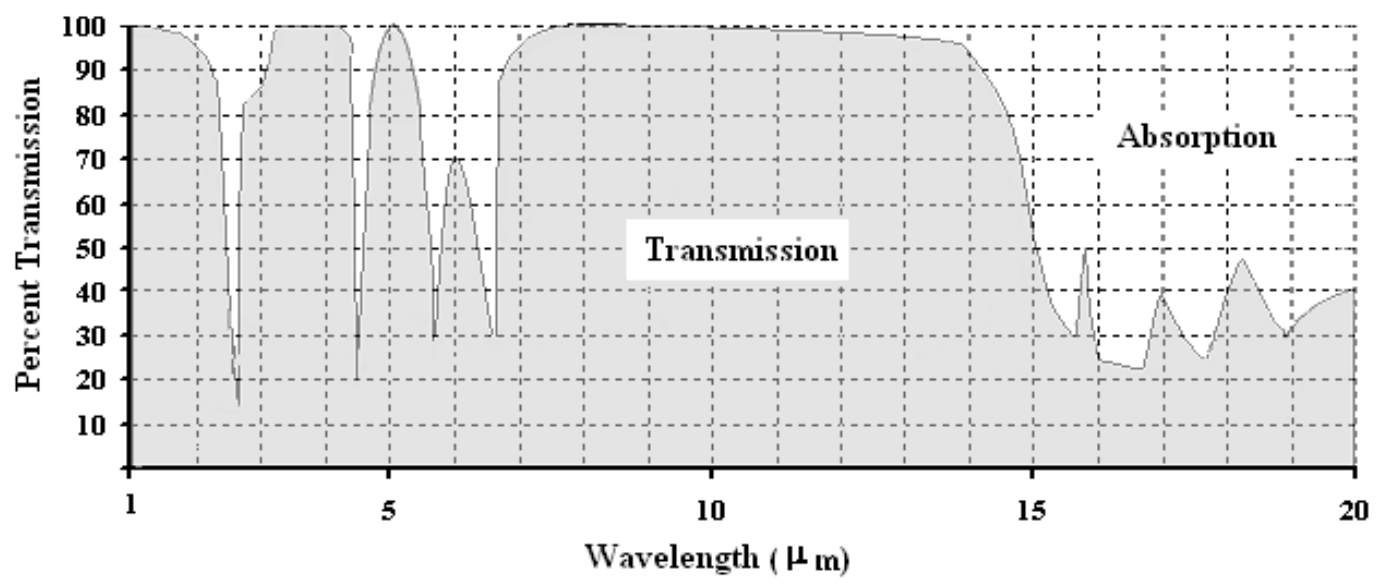

Figure 2.5.2 Infrared atmospheric transmissions for a 10m path at sea level (50\% rel. humidity) (Kaplan 1999).

The difficulties encountered with transmitting media occur when the target is viewed by an instrument through another solid object such as glass or quartz. The energy emitted by the objects at ambient temperature $\left(30^{\circ} \mathrm{C}\right)$ has wavelengths of $10 \mu \mathrm{m}$ for which the glass and 
quartz are opaque. Therefore, other materials such as Zinc Selenide (ZnSe), Platinum Selenide (PtSe), or KRS-5 are chosen as the lens material in low temperature infrared equipment. The characteristics of the lens material will always have some effect in the temperature measurement, but the attenuation can always be corrected by pre-calibrating the instrument with a sample window placed between the instrument and a target of known temperature (Kaplan 1999).

It is important to note that the infrared sensors work properly when all the following spectral ranges coincide.

- The spectral range over which the target emits.

- The spectral range over which the media transmits.

- The spectral range over which the sensor (the instrument) operates.

\subsubsection{Measuring Instrument}

The schematic view of an infrared radiation thermometer is as shown in the Figure 2.5.3. Receiving optics (such as infrared lens) are necessary in order to focus the energy emitted by the target on the surface of the infrared sensor which in turn converts it into electrical signals.

When an infrared radiation thermometer (point sensing instrument) is aimed at a target, it collects energy within a "collecting beam" the shape of which is determined by the configuration of the optics and the detector. The cross section of this beam is called the "field of view" of the instrument and it determines the size of the area on the target surface that the instrument can measure.

Infrared sensing instruments are traditionally classified into three groups pointsensing, line-scanning and thermographic (directly producing thermal images). Point- 
sensing devices, commonly called infrared radiation thermometers, collect radiant energy from the spot or the area on the surface of the target and provide an output indication, usually in terms of target temperature. Line-scanning instruments provide an output generally as an analog trace of the radiant energy distribution along a single straight-line projection from the surface. Thermographic instruments provide an image or thermal map or the energy distribution over an area on the target surface (Kaplan 1999).

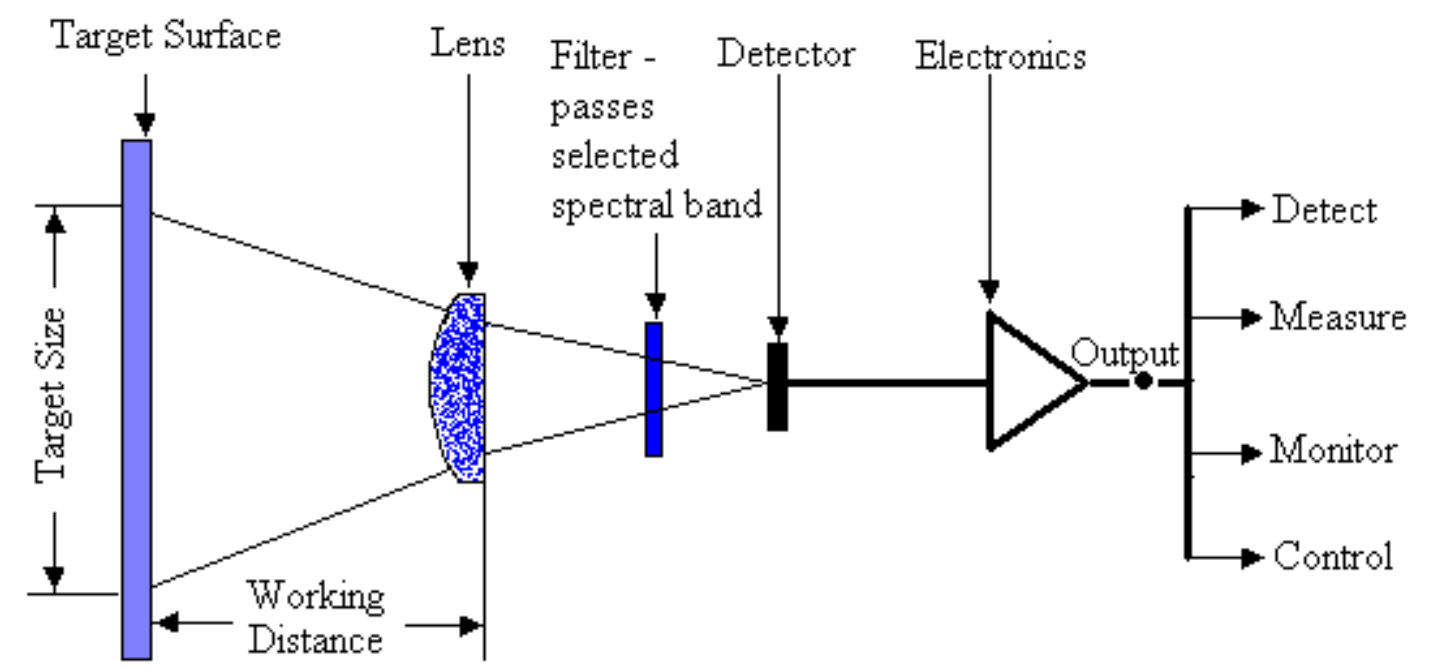

Figure 2.5.3 Schematic view of an infrared radiation thermometer (Kaplan 1999).

There are two types of infrared optics - refractive and reflective. Refractive optics (lenses), which are transparent to the desired wavelengths, are used mostly in cases of high temperature measurement where minor throughput losses in energy can be ignored. The reflective optics (mirror), which are a bit complicated in arrangement, are used for low temperature measurement where energy levels are already low and throughput energy losses can not be tolerated (Kaplan 1999).

An infrared interference filter is placed in front of the sensor to limit the spectral range or the "band" of the energy reaching the sensor. 
The processing electronics unit amplifies and conditions the signal from the infrared detector and introduces corrections for detector ambient temperature drift and target surface emissivity etc. Generally, the output is either analog or digital, with temperature readings or thermal contours or thermographs displayed on a screen.

An infrared camera is a spectral radiometer measuring the energy emitted by the surface of the object at temperatures above absolute zero. Polynomials are commonly used to convert the gray level values ' $\mathrm{g}$ ' obtained from the IR camera into temperature $\mathrm{T}$.

An example of such equation is (Maldague 2000):

$$
\mathrm{T}\left({ }^{\circ} \mathrm{C}\right)=-13.4+0.05 \mathrm{~g}-1.6 \times 10^{-5} \mathrm{~g}^{2}+2.2 \times 10^{-9} \mathrm{~g}^{3} \ldots
$$

Such equations are valid in a given span of temperature provided that the observed object's emissivity is high and the object is at a close distance.

\subsection{Quantitative Analysis}

When a quantitative analysis is required, some pre-analysis of the experiment is convenient. This is called a "direct problem" which consists of "predicting" the thermal behavior of the surface under consideration either analytically (for simple situations) or through heat transfer modeling by finite elements or finite differences. Dedicated software packages are available from various vendors (COSMOS/M, Thermo.Heat 3D). Such preanalysis is useful to establish the limits of the effectiveness of the procedure, to consider different defect geometries and to determine their detectibility without the expense of making and testing the corresponding specimens.

Once experimental results are available, the relation between the anomalies and the thermographs is established. By using the "inverse problem" techniques, given hotspot can be quantitatively characterized (Maldague 2000). 


\subsection{Infrared Non-Destructive Testing (IRNDT) (Maldague 2000)}

IRNDT is aimed at detecting subsurface anomalies such as delaminations, cracks, etc. in the objects of interest. The presence of such anomalies results in non-uniform surface temperature distribution of the object, which can be observed by taking an infrared image.

IRNDT is used in two schemes, passive and active. In the passive scheme, the natural temperature differences on the surface due to the subsurface anomalies are observed whereas in active scheme heat is induced into the object by external heating sources. An example of passive case is IRNDT and evaluation of leaky roofs. An example of active type is, IRNDT of an aircraft wing panel, made of fiber reinforced composite material, which is tested after heating it uniformly with an external heating source such as a heating gun or a quartz lamp.

\subsubsection{Passive Thermography}

As per the first law of thermodynamics, which relates to law of conservation of energy, a significant amount of heat is released in any (industrial) process consuming energy (because of the law of entropy). Therefore, temperature can be one of the important parameters that indicate proper operation. Common applications of the passive scheme in IRNDT are in buildings, electrical and electronic components (printed circuit boards), pipes carrying non-ambient temperature fluids in industries or households, medical field, etc. In these applications, abnormal temperature profiles indicate a potential problem. In passive thermography, the key words are the temperature difference with respect to the surrounding area, often referred to as ' $\Delta \mathrm{T}$ ' or the 'hotspot'. A $\Delta \mathrm{T}$ of $1-2{ }^{\circ} \mathrm{C}$ can be generally perceived as suspicious, whereas a $4{ }^{\circ} \mathrm{C}$ differential is a strong evidence for the presence of anomaly. In most cases, passive thermography is rather 'qualitative', as the goal is to pinpoint anomalies (of the type go/no-go). These are mainly based on the empirical rules applied by experience. 
Sometimes investigations done by passive thermography are also quantitative. In these cases, a direct thermal model is necessary. An example of such application was for analyzing the needles used for sewing in the automobile industry (for seat cushions, airbags, etc.). In this study, a model was developed to simulate the needle heating during high-speed sewing. This helps in understanding the exact behavior of the needle, which can be compared with the actual tests results. Heating (up to $100-300{ }^{\circ} \mathrm{C}$ ) of the needle takes place because of the friction between the needle and the fabric. The sewing is done at a very high speed with 1000 to 3000 motor rpm. Understanding the mechanisms of needle heating allows optimizing the sewing techniques or improving the needle design or needle cooling thereby improving the quality of the output.

\subsubsection{Active Thermography}

The active type has numerous applications in NDE. One advantage of active thermography is that since the heat is applied by an external source, the variations in the surface temperature with respect to time can also be used as a parameter in the evaluation of the object of interest. There are various types of evaluations such as:

- Pulsed thermography

- Step heating

- Lockin thermography (modulated thermography) and pulsed phase thermography

- Vibrothermography

\subsubsection{Pulsed Thermography}

Pulsed Thermography (PT) consists of heating the specimen and then recording the temperature decay curve. The temperature of the material changes rapidly after it receives the initial pulse because the thermal front propagates by diffusion under the surface, according to 
the Fourier diffusion equation. This pulse energy can be imparted into the specimen by lamps, flashes, laser beams, air and water jets, etc. The presence of a defect reduces the diffusion rate and hence that region appears with different contrast when viewed with an IR camera. The deeper defects will appear later and with reduced contrast. The behavior of the target object is analyzed either during the rising surface temperature or during the decay. The observation time ' $t$ ' is a function of the square of the depth ' $z$ ' (in a first approximation) and the loss of the thermal contrast ' $C$ ' is proportional to the cube of the depth (Maldague 2000).

$$
t \propto \frac{z^{2}}{\alpha} \quad, \quad C \propto \frac{1}{z^{3}} \quad \text { and } \quad \alpha=\frac{K}{\rho c}
$$

where, $\alpha$ is the thermal diffusivity of the material, $K$ is the thermal conductivity, $\rho$ is the mass density, and $c$ is the specific heat.

These relations are empirical in nature and cannot be applied to the defects at all depths. An empirical rule of thumb is that the radius of the smallest detectable defect should be at least one to two times larger than its depth under the surface. Further, this rule is applicable only to homogeneous isotropic materials, and for anisotropic materials the surface temperature behavior is more complex.

The surface inspection can be either by reflection (wherein the heating source and the detector are on the same side of the object) or by transmission, where they are on opposite sides of the object (mostly for planar objects).

The knowledge of the evolution of thermal contrast above the defect allows backcalculation of defect parameters such as depth, diameter, and thermal resistance. This can be further checked with the inverse heat transfer modeling. A common definition of the thermal contrast ' $C$ ' is given by (Maldague 2000): 


$$
C(t)=\frac{T_{i}(t)-T_{i}\left(t_{o}\right)}{T_{s}(t)-T_{s}\left(t_{o}\right)}
$$

where, $T$ is the temperature signal, $t$ is the time variable, and the subscripts $i$ and $s$ refer to the defective location pixel and the defect-free location pixel in the image, respectively. The contrast $C(t)$ is a function of time and for quantitative analysis, its maximum value $C_{\max }$ (computed at $t_{\max }$ ) is of interest.

In case of target objects which are already at higher than ambient temperature (due to manufacturing process for instance), it may be even convenient to apply negative heat, that is, to cool the object by blowing cold air or spraying cold water or cold liquid etc. Obviously, the thermal front propagates the same way whether it is hot or cold. An advantage of a cold thermal source is that it does not induce spurious thermal reflections into the IR camera as in case of hot thermal source. To suppress the adverse effect of the surrounding environment, ' $C$ ' is computed with respect to the temperature distribution at time $t_{o}$ (i.e., before heating) and normalized by the behavior of a defect-free area so that a unit value is obtained over a non-defective area.

The main advantage of the PT approach is the ease of deployment in the field. In addition, it is relatively fast considering the large areas that can be covered in small duration of time. Typical thicknesses of most common materials require an observation time of less than 1 minute (e.g. about $40 \mathrm{~ms}$ for $2 \mathrm{~mm}$ of $\mathrm{Al}$ to $30 \mathrm{sec}$ for a $2 \mathrm{~mm}$ thick graphite epoxy).

\subsubsection{Step Heating}

Contrary to the PT scheme in which the temperature decay is of interest (after application of the heat pulse), in step heating the increase of temperature is monitored during the application of a step heating pulse ('long pulse'). Variations of surface temperature with time are related to specimen features. This technique is sometimes referred to as 'time-resolved 
infrared radiometry' or 'TRIR'. TRIR is used in applications such as coating thickness evaluation (including multi-layered coating). For instance, the following empirical relationship provides the coating thickness $\mathrm{L}$ once the thermal transit time $\mathrm{t}_{\mathrm{c}}$ is determined (Maldague 2000):

$$
\mathrm{t}_{\mathrm{c}}=\frac{0.36 \mathrm{~L}^{2}}{\alpha}
$$

where, $\alpha$ is the thermal diffusivity. The coating specimen is heated and the temperature versus the square root of time is plotted as shown in Figure 2.7.1.

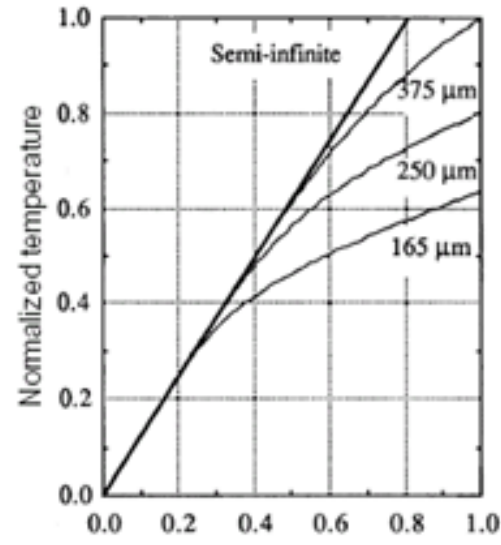

(a) Square root time (root-s)

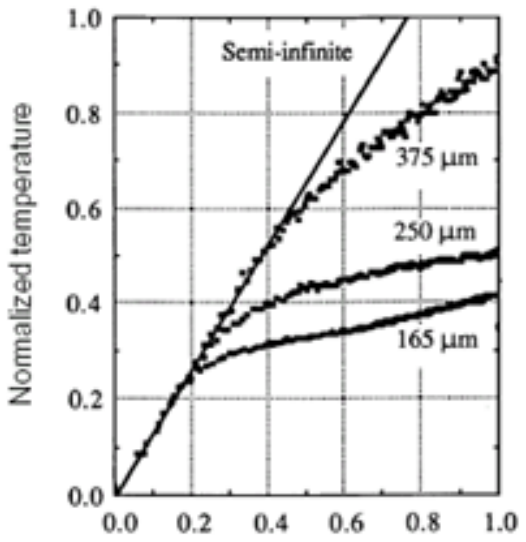

(b) Square root time (root-s)

Figure 2.7.1. Temporal evolution of normalized temperature for a series of zirconia coatings of different thickness for a step heating pulse of 1s. (a) theoretical calculations (b) experimental results (Maldague 2000).

The thermal transit time is observed (Figure 2.7.1) when the curve begins to depart from the semi-infinite case (which is a straight in the plots). The uniform heating of the specimen is very important in conducting such experiments.

\subsubsection{Lockin Thermography}

Lockin Thermography (LT), also known as Modulated Thermography (MT), is based on thermal waves generated inside the specimen under study, in the permanent regime. The specimen is subjected to a sine-modulation heating at a frequency $\omega$, which introduces highly attenuative and dispersive thermal waves of frequency $\omega$ inside the material (in the region 
close to the surface). The resulting oscillating temperature field in the stationary regime is recorded through its thermal infrared emission with an infrared camera. The term "lockin" implies the need to monitor the exact time dependence between the input sine-modulated temperature signal and the recorded signal. This can be done with a lockin amplifier in a point by point laser heating or with a computer for full-field of view (Maldague 2000). The instrumental set-up for LT is same as that for PT, except for the heating source which is designed to provide permanent sine modulated heating (either laser point heating or full-field heating).

The points obtained on the output signal are used to compute both the magnitude ' $\mathrm{A}$ ' and the phase shift ' $\phi$ ' with respect to the reference signal (only few points per cycle are required if the input and output signals are sinusoidal). The magnitude image $\mathrm{A}$ is proportional to local optical and surface features. The phase image is related to the propagation time and is independent of the local optical and surface features. This is one of the advantages of LT because the local surface features (such as non-uniform heating) do not affect the phase image (Maldague 1996, 2000).

The depth range of magnitude image is roughly given by the thermal diffusion length $\mu$ expressed by (Maldague 2000):

$$
\mu=\sqrt{2 k / \omega \rho c}
$$

where, $\mathrm{k}$ is the thermal conductivity, $\rho$ is the density, $c$ is the specific heat and $\omega$ is the modulation frequency. In case of phase images, the depth range is about twice as large. As per Equation 2.7.4, the higher modulation frequencies will restrict the analysis in a near surface region while lower frequencies will allow probing deeper under the surface. While LT could yield better results than PT, the disadvantage of LT is that it takes significant 
acquisition time since one needs to cover at least one modulation cycle. For example, it takes 2 minutes for $2 \mathrm{~mm}$ thick CFRP at a modulation frequency of $0.03 \mathrm{~Hz}$. In addition, if a wrong heating frequency $(\omega)$ is used, the defect may be missed.

Another field application of LT is the characterization of the electromagnetic fields, especially their interaction with metallic structures. This technique is useful in evaluation of thin films, such as those introduced in horn type radar antennas. The film to be tested is coated with magnetic paint sensitive to electromagnetic field or an electrically conductive coating. The heating of these coatings can be related to the surface currents and the

electromagnetic field. In the steady state regime the high thermal conductivity of the structure (coated film) distorts the coating heating which does not witness accurately the electromagnetic field and surface currents. However, in the modulated regime, if the modulation frequency is sufficiently high, so that the diffusion length $\mu$ is smaller than the coating thickness, the modulated heating will not be blurred by the thermal diffusion into the metallic substrate. In this application, the magnitude image is of interest rather than the phase image, since the magnitude is proportional to the intensity of the source and thus to the electromagnetic field intensity.

\section{Pulsed Phase Thermography (Maldague 1996)}

Another improvement in the field of thermography is "Pulsed Phase Thermography" (PPT). A simple mathematical formulation, which links PT and LT, is used to derive the advantages of both the techniques. In LT, a single frequency is tested in the stationary regime, whereas in PT, only the contrast of the emitted infrared thermograph is used and frequencies of the input/output thermal radiation are not taken into consideration. 
The pulse phase thermography is based on the Fourier transform. After the specimen is heated with an external source, the sequence of infrared images indicating the temperature decay is recorded and for each pixel $(i, j)$, and the temporal evolution $f(x)$ is extracted from the image sequence (where $\mathrm{x}$ is the index in the image sequence). Next, the broad spectra of thermal wave frequencies are unscrambled using Discrete Fourier transform using:

$$
\mathrm{F}(\mathrm{u})=\frac{1}{\mathrm{~N}} \sum_{\mathrm{n}=0}^{\mathrm{N}-1} \mathrm{~h}(\mathrm{x}) \exp [-\mathrm{j} 2 \pi u x / N]=\mathrm{R}(\mathrm{u})+\mathrm{jI}(\mathrm{u})
$$

where, $\mathrm{R}(\mathrm{u})$ and $\mathrm{I}(\mathrm{u})$ are real and imaginary components of $\mathrm{F}(\mathrm{u})$. The phase $\phi$, is computed for each of the transformed terms using:

$$
\phi(\mathrm{u})=\tan ^{-1}\left(\frac{\mathrm{I}(\mathrm{u})}{\mathrm{R}(\mathrm{u})}\right)
$$

The range of frequencies span from zero to $1 / \Delta \mathrm{x}$ (where $\Delta \mathrm{x}$ is the time interval between the images, that is, the sampling rate). Corresponding to the maximum value of the acquisition rate $\mathrm{AR}$ (in $\mathrm{Hz}$ ), the minimum value of the $\Delta \mathrm{x}(=1 / \mathrm{AR})$ can be used to determine the frequency increment $\Delta \mathrm{u}=[1 /(\mathrm{N} \Delta \mathrm{x})]$, where $\mathrm{N}$ is the number of images. For example, a maximum acquisition rate of $52 \mathrm{~Hz}$ corresponds to a $\Delta \mathrm{x}$ of $19 \mathrm{~ms}$. A sequence of 32 images yields a frequency increment $\Delta \mathrm{u}=1 /(32 * 19 \mathrm{e}-3)=1.6 \mathrm{~Hz}$. The important point to be noted here is that we are considering the transient regime (unlike LT where the acquisition is done in the permanent regime). For instance in the above example, if the frequency of interest is $1.6 \mathrm{~Hz}$, only the first cycle of modulation will be available. Consequently, instead of analyzing the phase images at a particular frequency, the better approach would be to look at the maximum value of the phase since the final values of the $\phi$ and A (amplitude) have not 
yet settled. Such $\phi_{\max }$ image is obtained by considering all the pixels $(\mathrm{i}, \mathrm{j})$, and computing the max values using equation 2.7.6.

\subsubsection{Vibrothermography}

Vibrothermography (VT) is a technique where under the effect of externally induced mechanical vibrations, direct conversion from mechanical to thermal energy occurs and heat is released due to friction precisely at the locations of defects such as cracks and delaminations. By changing (increasing or decreasing) the 'mechanical excitation frequency', local thermal gradients appear or disappear at specific resonant frequencies (Maldague 2000). Direct theoretical modeling allows determination of such suitable excitation frequencies.

The mechanical excitation is induced into the specimen with the help of an ultrasonic transducer, attached to the specimen (alternately the specimen could also be immersed in an ultrasonic bath). A high frequency ultrasonic signal (typically $40 \mathrm{kHz}$ ) is modulated with a low frequency signal, which creates a thermal wave of desired wavelength as in conventional LT. The high frequency acts as a carrier delivering heat energy right into the specimen. This technique, called "loss-angle heating at ultrasonic frequencies" is reported to detect deeper and smaller defects while the selective heating allows a better differentiation among detected defects. Vibrothermography has been used in applications such as detection of corrosion, vertical cracks and delaminations (Maldague 2000).

The advantages of vibrothermography include the ability to locate flaws that are hardly detectable by conventional IR thermography (such as closed cracks), and the ability to inspect large areas (Maldague 2000). The disadvantage is that the set up required for mechanical loading might be very complicated, specially for large structures, which will most likely render this technique unsuitable for bridge deck type applications. 


\section{CHAPTER 3}

\section{LITERATURE REVIEW ON INFRARED APPLICATIONS}

Infrared thermography has been used as one of the effective nondestructive testing and evaluation techniques. There are many advantages, which make this technique more suitable than other techniques. However there are some disadvantages of using this technique as well. The advantages and disadvantages are summarized in Chapter 6. Continuous research is going on to improve the existing testing and evaluation techniques and to overcome the disadvantages.

In this chapter, literature review of the applications of infrared thermography for nondestructive testing and evaluation of the Fiber Reinforced Polymer (FRP) composite materials are presented. The details of the field tests conducted on some bridges and other structures and the corresponding observations are also presented.

\subsection{Detection of Subsurface Anomalies in Composite Bridge Decks Using Infrared} Thermography (Alqennah 2000)

\subsubsection{Laboratory Experiments}

This section presents laboratory experiments conducted on the FRP deck specimens at West Virginia University. The laboratory set-up was as follows.

\section{Equipment set-up:}

Two infrared cameras, Insight 80 Series (spectral range 8-11 $\mu \mathrm{m}$ ) and FLIR Prism Single Point (spectral range 3-5 $\mu \mathrm{m}$ ), with a resolution of $0.1^{\circ}$ and $0.2^{\circ} \mathrm{C}$, respectively, were used to measure the temperature differences on the specimens' surface. The color modes of the cameras gave different colors (white, pink, green, blue and black) with different intensities. As the surface temperature of the specimen increases, the color intensity 
increases. The infrared cameras were connected to a 9-inch TV monitor with a built in VCR, which were used to display and record the images. Quartz tower heater, heat gun and solar radiation were the heat sources used to heat up the specimens. Use of negative heat source (cooling) using liquid Carbon dioxide $\left(\mathrm{CO}_{2}\right)$ at $-40^{\circ} \mathrm{C}$ was also explored.

\section{Specimen set-up:}

Four composite deck specimens made by Transpo Industries, NY, were used in this study. Built in delaminations were created in the specimens between the wearing surface and the FRP deck. The delaminations were made of different sizes, with different filler material and at different locations. The wearing surface composed of a mixture of T-48 Epoxy, Basalt aggregate, sand and silicon. The cross-section of the specimen is as shown in Figure 3.1.1.

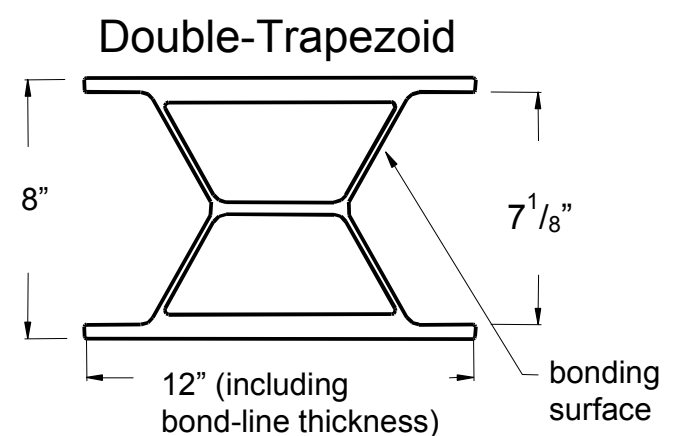

Figure 3.1.1 The cross section of the composite bridge deck specimen (Alqennah 2000).

Sample description and test results:

Sample 1 was of 12"x 16 " size with 2"x 2" debonding created between the wearing surface and the FRP deck using the duct tape. The sample was as shown in Figure 3.1.2a. Figure 3.1.2b shows the infrared image of the sample. The sample was tested using both the cameras and neither could detect the simulated debonding.

Sample 2 was a 12" x 24" composite deck specimen with several built in delaminations (as shown in Figure 3.1.3). The sample was heated to different temperatures ranging from $20^{\circ} \mathrm{C}$ to $80^{\circ} \mathrm{C}$. Different heating sources (quartz tower heater, heat gun, solar 


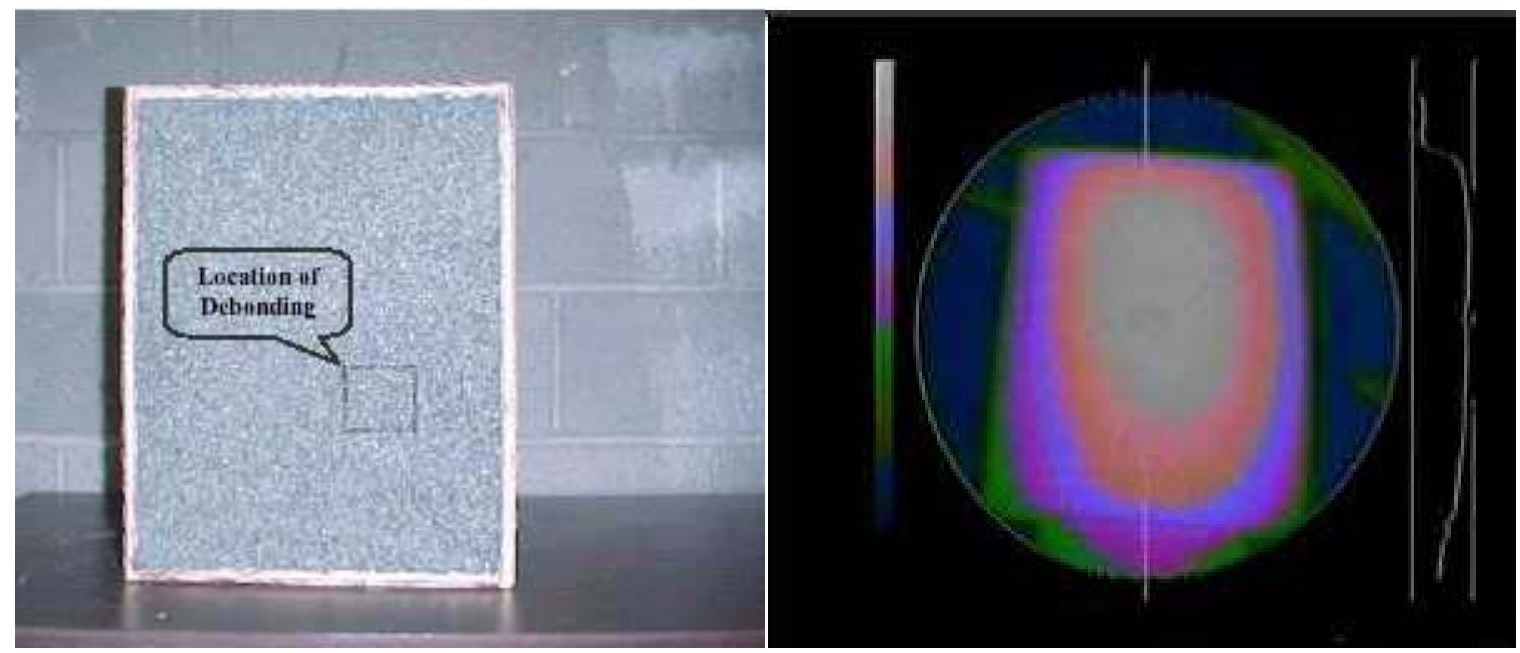

Figure 3.1.2 (a ) Photograph, and (b) Infrared image of Sample 1 (Alqennah 2000).

radiation and negative heating by using liquid $\mathrm{CO}_{2}$ ) were used. Many infrared images were taken, but none were able to show the delaminations. Uniform heating could not be achieved with the heating gun.

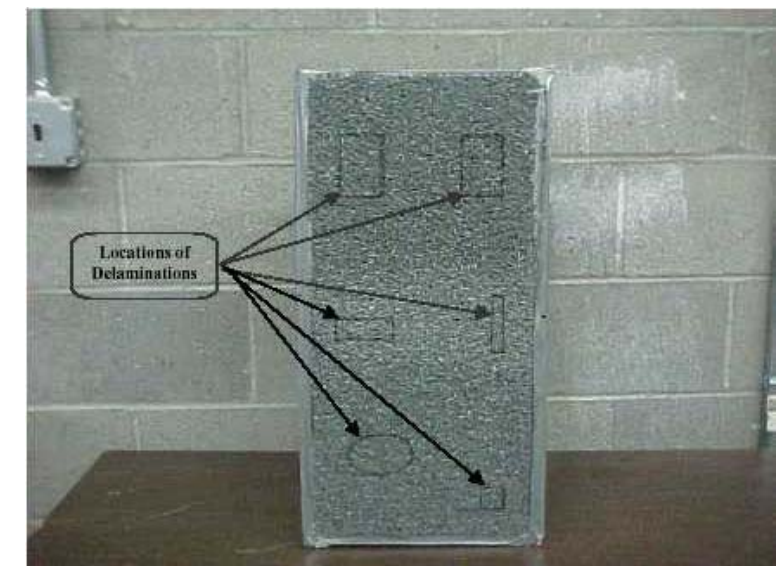

Figure 3.1.3 Photograph of Sample 2 (Alqennah 2000).

Sample 3 (shown in Figure 3.1.4a), was a specimen of size 12"x 16" with an 11"x 7.5"dimension air gap (of thickness 0.05 ") built in between the wearing surface and the deck. The sample was heated between the temperature ranges of 45 to $75^{\circ} \mathrm{C}$ using quartz tower heater. The temperature difference between the sound area and delaminated area was about $7^{\circ} \mathrm{C}$, clearly visible in the Infrared image. The corresponding infrared image of the specimen is as shown in Figure 3.1.4b. 


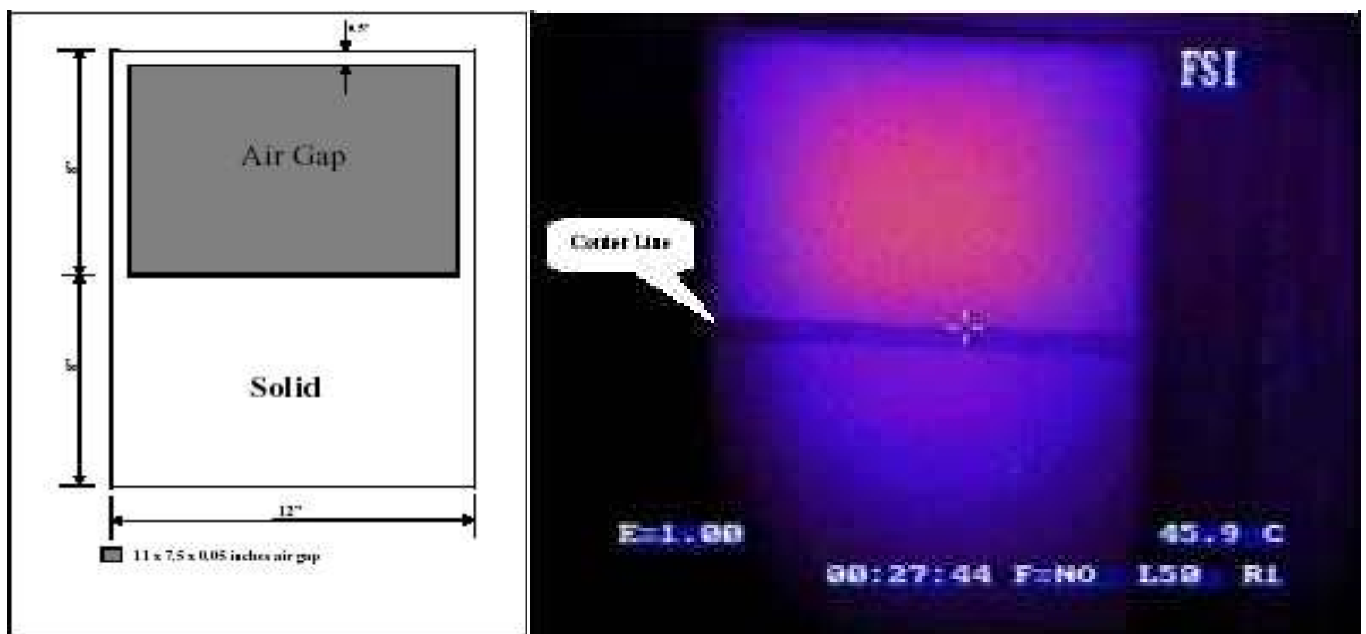

Figure 3.1.4 (a) Sample 3 (Alqennah 2000). (b) Infrared image of the Sample 3 (Alqennah 2000).

For Sample 4, a 12"x 16" FRP composite deck specimen with two subsurface delaminations consisting of $0.05 "$ thick air gaps were constructed as shown in Figure 3.1.5a. The specimen was heated up to $82^{\circ} \mathrm{C}$ using quartz tower heater. Figure $3.1 .5 \mathrm{~b}$ shows the infrared image of the specimen. Good contrasts were achieved and the delaminations were seen clearly.

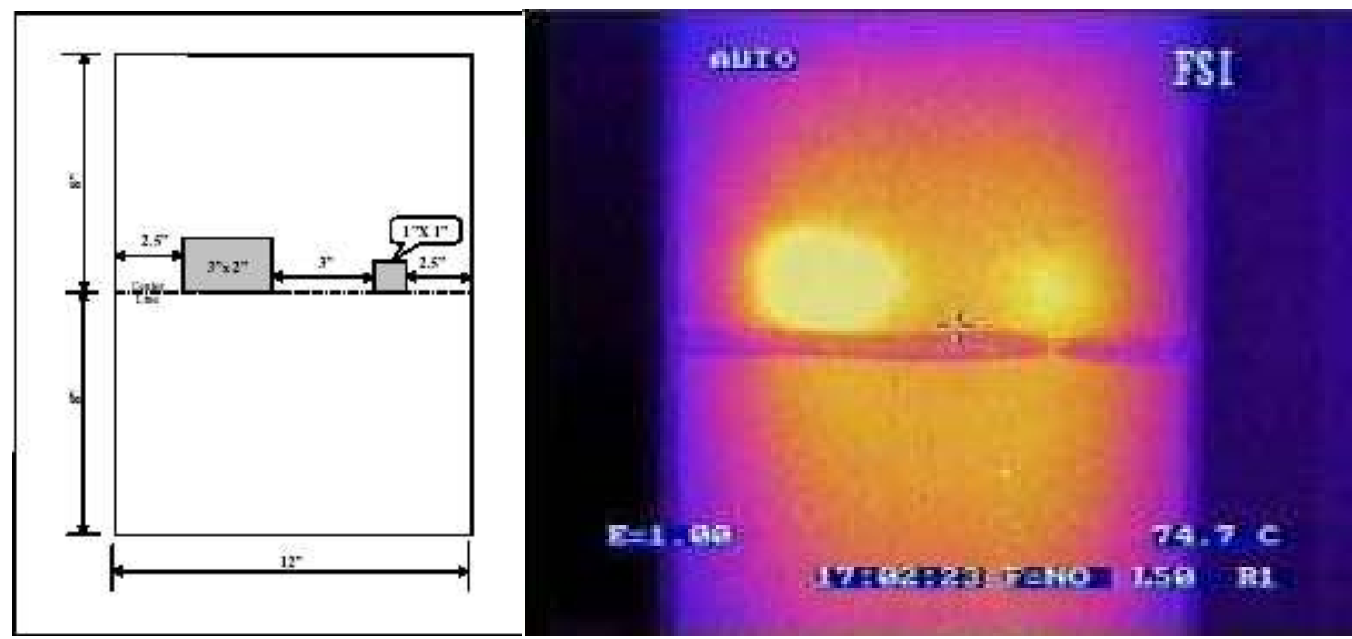

Figure 3.1.5 (a) Sample 4 (Alqennah 2000). (b) Infrared image of the Sample 4 (Alqennah 2000).

\section{Conclusions:}

Laboratory experiments on FRP composite bridge deck specimens have shown that infrared thermography can be applied successfully for the detection of subsurface anomalies. A 
delamination as small as 0.005 " thick under a $3 / 8^{\text {th }}$ inch wearing surface is detectable using this technique.

\subsubsection{Field Studies}

Infrared thermography was used for the condition assessment of two composite bridges (Laurel Lick bridge and Wickwire Run bridge). These bridges are built with FRP composites. The deck section, 8 " in depth, is made of full-depth hexagons and half depth trapezoids. The deck is supported over longitudinal beams. A thin layer of concrete overlay or wearing surface is applied on the deck.

The equipment set up for the field was same as that for the laboratory except for the heat source (solar radiation was used in the field). The average ambient temperature while taking the images was around $24{ }^{\circ} \mathrm{C}$. The decks were divided into one foot wide lanes for testing. The camera was mounted on a cart and the images were continuously recorded on a video tape.

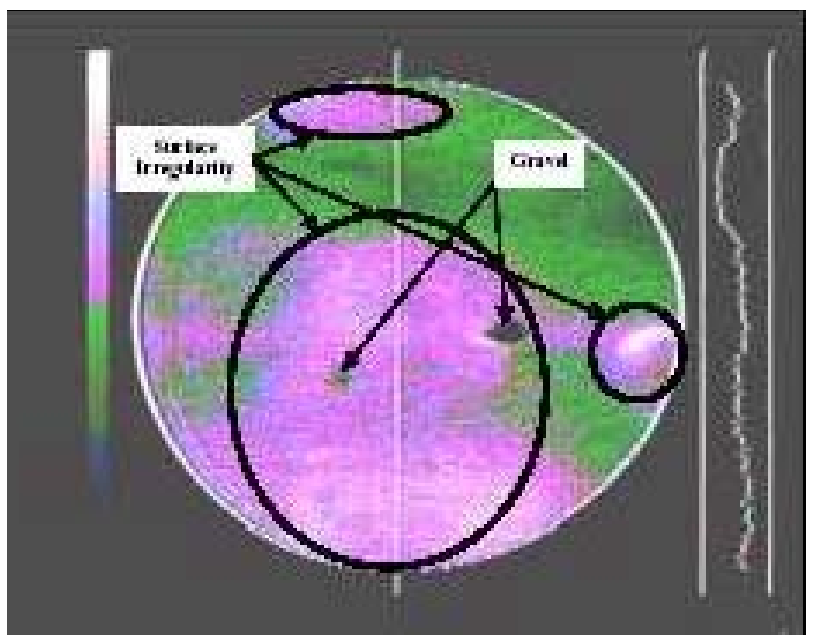

Figure 3.1.6 Infrared image of Laurel Lick bridge deck showing surface irregularities (Alqennah 2000).

Figure 3.1.6 shows the infrared image taken on the deck surface of Laurel Lick bridge. Figure $3.1 .7 \mathrm{a}$ and $3.1 .7 \mathrm{~b}$ show the photograph and the corresponding infrared image of a surface irregularity on the Wickwire Run bridge, respectively. Both bridges are 
relatively new (constructed in 1997) and did not have any subsurface delaminations as indicated by the thermographs. However, some cracks could be seen on the deck surface. Care must be taken while interpreting the thermographs because the radiation reflected off the adjacent structures and shadows can easily be mistaken for the defects.

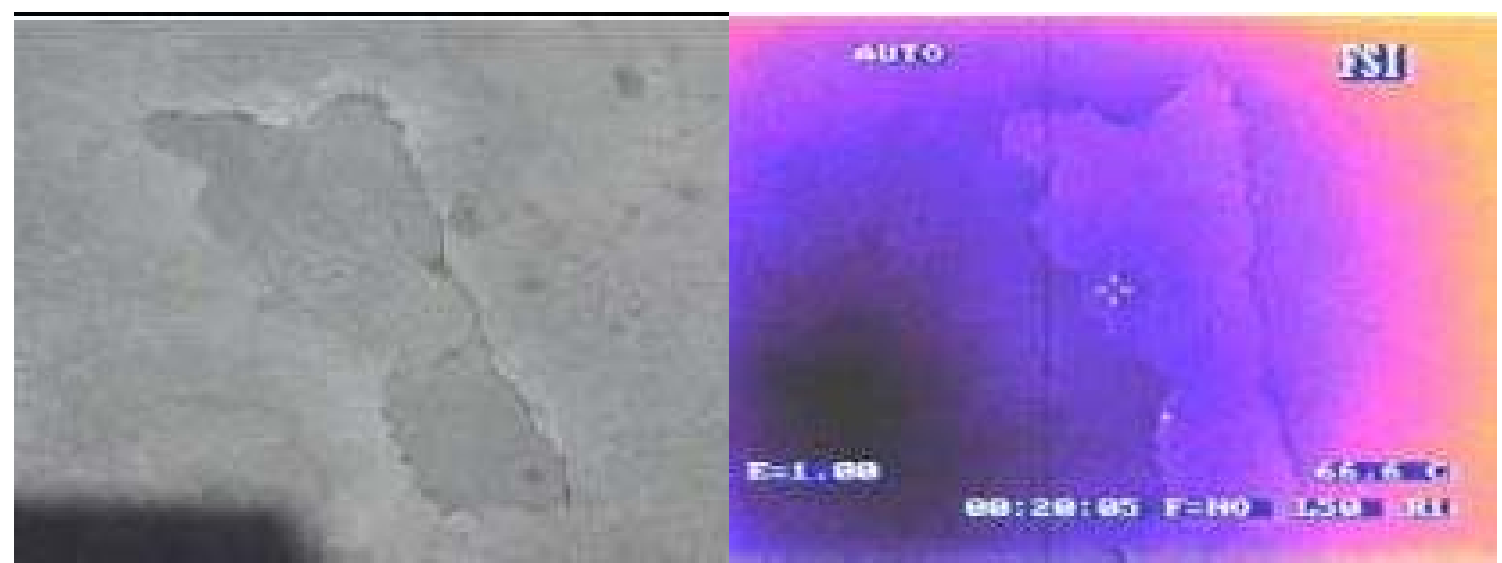

Figure 3.1.7 (a) Surface irregularity (Alqennah 2000). (b) Infrared image of the surface irregularity (Alqennah 2000).

Further, these test were conducted for the evaluation of the FRP wraps on the columns of another bridge (Pond Creek bridge) to detect any debonding between FRP wraps and the concrete columns. The thermographs did show some temperature differentials indicating either de-bonding or de-laminations in the wrap. Figure 3.1.8 shows an infrared image of one of the columns of the Pond Creek bridge.

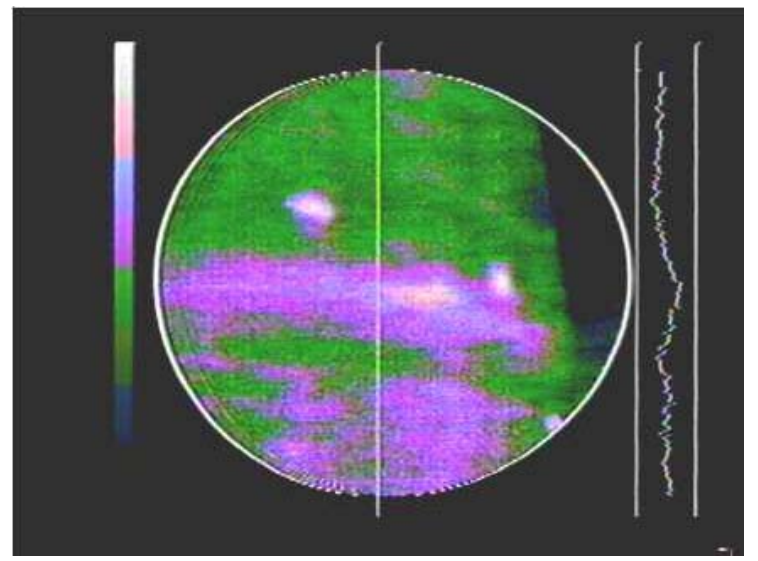

Figure 3.1.8. Infrared image of one of the columns of Pond Creek bridge (Alqennah 2000). 


\subsection{NDE of Composite Seismic Retrofits to Bridges (Johnson et al. 1999)}

\subsubsection{Abstract and Background}

In recent years, seismic retrofitting of bridge columns and rehabilitation of other concrete structures are being done using composite materials. Broadly, there are three main methods of wrapping columns with composite wraps. They are hand lay-up, pre-cured shells and machine wraps. Each method has its own shortcomings which result in the introduction of flaws in the wraps.

In the hand lay-up method, the composite fabric (which comes in wide rolls) is cut to the required shape and placed manually on the column after dipping it in the resin. It is then spread over the surface uniformly and is pressed to squeeze the extra resin and trapped air out. Then it is allowed to cure. There is another hand lay-up method, wherein the fabric comes in $25 \mathrm{~cm}$ wide rolls, with a paper backing. The resin is applied on the cleaned surface over which the fabric is placed with the paper backed surface facing outwards. Then the paper is removed and resin coating is applied. This is done to have resin fully wet the fabric.

In case of pre-cured shells, they are constructed using fiberglass reinforced sheets of molded plastic that are stitched into non-crimp fabrics to form a strong continuous-strand mat. The mat is then saturated with resin, molded and cured to form a shell of shape and size that fits the column. The shell is then slit and trucked to the job site. The shell is then opened along the slit, stretched and snapped onto the column coated with the resin. The adjacent shells are placed butting against each other so that the split lines never line up and there is always staggering of split lines. After all the shells are placed on the column, cinching straps are tightened over the shells to squeeze out excess adhesive and tighten the shell onto the column. 
In the third method of wrapping, a machine is used. The machine assembled at the job site, involves a circular track around the column, which is typically hung form the chains. The spools of fiber and the epoxy bath are rotated around the column along the circular track. The machine climbs up the chain and wraps the column with fibers.

These methods of wrapping, with their own inherent shortcomings, may result in the inclusion of flaws such as debonds at the composite-concrete interface or within the composite itself.

\subsubsection{Thermography System}

The camera used for the study was a $256 \times 256 \mathrm{InSb}$ FPA, in the $3-5 \mu \mathrm{m}$ band, with an onboard Stirling cycle cooler. This camera had a range of Germanium lenses (standard, wide angle and telephoto) with sufficient flexibility for wide range of inspection applications. The data was stored in two ways. An ongoing record of the inspection was done on Hi-8 format videotapes and when a feature of interest was noted in the infrared image, a higher resolution digital image was acquired via the cameras parallel interface and stored on a portable computer. Typically, the temperature gradient was established by heating the target surface for some predetermined time and then removing the source. The time of heating and the heat intensity had to be matched to the type of the structure inspected and the depth of the flaws that needed to be imaged. Shallow defects are visualized better when the gradient is established quickly and for this purpose photographic flash lamps were used. Where there were deeper flaws or where the materials had low thermal conductivity, a larger thermal input energy was required to get the required thermal gradient. For one of the retrofit systems, a line of eleven overlapping 500W lamps maintained at a distance of $50 \mathrm{~mm}$ and scanned at $\sim 0.5 \mathrm{~m} / \mathrm{sec}$ was effective. Though this system provided uniform heating it 
required the column to be within the arms reach. The use of high intensity arc lights may work well for more remote inspection. For a column, which was exposed to sunlight for some time of the day, the advantage of direct solar heating was utilized.

\subsubsection{Results}

The infrared images obtained for various column retrofit methods are presented in this section. In the thermal images, lighter colors were assigned to regions of elevated temperatures, which are indicative of debonding or porosity.

Figure 3.2.1 shows the infrared image (right) of a rectangular column (photo - left), which was wrapped by hand lay-up method. Before the thermography inspection, the column was tap tested. The photograph shows the chalk marks made by tap testing, for later comparison. Localized regions of elevated temperatures are indicative of the debonding and correlate well with the tap test results.
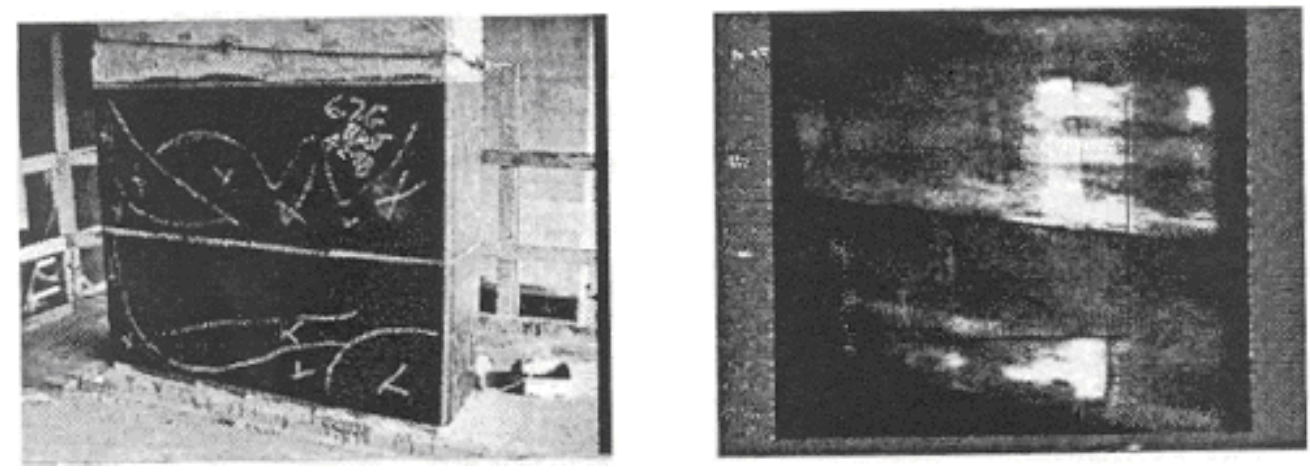

Figure 3.2.1. Photographic and thermographic images of west (larger) and south face of a hand wrapped column. Extensive debond indications were noted at the edges of the wrap. This column shows the most extensive debonding of all the columns investigated as part of this inspection. Essentially the entire lower half of the top wrap was debonded. Tap test results outlined with chalk show similar results (Johnson et al. 1999).

The Figures 3.2.2 to 3.2.4 presented below resulted from inspections of cylindrical columns, which had been retrofitted with pre-cured shells. From the Figure 3.2.2, it is evident that the small debonds are likely to occur close to the slits or butt ends where the use of cinching straps may not be very effective. 


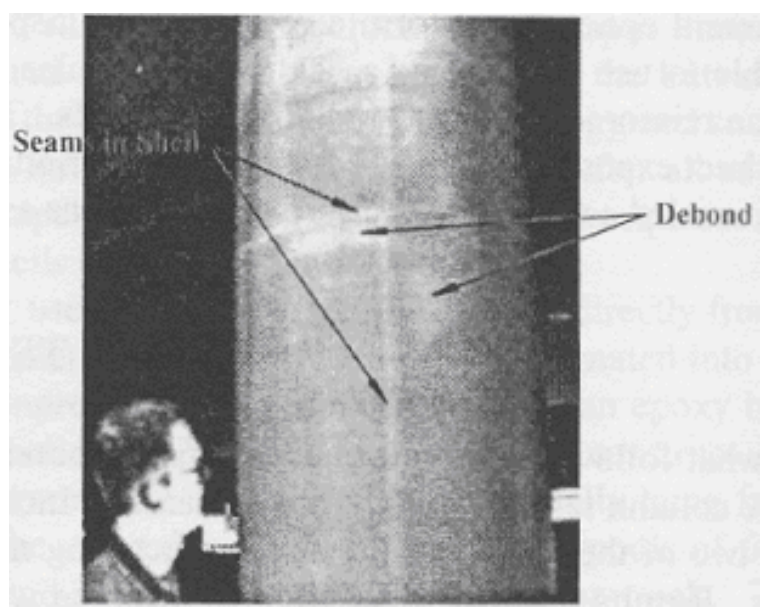

Figure 3.2.2. Thermographic image of a cylindrical column retrofitted with a pre-cured shell showing small debonds. For this type of column, debonds tend to be close to the slits or butt ends where the cinching straps may not have been effective. The seams in the shell were also quite evident (Johnson et al. 1999).

The two images in the Figure 3.2.3 are the thermographs of two sides of the same column. Large debond is seen in the left image which can occur when the spray adhesive partially cures before the straps are tightly cinched. In the right image the debond could be seen only after heating for a longer time, indicating the defect to be present farther below the surface.
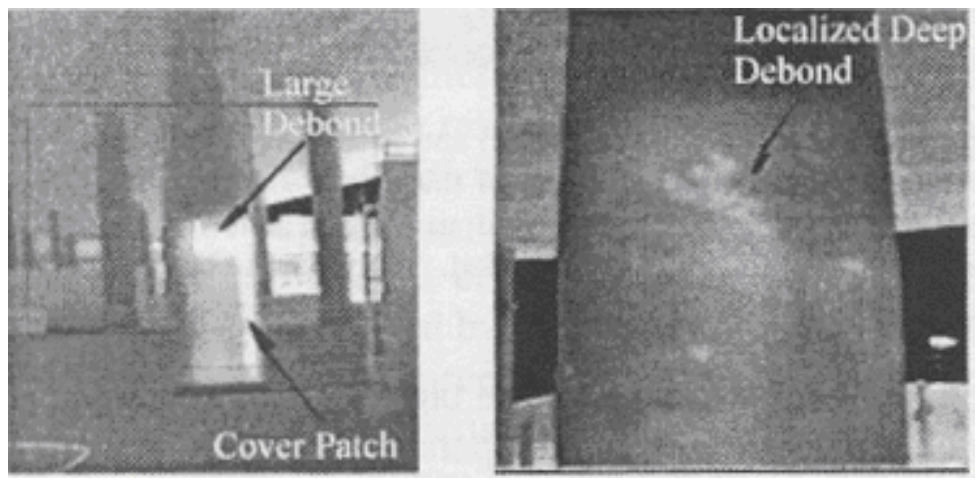

Figure 3.2.3 Thermographic images showing a cylindrical column retrofitted with a pre-cured shell showing large debonds and a localized deep debond (Johnson et al. 1999).

Figure 3.2.4 shows the thermograph of a column with prefabricated shell in which a core specimen was removed. The enlarged view of this opening is shown in the photograph in the right. The debond between the shell and the underlying concrete is clearly visible in the photograph and measured approximately $4 \mathrm{~mm}$. 


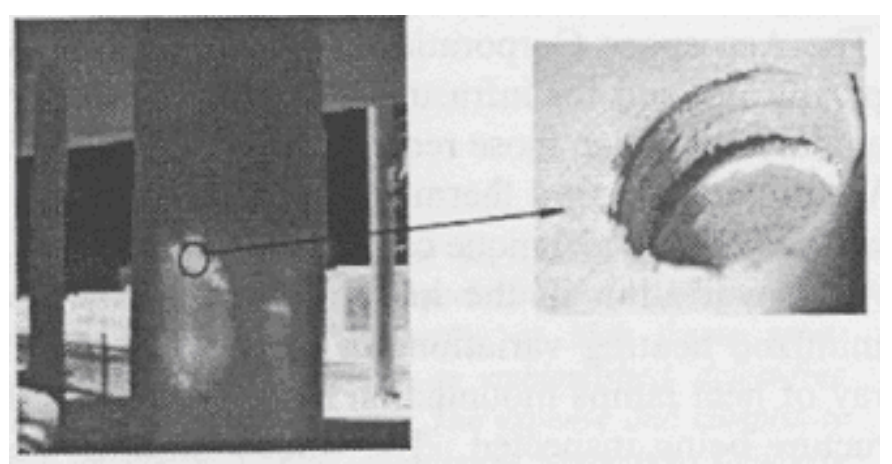

Figure 3.2.4 Core-section of a large debond discovered in prefabricated shell. The gap between the shell and the underlying concrete measured approximately $4 \mathrm{~mm}$ (Johnson et al. 1999).

No debonds of any significance were found on machine wrapped circular columns. Laying down the fibers one strand at a time, precludes the formation of large debonds. However, slight concavities on the column surfaces cause the air gaps to get trapped underneath the wraps.

\subsubsection{Discussion}

Infrared thermography is a noncontact optical inspection technique, the primary requirement of which is an unobstructed line of sight to the target area. It can be used to inspect large areas in short time. For instance, Figure 3.2.5 shows a glass/polyester shell bonded bridge column of a working bridge under I-10 freeway in Los Angeles, CA. An initial IR survey from over 50 feet away showed clear indication of less than 2 -inch diameter flaws, which were confirmed as voids during subsequent coring. However, there are other problems such as uneven heating. A linear array of heat lamps mounted on wheeled base was used for heating. The wheels hold the heat lamps at a constant distance away from the surface. Even though uniform heating is achieved, temperature variations of the surrounding environment may affect the images. Cold winds blowing in one direction cool that side of the column faster than the other side causing a temperature differential. The images taken at different times of the day show variations because of the concrete getting heated by the solar 
radiation. There is an additional problem associated with the pre-cured shells, where the adhesive is a poor conductor and its thickness varies substantially. If these variations are not accounted for, the image appears to have large debonds, which in reality, are areas of thick adhesives. The emissivity of the surface under inspection can change due to dirt particles clinging to the surface and even the instruments can be ruined by the dirt.

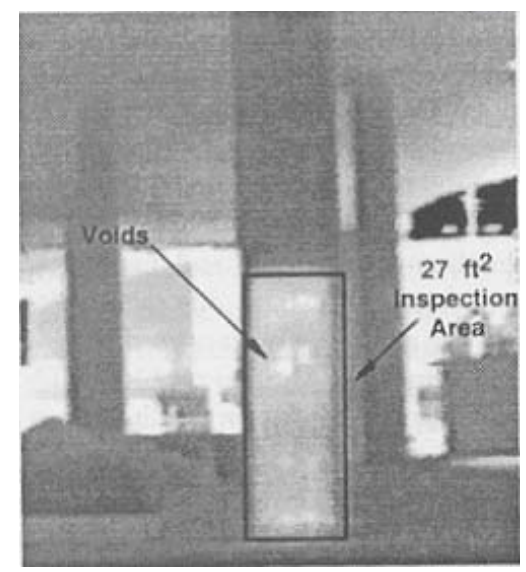

Figure 3.2.5 Sample thermographic image from an IR inspection with the imager located over $50 \mathrm{ft}$. from the column. Void indications with features of less than 2 inch were clearly visible in the outlined inspection area. The scan took less than one minute to perform (Johnson et al. 1999).

\subsubsection{Summary}

Three methods of retrofitting of the bridge columns with composite wraps were presented. The use of infrared thermography for the inspection of such retrofits for voids and debonds was demonstrated. Advantages of infrared thermography such as remote inspection capability, decreased inspection times and convenient means of data archival were identified. 


\subsection{Automated Thermographic Defect Recognition and Measurement (Shepard et}

\section{al. 1999)}

\subsubsection{Introduction}

In various applications such as detection of trapped water in honeycomb panels, assessment of solar panel adhesion, wing fastener corrosion detection and evaluation of composite repairs, Pulsed Thermography has been used as an effective Nondestructive Inspection (NDI) technique. However, the reality is that the present day thermographic NDI practices carried out outside the research laboratories are qualitative and require subjective assessment by a human operator. A trained inspector is required to make reject or repair decisions typically based on the visual inspection. Although methods of quantitative thickness and defect depth measurements have been developed using Pulse thermography, most are based on the analysis of contrast curves that require defect free reference region to be picked by the operator and hence they have not proved to be reliable, especially for deeper flaws. Temporal analysis of each pixel in the image is also used as a means of defect depth measurements. In these methods (temporal analysis or contrast curve analysis of single image) false calls due to surface markings, emissivity variations, reflections and normal variations of the material composition are difficult to avoid without an expert.

\subsubsection{Theory}

The 3-Dimensional diffusion equation of the thermal response of a thick (semiinfinite) opaque solid sample with an insulating subsurface defect, immediately after illuminated by spatially uniform light pulse, is described by,

$$
\nabla^{2} T-\frac{1}{\alpha} \frac{\partial T}{\partial t}=0
$$


where, del operator $\nabla^{2}=\frac{\partial^{2}}{\partial x^{2}}+\frac{\partial^{2}}{\partial y^{2}}+\frac{\partial^{2}}{\partial z^{2}}, \alpha$ is the thermal diffusivity and $\mathrm{T}=\mathrm{T}(\mathrm{x}, \mathrm{y}, \mathrm{z})$, is the temperature of the sample. Using a simple separation of variables, one may treat this equation in such a way that a defect signature based on both spatial and temporal characteristics of the surface profile becomes evident.

In a defect-free sample, at a point far away from the edges, lateral heat flow components cancel and the temperature distribution can be approximated by

$$
\frac{\partial^{2}}{\partial z^{2}} T-\frac{1}{\alpha} \frac{\partial T}{\partial t}=0
$$

Contrary to that, the presence of an insulating subsurface defect obstructs the flow of heat into the sample and the incident thermal energy is trapped between the defect and the sample surface. The trapped energy flows towards cooler areas surrounding the defect in the lateral direction, which will be the dominant cooling mechanism in the region. The temperature distribution in this case can be approximated by

$$
\nabla_{x, y}^{2} T-\frac{1}{\alpha} \frac{\partial T}{\partial t}=0
$$

The interpretation of pulsed thermography results is made easy by the above method of separation of diffusion equation and further it helps in understanding the results better. For the quantitative defect depth measurement (Ringermacher et al. 1998, Vavilov 1994, Han et al. 1998, Plotnikov et al. 1999) the diffusion equation in the form of Equation 3.3.2 is used to identify the peak slope or peak contrast amplitude of the contrast curve. Others have made use of Laplacian operator (Almond et al. 1996) to exploit the spatial "curvature" of the surface temperature distribution over a defect suggested by the Equation 3.3.3. 

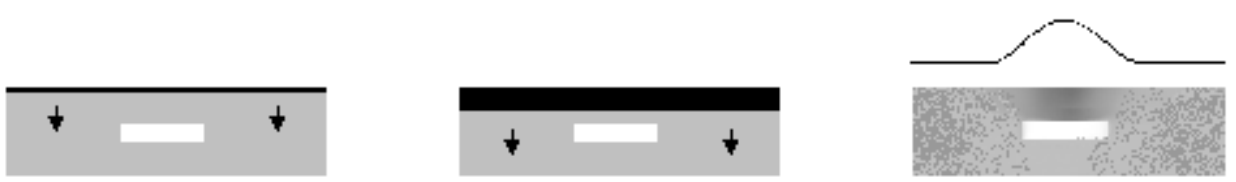

Figure 3.3.1 Heat flow due to a flash pulse. Initially the pulse causes thin layer of uniform heat on the surface (Left). Heat flows into the sample (Center). When a defect is encountered, the heat is trapped between the defect and the sample surface, giving rise to lateral heat flow above the defect (Shepard et al. 1999).

The analysis of pulsed thermographic data can be separated into two distinct time regimes as a result of the separation of the diffusion equation, a regime before the incident heat reaches the buried defect and that after it reaches the buried defect. The time at which the transition between the regimes occurs depends on the depth of the defect. Until the transition time is reached, the surface above the defect and the rest of the area behave in the same manner. After the elapse of the transition time, the dominant influence on the surface temperature above the defect is the lateral heat flow as per Equation 3.3.3.

\subsubsection{Experiment}

The separation of the diffusion equation can be utilized for automated defect detection and depth measurement. The basic concept can be illustrated by considering the behavior of a point located on the surface above a defect at known depth. In the experiment, the post-flash temperature-time behavior of this point (a single pixel) was continuously monitored for three different plies with different defect depths. This measurement was
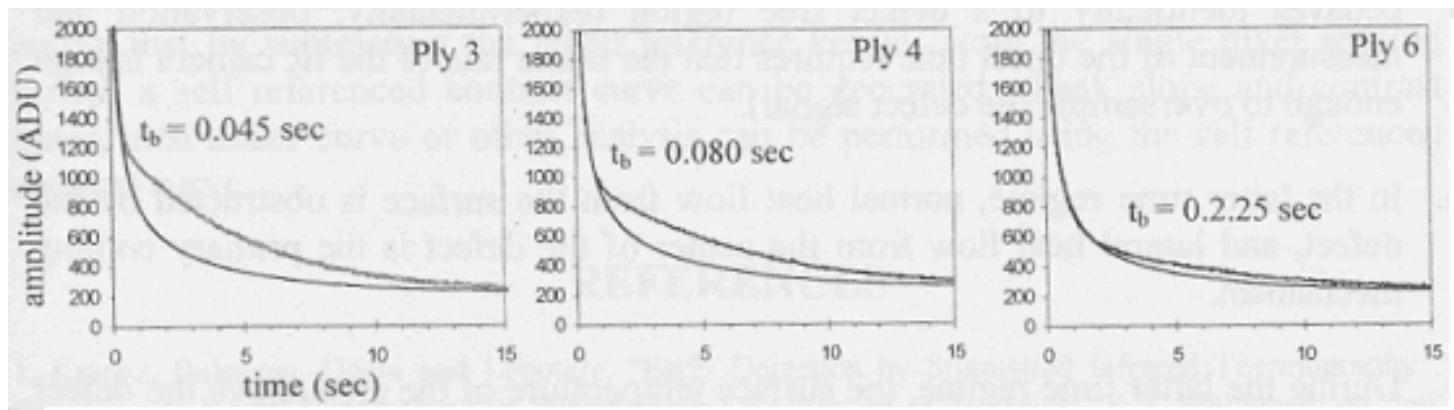

Figure 3.3.2 Comparison of single pixel (gray) and 25x25 pixel mean (black) above 0.25" diameter delaminations at plies 3, 4 and 6 in graphite epoxy laminate. Breakpoints appear at progressively later times for deeper defects (Shepard et al. 1999). 
compared with the mean temperature of $25 \times 25$ pixel rectangle surrounding it. The behavior of the single pixel and the rectangle surrounding it will be the same until they separate at time $t_{b}$, the break time at which the transition between Equations 3.3.2 and 3.3.3 take place.

Figure 3.3.2 shows the plots for the different depths of the defects. The separation between the two lines occurs because the larger area $(25 \times 25$ pixel rectangle) was much less sensitive to the emerging curvature of the defect than the single pixel right above the defect. It can be seen that as the defect depth increases, the break time, $t_{b}$ also increases.

If the break times for various depths of the defect are plotted against the square of the depth, a plot obtained is as shown in Figure 3.3.3. It exhibits an excellent straight-line fit suggesting that the break time can be used as a measure of the defect depth.

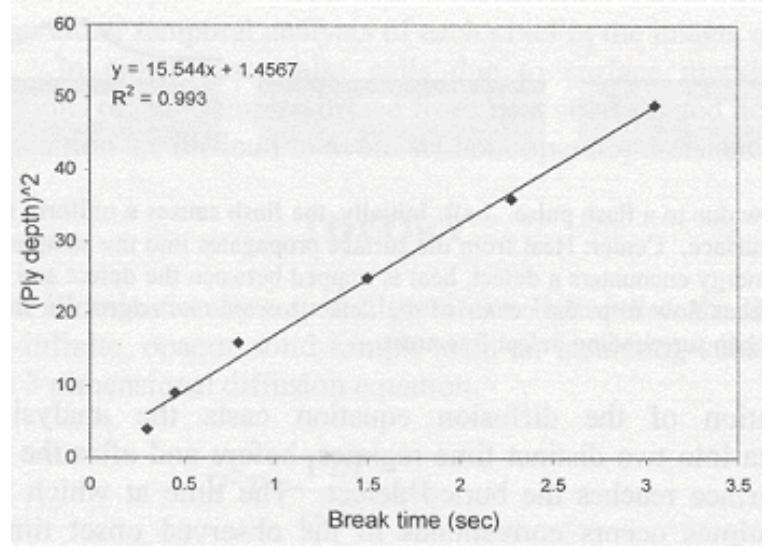

Figure 3.3.3 Break time vs. square of defect depth for a graphite epoxy panel with six simulated delaminations at various depths (Shepard et al. 1999).

\subsubsection{Discussion}

Comparison of the behavior of the surface temperature at a point above a defect to the temperature above a defect-free region, leads to the identification of the characteristics that serve as a signature of a subsurface defect. There is a distinct onset time during which the surface above the defect behaves the same as the defect-free region. To correctly delineate this onset time, a high frame rate IR camera is required. After this onset time, the normal heat 
flow from the surface is obstructed by the defect and the lateral heat flow from the defect region is the primary cooling mechanism.

A program was developed to automatically search a sequence of IR images for pixels that display these signature characteristics. Using an optimized algorithm, a 300-frame (256x256 pixel) image sequence could be analyzed in approximately 5 sec. The result presented in gray scale image is as shown in Figure 3.3.4. A reference standard with a single defect at a known depth can be used to calibrate the program according to the relationship

$$
d=\left(\alpha t_{b}\right)^{1 / 2}
$$

where, $d$ is the defect depth, $\alpha$ is the thermal diffusivity and $t_{b}$ is the break time.

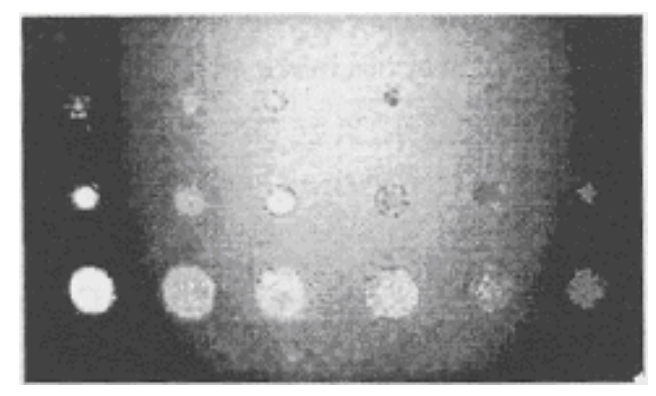

Figure 3.3.4 Self-referenced image of graphite epoxy panel with simulated 0.25 ", 0.5 " and 0.1 " delaminations at plies 2 through 6 . Only defect areas are indicated in color, which has been scaled to indicate depth. The image was generated from a 300 frame sequence in 5 seconds (Shepard et al. 1999).

\subsubsection{Conclusion}

For defining a defect signature and identification of true subsurface defects without human intervention, parameters such as the characteristics of onset time, lateral heat flow and non-uniform temperature distribution can be used. It is worth noting that by subtracting the larger reference kernel from single pixel sensing kernel, a self-referenced contrast curve can be generated. Peak slope and contrast times, area under the curve and other analysis can be performed using the self-referenced the contrast curve. 


\subsection{Temporal Treatment of a Thermal Response for Defect Depth Estimation}

(Plotnikov and Winfree 1999)

\subsubsection{Introduction}

Transient thermography is gaining popularity as a NDT\&E tool, because of its rapidness and remoteness. Flaws in a component may induce thermal contrast in surface thermograms. The quantitative ability of this technique can be improved by estimating the depth of the flaws. From one scan, it is possible to locate the flaw regions (due to corrosion) and their implications on the structural integrity.

The research reviewed here focused on 8 and $20 \mathrm{~mm}$ thick composite aircraft components with varying defect depths. A long square heating pulse $(\cong 8.5 \mathrm{~s})$ and several minutes of observations are required to receive adequate thermal response for depth determination. A three dimensional finite difference model of heat propagation in solids in Cartesian coordinates was used to simulate the thermographic process.

\subsubsection{Processing of the Thermal Response in Time Domain}

To estimate the defect depth, temporal characteristics of the thermal response received from the exited surface is used in most of the algorithms. The flaw depth is parameterized in terms of a specified point on the thermal contrast curve or divergence point between two temperature evolution curves (one from an inspected area and another from a flawless area). For this, first it is necessary to get smooth contrast curve for each pixel in the thermogram and second to locate the characteristic point. Calculating thermal contrast involves extracting two temperature time evolutions (for inspected area and for reference area). By locating the characteristic point on the thermal contrast curve, it was possible to construct a new image with improved defect characterization. Since there are several 
characteristic points on the contrast curve, it was possible to construct several characteristic images.

\subsubsection{Comparison of Algorithms (Computational Approach)}

The purpose of this work was to perform a fair comparison of the informative characteristics such as, the thermal contrast - time evolution plots and various points on these plots, and highlight their strengths and weaknesses. The thermal contrast extraction from noisy experimental data is a complicated procedure involving careful application of noise reduction techniques. Hence, it was informative to study general features of the characteristics points using noise-free simulated thermal contrast curves. This helped to assess their behavior in an unbiased way. The simulated curves were smooth, which enabled invariant determination of informative parameters.
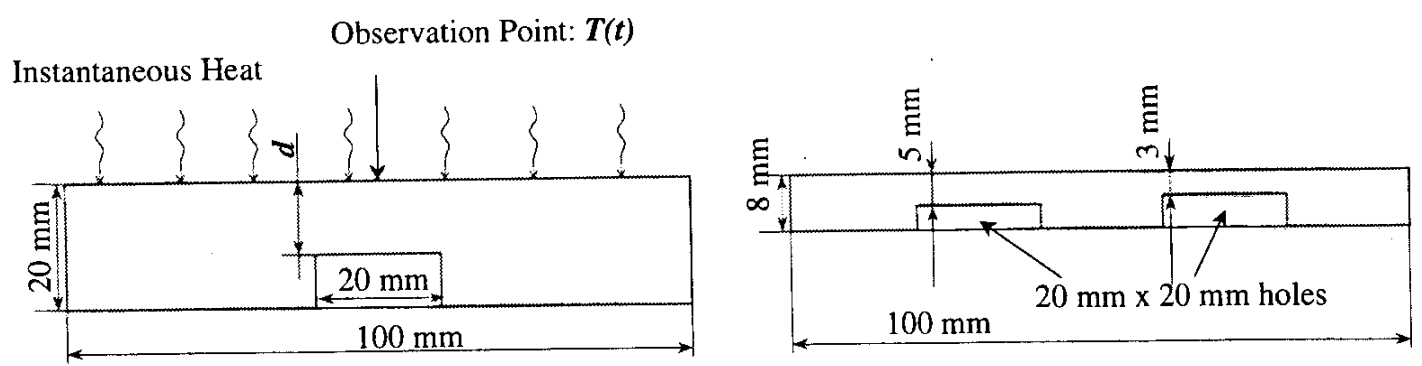

Figure 3.4.1 (a) Isotropic panel with one defect. (b) Isotropic panel with two defects (Plotnikov and Winfree 1999).

The cross sections at the centerline of one of the three-dimensional models that were used for numerical computations is presented in Figure 3.4.1.a and the other two defect depth configurations are as shown in Figure 3.4.1.b. Isotropic plates of composite material (plan dimensions $100 \times 100 \mathrm{~mm}^{2}$, thermal diffusivity $\alpha=1.4 \times 10^{-6} \mathrm{~m}^{2} / \mathrm{s}$, thermal conductivity $\mathrm{K}=2.7$ $\mathrm{W} / \mathrm{m} / \mathrm{K}$ ) with thicknesses shown in Figure 3.4.1. were used to investigate the parameters of interest. The defect incorporated in the model was square non-conductive flat bottom void with $20 \mathrm{~mm}$ on a side. The void was located at a depth ' $\mathrm{d}$ ' below the surface. An 
instantaneous uniformly distributed heating pulse was used to excite the upper surface (Figure 3.4.1.a). An alternating direction implicit scheme was used to obtain a solution of the 3D thermal diffusion equation. Boundary conditions were chosen to simulate an adiabatic transient process. Temperature evolution functions were computed at the central point of the plate (above the center of the flaw) and at the corner of the plate (for the reference value). The time evolution of the thermal contrast was computed using Equation 3.4.1 from these two temperature functions.

Temperature evolution functions of a thermal response, for three different locations are shown in Figure 3.4.2.a. $\mathrm{T}_{\text {ref }}(\mathrm{t})$ is the average thermal response in a reference region as a function of time, t. $T_{3}(t)$ and $T_{5}(t)$ are the averaged thermal response for the regions above flat bottomed holes located 3 and $5 \mathrm{~mm}$ under the specimen surface (see Figure 3.4.1.b). The curves for 3 and $5 \mathrm{~mm}$ defect depths are noticeably different from the $T_{\text {ref. }}$ Since there was a sufficient thermal contrast, it was possible to characterize those defects.

A common form of a thermal contrast curve is given as follows:

$$
C(t)=\frac{T(t)-T_{r e f}(t)}{T_{r e f}(t)}
$$

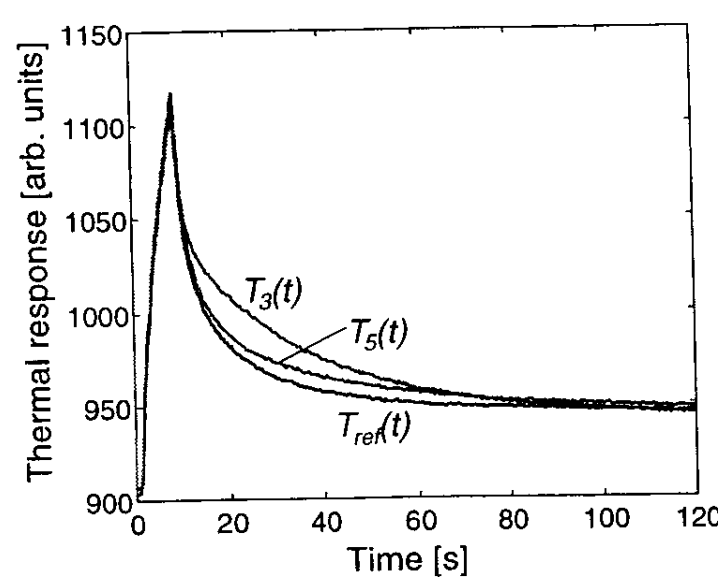

Figure 3.4.2 (a) Time evolution function (TMF) of thermal response (Plotnikov and Winfree 1999).

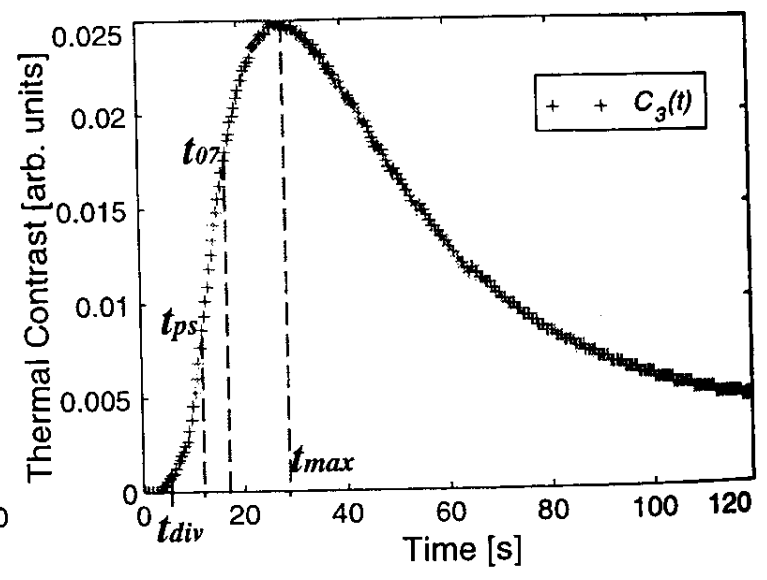

(b) TMF of thermal contrast. 
Figure 3.4.2.b shows the thermal contrast curve, $\mathrm{C}_{3}(\mathrm{t})$ obtained after smoothening with a low pass filter to reduce the noise. Several characteristic points could be identified on the contrast curve, which enabled defect depth determination. The point $t_{\text {div }}$, corresponds to the moment the temperature signal above the inspected point diverges from the reference signal (Figure 3.4.2a). Establishing of a threshold level is required to identify this point on the time evolution curve (Karpez et al. 1994). Another point was $t_{\mathrm{ps}}$, the point corresponding to the time when the contrast curve had the peak slope (Favro et al. 1996). This point was determined by seeking the first derivative of the thermal contrast - time evolution function. Other time parameters are also commonly used for defect depth estimation. They are the time of maximum contrast, $\mathrm{t}_{\max }$ and the time at which the contrast reaches 0.72 times the maximum contrast value, $\mathrm{t}_{07}$ (this is reported as a more stable value).

For the model considered in Figure 3.4.1.a (100x100x20 mm $\mathrm{mm}^{3}$ with $20 \times 20 \mathrm{~mm}^{2}$ defect size), the time related parameters corresponding to the simulated thermal contrast curves were computed with d varying from 1 to $19 \mathrm{~mm}$. The results are shown in the Figure 3.4.3.a. The parameters were dependent on the defect depth variation and therefore could be used for defect depth estimation. Also, the defect size variations have an impact on the parameters. Figure 3.4.3.b shows the same characteristic times for defects of sizes $10 \times 10 \mathrm{~mm}^{2}$ and $40 \times 40$ $\mathrm{mm}^{2}$ dimensions. The early time parameters $\left(\mathrm{t}_{\mathrm{div}}\right.$ and $\left.\mathrm{t}_{\mathrm{ps}}\right)$ were approximately independent of the flaw sizes for shallow depth defects and differed significantly for deeper defects. The later time parameters $\left(t_{07}\right.$ and $\left.t_{\max }\right)$ had large dependence on flaw size for shallow depths. Since the boundary condition of the model was approximated as an adiabatic transient process the material above the flaw approximated to a thermally insulated material for an initial period after heat application in case of wide defects. For a one-dimensional case, the 
contrast never achieves a maximum and hence the timing of the maximum is a function of both the size and depth of the flaw.

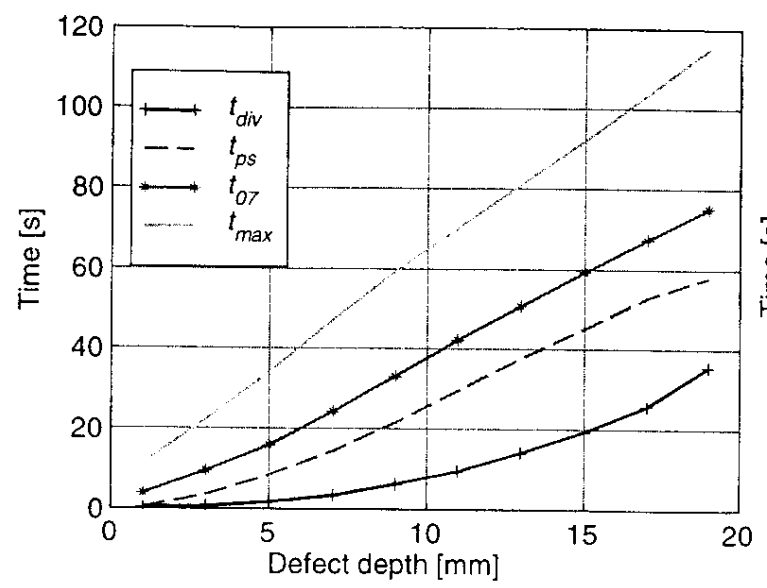

(a)

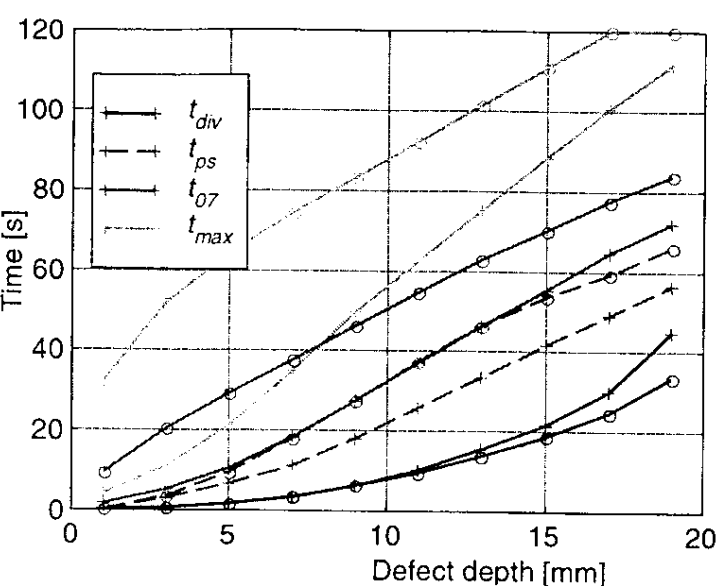

(b)

Figure 3.4.3 Temporal informative parameters for variable depth of a square non-conductive void (data from simulated thermal contrast evolutions). a) defect size is $20 \times 20 \mathrm{~mm}^{2}$; b) defect size is $10 \times 10 \mathrm{~mm}^{2}$ (shown in ++-+ ) and 40x40 $\mathrm{mm}^{2}$ (shown in o-o-o) (Plotnikov and Winfree 1999).

The next phase of the simulation was obtaining the lateral profiles of these timerelated parameters above the defects. It was informative to observe two defects in close proximity. The model configuration used is shown in Figure 3.4.4. Anisotropic media was considered (thermal diffusivity $\alpha=0.7 \times 10^{-6} \mathrm{~m}^{2} / \mathrm{s}$ along the depth and $1.8 \times 10^{-6} \mathrm{~m}^{2} / \mathrm{s}$ in-plane, and $1.4 \times 10^{-6} \mathrm{~m}^{2} / \mathrm{s}$ along and across the defect centerline, respectively).

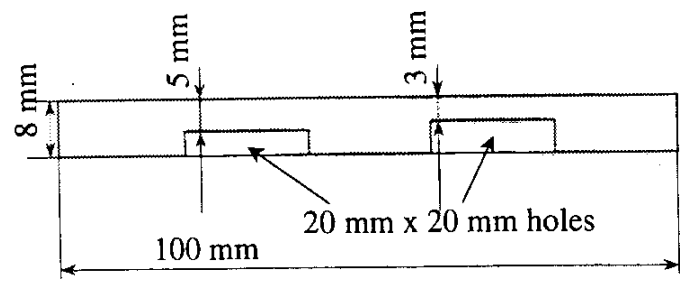

Figure 3.4.4 Anisotropic panel with two defects (Plotnikov and Winfree 1999).

Two-dimensional distributions were obtained for all informative parameters from the simulated thermal response. The lateral profiles above the two voids located 5 and $3 \mathrm{~mm}$ 
under the surface are presented in the Figure 3.4.5.a. Presence of the defects is evident in the reduced value regions of the characteristic time curves. Shallower depth defect is much more clear than the deeper defects. A series of simulated thermal images were stored in a binary format with a limited dynamic range to represent the measurement. This resulted in the introduction of noise into the time derivative and hence the $t_{\mathrm{ps}}$ profile is noisier. It is the case even in experimental results. The late parameters, $t_{07}$ and $t_{\max }$ provided better lateral separation of the defects because of their better in-depth penetration.

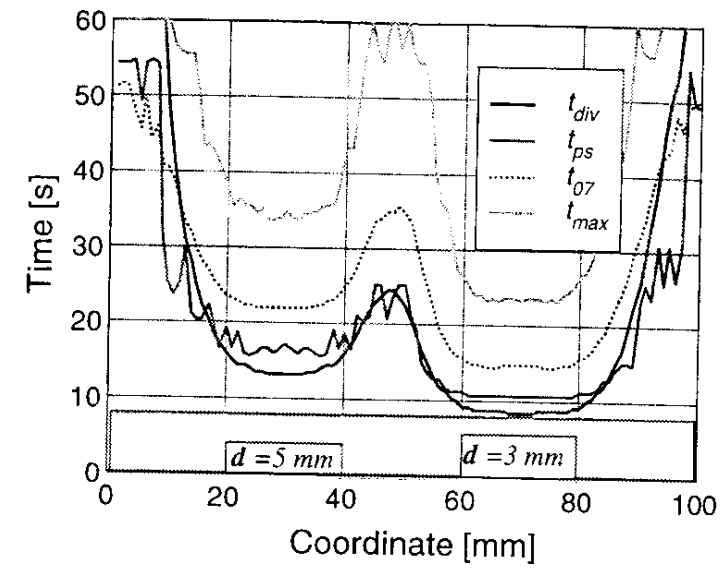

(a)

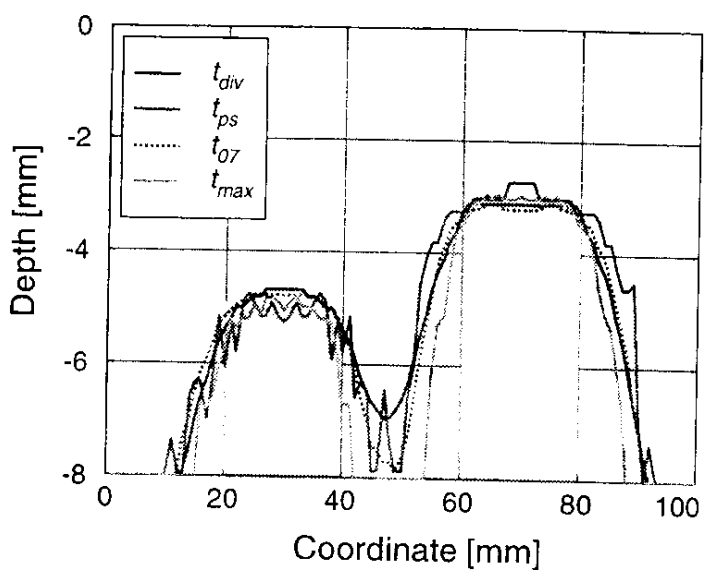

(b)

Figure 3.4.5 (a) Characteristic time profiles and (b) depth profiles, obtained from simulated data set (Plotnikov and Winfree 1999).

To characterize the defect depth a simple data inversion procedure was applied using a polynomial

$$
d=a \cdot \sqrt{t_{c h a r}}+b \cdot t_{c h a r}+c
$$

where, $t_{\text {char }}$ is one of the temporal informative parameters used. The constants $a, b$, and $c$ were determined separately for each parameter. The estimated depths and the actual geometry of the voids are shown in Figure 3.4.5.b.

Variations of the defect depths over a wide range in the simulated model highlighted some expected limitations of the technique. For example, it was difficult to obtain a depth 
profile based on $t_{\text {div }}$ parameter for shallow (less than $2 \mathrm{~mm}$ ) defects. The depth estimations based on $t_{\max }$ parameter had a noticeable crater-like surface for shallow defects. The deeper defects (greater than $6 \mathrm{~mm}$ ) estimated from $\mathrm{t}_{\mathrm{ps}}$ resulted in noisy profiles, but for other parameters deeper defects resulted in more rounded profile estimates.

\subsubsection{Comparison of Algorithms (Experimental Approach)}

The validation of the results of computational approach by experiments was very important. Measurements were performed on a piece of an aircraft wing box structure composed of thick stitched graphite-epoxy composite polymer. The panel had a thickness of $8 \mathrm{~mm}$ with 5 flat bottom $20 \times 20 \mathrm{~mm}^{2}$ holes machined into the backside. A thermal flux pulse lasting 8.5 seconds was applied to the front surface by two quartz lamps with a total power of $1.5 \mathrm{~kW}$. A series of 150 thermal images of $256 \times 256$ elements each with a sampling rate of $2.5 \mathrm{~Hz}$ were acquired for post processing.

The thermal contrast, as noted earlier, was computed for the quantitative information of the experimental data. Three commonly used forms of equation for contrast computations are

$$
\begin{aligned}
& C(t)=\frac{T(t)-T_{r e f}(t)}{T_{r e f}(t)-T_{r e f}(0)} ; \\
& C(t)=\frac{T(t)-T(0)}{T_{r e f}(t)-T_{r e f}(0)} ; \\
& C(t)=\frac{T(t)-T(0)}{T\left(t_{h}\right)-T(0)}-\frac{T_{r e f}(t)-T_{r e f}(0)}{T_{r e f}\left(t_{h}\right)-T_{r e f}(0)},
\end{aligned}
$$

where $t_{h}$ is the time of the heating pulse, when the thermal response has the highest magnitude. Even though all three equations are used, Eq. 3.4.3 provided the poorest result and the Eq. 3.4.5 provided the clearest defect images in the timegrams shown in Figure 3.4.6. 
It is worth noting that the time evolution function could be constructed for a segment of several (for instance $3 \times 3$ ) pixels. This furnished a lower noise level. However the increase in the possible permutations made it difficult to compare the contrast extraction techniques.

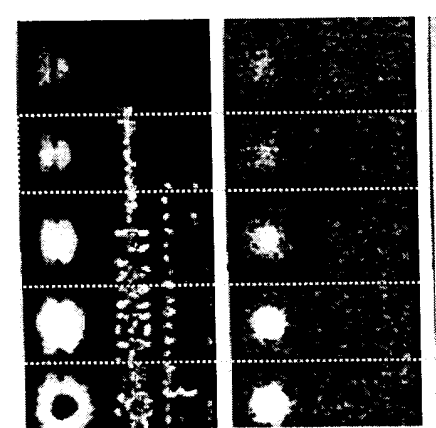

(a)

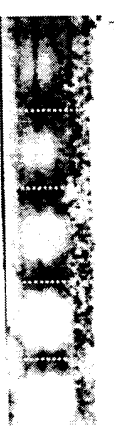

(c)

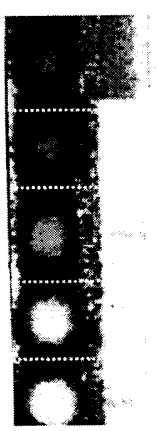

(d)

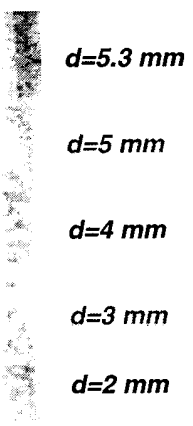
Figure 3.4.6 Timegrams $t_{\text {char }}(i, j)$ of the $8 \mathrm{~mm}$ composite panel with flat bottom holes of various depths obtained
by using different informative parameters. (a) $t_{\text {div }}$; (b) $t_{p s}$; (c) $t_{07} ;$ (d) $t_{\max }$ (Plotnikov and Winfree 1999).

To compute the defect depth, Eq. 3.4.2 was applied to the obtained characteristic time distributions. The estimated depth from $t_{\text {div }}$, yielded an inaccurate representation of the shallowest defect. A gray scale depth image obtained by averaging the depth profiles estimated from three other timegrams $\left(t_{p s}, t_{07}\right.$, and $\left.t_{\max }\right)$ is shown in the Figure 3.4.7. The comparison between the estimated and the actual (dotted line) bottom profiles for the centerlines of the defects is also shown. The reconstructed profiles for the defects have round edges and also the noise in the defect- free area is pronounced.
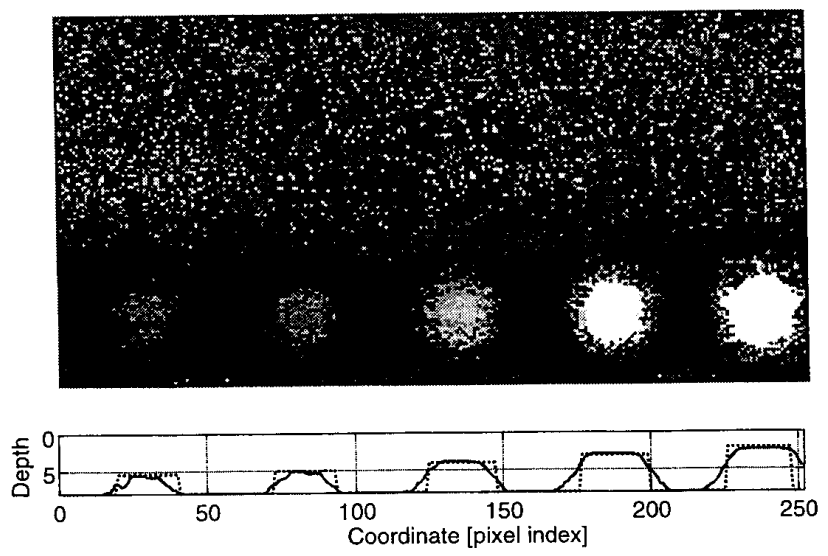

Figure 3.4.7. 2D contrast image and average depth profile (Plotnikov and Winfree 1999). 
To overcome the above said limitations, an initial defect free map was constructed using pulse phase technique followed by Laplacian defect shape extraction (Plotnikov and Winfree 1999). The defect planar geometry in the resulting defect map provided a much more accurate representation of the real defect geometry. A masking of the depth profile with this binary defect map yielded an accurate representation of the internal structure. The 3D representation of this result is shown in Figure 3.4.8.

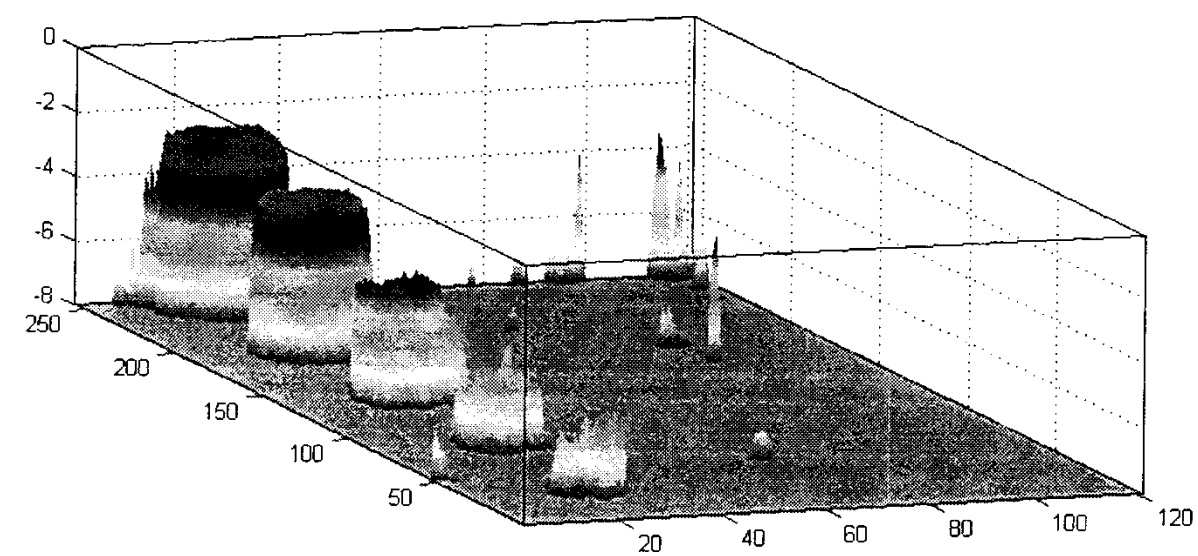

Figure 3.4.8. 3D image of the flat bottom holes in the 8-mm composite panel obtained with the thermal technique. Vertical scale is given in $\mathrm{mm}$, horizontal scales are in pixels (approx. $0.86 \mathrm{pixel} / \mathrm{mm}$ ) (Plotnikov and Winfree 1999).

\subsubsection{Conclusion}

For large defects (lateral dimensions greater than twice the panel thickness), all considered parameters were found suitable for defect depth determination. The best results were obtained by averaging the depth profiles obtained based on several characteristic points on the thermal contrast curves. Care must be taken when using early time parameters ( $\mathrm{t}_{\text {div }}$ and $t_{p s}$ ) for the estimation of shallower defects. Optimum sampling rate should be available with the instruments to capture accurately the points of interest. The information on the defect depth available over the entire time interval from $t_{\text {div }}$ to $t_{\max }$ could be used, along with good curve fitting techniques, for developing a robust method of depth detection. 


\subsection{Enhanced Spatial and Depth Resolution of Pulsed Thermographic Images}

\section{(Lhota et al. 2000)}

\subsubsection{Introduction}

There are various types of nondestructive evaluation techniques developed using active thermography, in which the surface of a solid is heated (or cooled) and the changes in the surface temperature over a period are monitored using an infrared camera. Since the presence of the defects affects diffusion of heat, they cause temperature differences on the surface, which can be captured by an infrared camera. It is possible to see the indications of the subsurface defects by simply observing the continuous output of the infrared camera through a display device or capturing individual frames at particular times. Additional signal / noise improvement is typically gained by simple image math (such as image subtraction or averaging).

The defect identification by an inspector, in some cases, is hindered by the spatial noise and/or by the thermal blurring due to lateral diffusion. An advanced spatial filtering technique using a point spread function based on a previously proposed concept of Thermal Modulation Transfer Function has been developed to remove this blurring (Shepard et al. 1999).

\subsubsection{Simple Spatial Filtering Techniques}

The presence of spatial noise and the artifacts in the infrared images hide the defects and hinder their identification. Usually, spatial noise is caused by the non-uniform heating of the specimen or by the noisy electronic environment of the camera. These noises have distinct spatial frequency components. An enhanced image, without the noises, that is easier to evaluate was obtained by spatially filtering out the noise frequency components. 
This was achieved as follows:

- The image was transformed to the spatial frequency regime using a two dimensional Fast Fourier Transform (2D FFT).

- The noise frequency components were identified and their amplitudes were reduced.

- The modified 2D FFT data was transformed back to a spatial image with an inverse 2D FFT.

The effectiveness of the above mentioned technique was demonstrated by the pulsed thermographic image of a large metal honeycomb panel (Figure 3.5.1). The heating was not uniform due to the inspection system being moved back to cover a larger region than normal. The resulting image was brighter in the center than in the edges. By varying the colorbar scaling, all regions of the sample could be evaluated, but not in a single image. The image was spatially filtered using a high pass filter (removing the low frequency components). The resulting flatter image was simpler to evaluate.
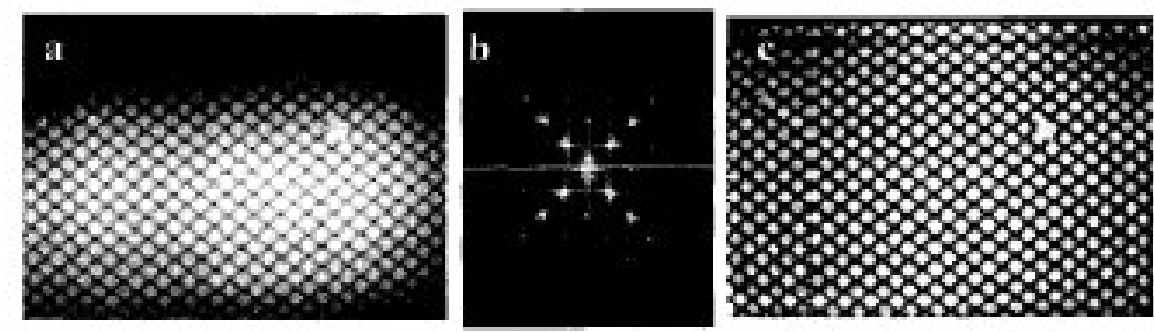

Figure 3.5.1. a) Image which resulted from non-uniform heating. b) The amplitude plot of the 2D FFT of the image with the low frequency components at the center. c) Reducing the low frequency components flattened the image for better inspector evaluation.

Spatial filtering technique was also found to be useful in the evaluation of a sequence of images. An important method of evaluating thermographic data was creating a slope (time derivative) image from an image sequence. In an electronically noisy environment (e.g. number of inductors and transformers in the immediate vicinity), the infrared images have spatial noise that has regular pattern and changing in time. Figure 3.5.2.a shows a pulsed 
thermographic image of a composite part with a diagonal pattern (due to electrically noisy environment). The noise pattern's general shape remained constant, with the pattern shifting slightly in successive images. Although the noise appeared subtle in the raw image, the time variation resulted in the noise dominating in the slope image (Figure 3.5.2.b) required for the inspector's evaluation. The spatial frequency components associated with the diagonal patterns were filtered out of each image of the sequence. The slope image (Figure 3.5.2.c) of the filtered image sequence reveled the subsurface details required for evaluation.
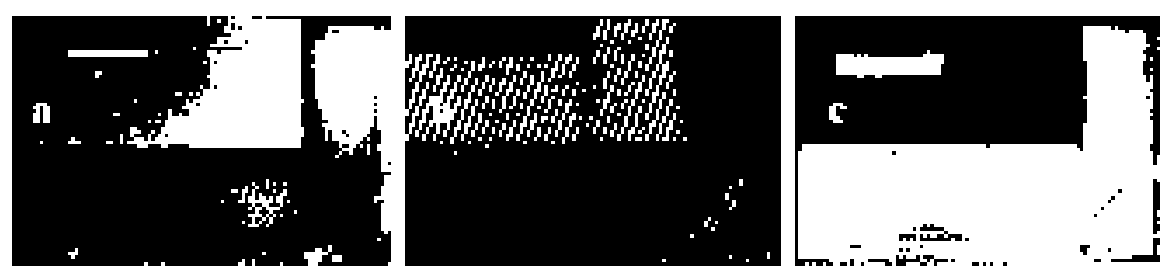

Figure 3.5.2. a) A subtle diagonal noise pattern was present in the image. b) The pattern was changing in time and dominates the slope image. c) After the sequence of images were each spatially filtered to reduce, the slope image of the filtered sequence reveals the desired subsurface details for the inspector's evaluation (Lhota et al. 2000).

\subsubsection{Inverse Filtering of the Blurred Data}

The advanced filtering technique is an extension of the Thermal Modulation Transfer Function (TMTF) concept (Shepard et al. 1998). TMTF allows the determination of critical defect size at a particular depth for a particular sample type. The observed values are compared with the calibration standards generated with programmed defects. The concept of critical defect size has its limitations because it increases as a function of depth due to the lateral diffusion of thermal energy away from the defect. In actual practice, the samples are evaluated on a case-by-case basis.

In the visual domain, the Modulation Transfer Function (MTF) is widely used to characterize optical system performance (Gonzalez and Wood 1992). The MTF is defined as the Fourier Transform of the point spread function (degree of modulation of the output signal 
of a particular target expressed as a function of the spatial frequency of the target). The resultant modulation (for targets with arbitrary spatial frequency content) is predicted once the MTF of that particular system is known. Though the MTF provides an extremely useful means of evaluating the optical imaging system performance, it does not reflect the ability of the thermographic imaging system to detect the subsurface defects. This is because in the thermographic case, the contrast of subsurface defect depends on factors including the depth of the defect, the lateral dimension of the defect and the overall thickness of the sample.

The TMTF is based on the relationship between the contrast or modulation and the aspect ratio of the defect characterized in terms of the spatial frequency or width of the narrowest dimension of the defect.

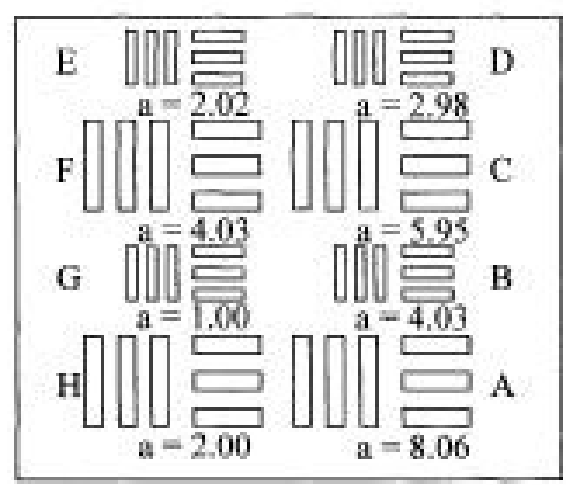

Figure 3.5.3. Diagram of the subsurface resolution target. The aspect ratio of the 8 target groups ranges from 1 to 8.06 (Lhota et al. 2000).

A calibration sample, as shown in Figure 3.5.3 was constructed to demonstrate the TMTF. It was made of 0.5 " thick steel plate with 8 clusters of target slots milled into the backside of the plate. Each cluster consisted of 3 horizontal and 3 vertical slots, with the spacing between each slot equal to the width of the slot. At each depth, there were high and low spatial frequency target clusters. The combinations of depths and spatial frequencies result in 8 distinct aspect ratios (slot width to depth ratio), ranging from 8 to 1 (Table 3.5.1). 
It is worth noting, as a "rule of thumb", that defects with aspect ratios less than 1 are typically not identifiable.

Table 3.5.1. Subsurface resolution target parameters.

\begin{tabular}{|l|l|l|l|}
\hline Group & Depth (in.) & Spatial Frequency (lines/in.) & Aspect Ratio \\
\hline A & 0.031 & 2.00 & 8.06 \\
\hline B & 0.031 & 4.00 & 4.03 \\
\hline C & 0.042 & 2.00 & 5.95 \\
\hline D & 0.042 & 4.00 & 2.98 \\
\hline E & 0.062 & 4.00 & 2.02 \\
\hline F & 0.062 & 2.00 & 4.03 \\
\hline G & 0.125 & 4.00 & 1.00 \\
\hline H & 0.125 & 2.00 & 2.00 \\
\hline
\end{tabular}

The images from a typical flash sequence in Figure 3.5.4 illustrate that although all eight target clusters were detectable, they were not all resolvable. The ability to resolve an individual bar element diminishes for deeper targets, as the contrast between the target clusters and the background decreases and lateral diffusion obscures the spaces between the target bars.
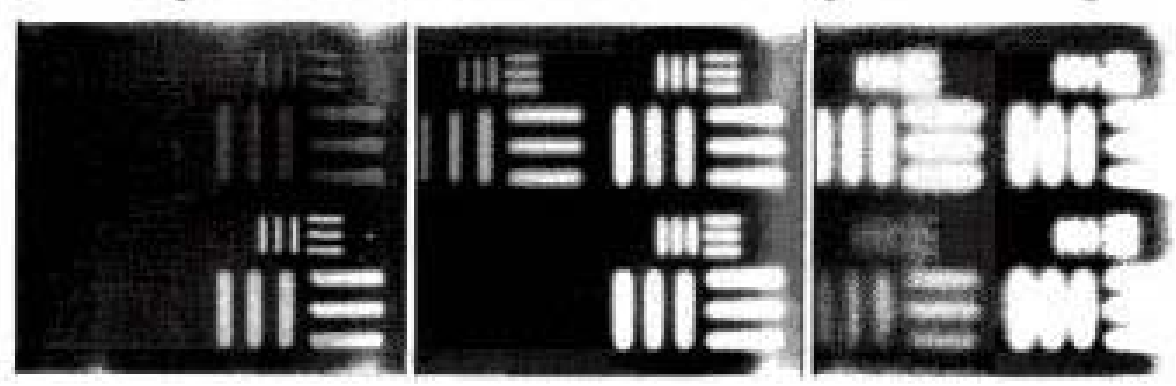

Figure 3.5.4. Pulsed IR image of the TMTF calibration target at 60(left), 161 (center) and $564 \mathrm{msec}$ (right) after flash heating. In each image, the histogram was scaled to optimize the contrast of particular target cluster of interest (Lhota et al. 2000).

The combination of depth and spatial frequency could be used to define a "thermographic MTF". In Figure 3.5.5, the modulation of each target group is plotted as a function of the dimensionless parameter Q, where

$$
\mathrm{Q}=\frac{1}{(\text { depth } * \text { spatial frequency })}
$$


Modulation was calculated using a variation (more traditional definition) where,

$$
M_{i}=\frac{\sum\left[I_{i}(\text { slot }) / 3-I_{i}(\text { space }) / 2\right]}{\sum\left[I_{i}(\text { slot }) / 3+I_{i}(\text { space }) / 2\right]}
$$

The above equation does not depend on a reference point and exploits the periodicity of the target clusters. The pre-flash amplitude of each $I_{j}$ was subtracted so that possible $M_{i}$ values ranges from 0 to 1 . The solid line shows a least square fit of a straight line to the data with $\mathrm{R}^{2}=0.9765$ and indicates that the aspect ratio of the defect provides a reasonable indicator of the resolvability of the defect. Below a threshold level of modulation, the target elements were not visually resolvable (approximately $4 \%$ of modulation). Figure 3.5.5 defines the minimum resolvable aspect ratio for the sample under consideration. The information gained from analysis of the resolution target can be generalized to other samples of the same type with defects of arbitrary size, shape and depth. As the input parameters such as power level, detector sensitivity or surface preparations are varied, a new TMTF needs to be generated.

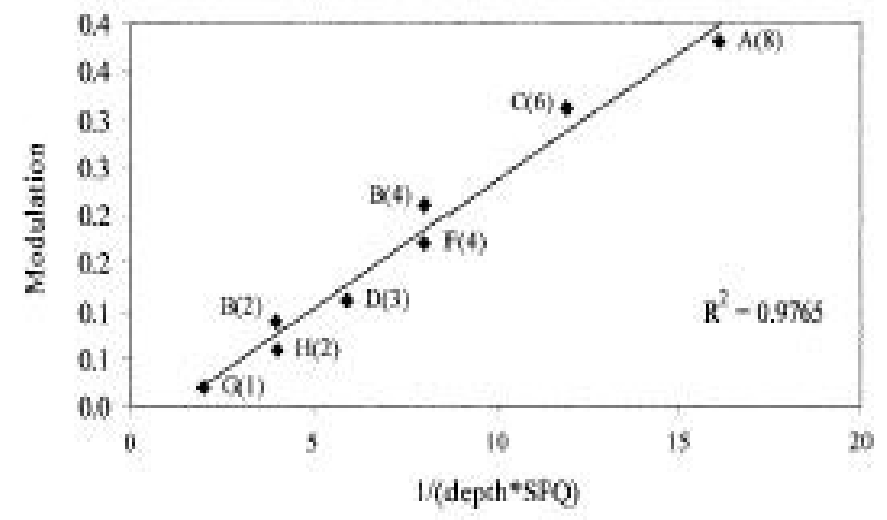

Figure 3.5.5. Modulation was plotted as a function of $1 /($ depth*spatial frequency). The target group aspect ratio is indicated next to each data point (Lhota et al. 2000). 


\subsubsection{Inversion of Lateral Diffusion Effects}

In optical image processing, it is a common practice to remove noise in the optical image and recover the missing or weak signal components by the process of image inversion. The image formation model is used as a base for the process, in which an image $\mathrm{i}(\mathrm{x}, \mathrm{y})$ is expressed as:

$$
i(x, y)=\int g(x, y) p(x-\alpha, y-\beta) d \alpha d \beta
$$

where $g(x, y)$ is the actual shape and contrast of the defect and $p(x, y)$ is a blurring function that describes the degradation of the image from ideal (due to the image system, atmospheric transmission, photographic paper, etc.). Equation 3.5 .3 is generally recognized as a convolution integral and can be rewritten in Fourier space as

$$
I(\alpha, \beta)=G(\alpha, \beta) \cdot P(\alpha, \beta)
$$

and the original shape function $g(x, y)$ can be extracted by taking the inverse Fourier transform of the expression

$$
G(\alpha, \beta)=\frac{P^{*}(\alpha, \beta)}{|P(\alpha, \beta)|^{2}} I(\alpha, \beta)
$$

The fact that point spread function varies as a function of time relative to the heating pulse in Pulsed Thermography, complicates the situation. A minimum resolvable spot size for a given depth beneath the sample surface was effectively defined earlier. This spot could be thought of as the Thermal Point Spread Function (TPSF) for the sample type under consideration. The image formation process for pulse thermography of a defect at a given depth could be recast so that the surface temperature of the sample could be expressed as:

$$
i_{\text {surface }}(x, y, t)=\int g(x, y, t) p(x-\alpha, y-\beta, t) d \alpha d \beta
$$


where $g(x, y, t)$ is the spot size at the particular time after flash heating as determined by the TMTF process described above. The actual shape of the subsurface defect can then be extracted from Equation 3.5.6 using the same procedure that was applied in the optical case shown in Equation 3.5.5 (this typically requires the use of parametric filter in the denominator to prevent spikes in $\mathrm{G}(\alpha, \beta)$ due to pixels with zero amplitude). The net result is shown in Figure 3.5.6 on the target clusters $\mathrm{G}$ and $\mathrm{H}$ (aspect ratios of 1 and 2, respectively). Though the individual bar elements of target $\mathrm{G}$ could not be resolved visually, the bars are evident in the inverse image. Similarly for a graphite epoxy sample, the resolution enhancement is evident as shown in the Figure 3.5.7.
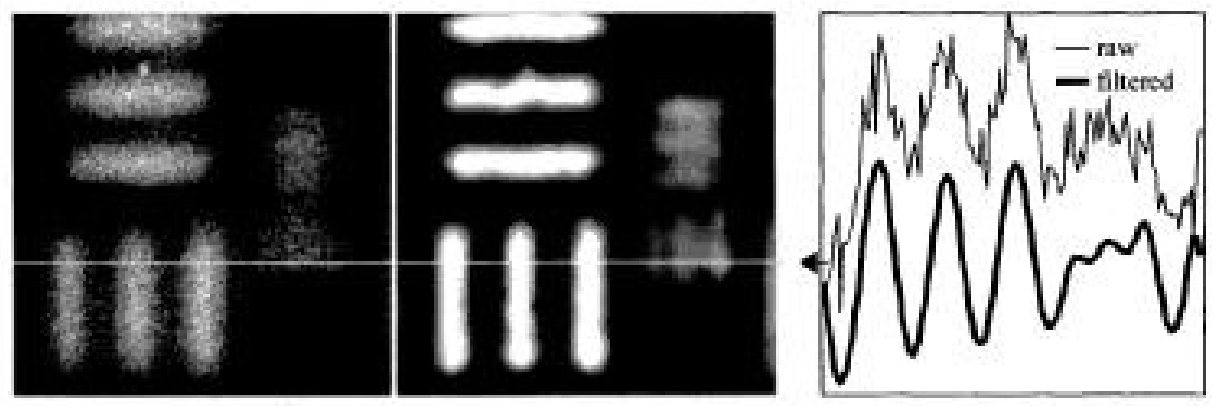

Figure 3.5.6. Raw image of resolution target clusters $\mathrm{G}$ and $\mathrm{H}$ (Left). Inverted image using the Thermal Point Spread Function obtained from TMTF analysis of the resolution target (Center). Line profiles of the target cluster images near the line (Right). The fine and bold lines represent the raw and inverted images respectively (Lhota et al. 2000).

\subsubsection{Conclusion}

The pulsed thermographic data could be evaluated by both traditional FFT and inverse filter image enhancement techniques. Traditional spatial filtering is particularly useful when the data acquisition conditions are not ideal, such as non-uniform heating or electrically noisy industrial environment. The approach described here provides a means of characterizing the performance of a thermographic NDT system on a particular type of 
sample. Once the characterization procedure is performed, the results could be used to predict the behavior of the same system on the samples of the same type.
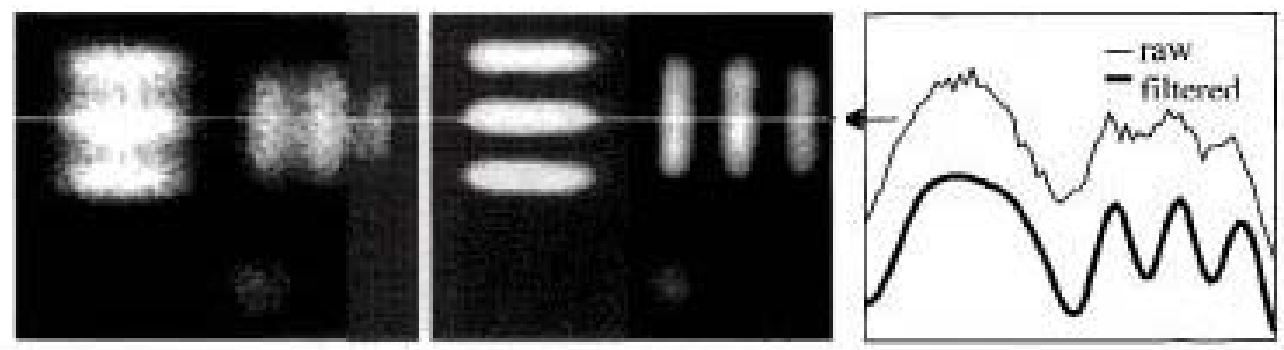

Figure 3.5.7. Raw image of composite resolution target (Left). Inverted image using the Thermal Point Spread Function obtained from TMTF analysis of the resolution target (Center). Line profile at the line through target cluster images (Right). The fine and bold lines represent the raw and the inverted data, respectively (Lhota et al. 2000).

Although the results presented in this paper used the modulation of a complex resolution target, equivalent results can be obtained for normalized contrast of a simple target (e.g. flat bottom holes). The TMTF plot can be interpreted to represent the minimum resolvable defect at a particular depth for the system/sample combination. The thermal image inversion is based on an empirically derived function and not on ideal Point Spread Function. The approach adopted made no assumptions of the properties of the sample material or the defect or the boundary conditions at the material/defect interface.

\subsection{Health Monitoring of FRP Bridge Decks (Miceli et al. 2001)}

\subsubsection{Abstract}

As per the fall 1989 statistics, about $41 \%$ of the nation's bridges are structurally deficient or functionally obsolete. The use of new materials such as glass fiber reinforced vinyl ester matrix composites is being explored to solve this problem. These materials are less affected by the corrosive environmental conditions and potentially provide a longer life span. These materials have additional benefits such as reduced dead loads. There is a lack of long term durability data concerning this material. This paper discusses the use of Infrared 
thermography for detecting the structural imperfections - delaminations, debonds, voids caused both during fabrication and in the field.

\subsubsection{Background}

Many structurally deficient bridges may be restored back by replacing their decks. The use of lighter material such as FRP for the decking system increases the load rating of the bridge. Since the long-term durability aspects of such materials are still unclear, nondestructive evaluation (NDE) methods need to be developed for the continuous condition assessment of the structures built with these materials. A two pronged approach was adopted in this research. One was to use the infrared thermography technique for the study of initiation and development of deterioration in the laboratory and the other was to develop the capabilities for field-testing.

The full picture of the nature of the long-term deterioration of FRP materials is unknown at this time because of the rapidly evolving nature of these applications. The faulty designs resulting in structural damages have resulted in shifting of focus from the more important durability issues to fixing of those design aspects.

In this particular research program, the initial decking system was rejected after preliminary mechanical testing and nondestructive evaluation suggested that the fabrication issues were yet to be resolved. The second deck developed damages around the points of attachment to the substructure. The third deck is presently being tested.

\subsubsection{Experimental Procedure}

The bridge decks were made of pultruded square cross sections sandwiched between an upper and lower pultruded plates with a layer of quartzite particles on an epoxy layer as a 
wearing surface at the top. The overall dimensions of one such module (pultruded by Strongwell, Inc. in Bristol, Virginia) is $15 \mathrm{ft}$ x $5 \mathrm{ft}$ and 7 inches deep (Figure 3.6.1).

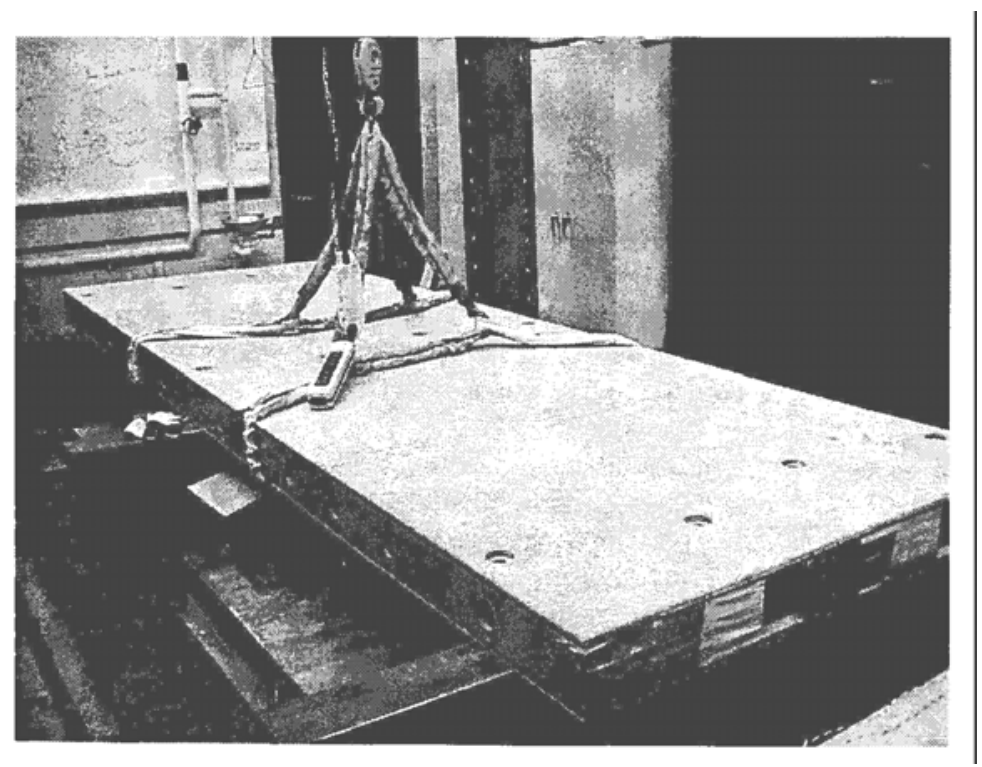

Figure 3.6.1. Deck section where the openings of some of the tubes have been blocked (Miceli et al. 2001).

Two major areas of concern were the presence of debonds (between the top plates and the tubes or between the tubes) and the absorption of moisture. Consequently it was determined that infrared thermography could be used to identify the debonds, whereas the problem of assessing moisture absorption is yet to be developed.

Raytheon Amber Radiance 1T image system was used for thermal imaging. The solar heating could not be effectively used for the top surface because of the quartzite wearing surface that erodes in the wheel paths and staining from the chemicals that drip from the truck traffic and cause variation in the surface thermal absorption. Consequently forced hot air through the tubes was considered as effective in heating the whole length of the tube. Since the disbonds disrupt the heat conduction, they could be seen in the thermal images. 


\subsubsection{Results and Discussion}

The first bridge deck was tested by forcing the hot air through individual tubes. Though the temperature differentials were observed indicating the presence of the disbonds, the differentials due to possible variations in the bond thickness and surface emissivity could not be ruled out. However, near the vicinity of the bolts connecting the deck to the beams below, there was a clear variation in the thermal image patterns before and after the application of the proof load (Figure 3.6.2).
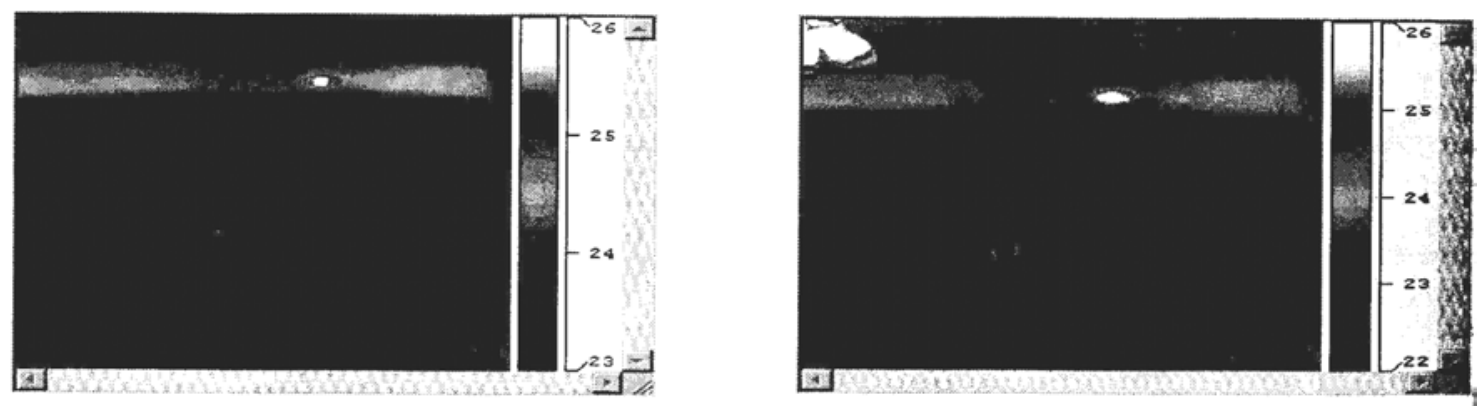

Figure 3.6.2. Thermal images before (left) and after (right) the proof loading of the same region of the bridge in the vicinity of an attachment bolt. The thermal pattern caused by hot air forced through a single tube clearly shows a disruption in the thermal pattern in the region around the bolt (bright spot) that increased in size after proof loading (Miceli et al. 2001).

A system for simultaneously forcing hot air into three different pairs of tubes was used in the field because of the restricted access. Also this could be done without affecting the traffic. The testing was conducted prior to sunrise to avoid the problems due to tire path wear of the quartzite surface and the staining as explained above.

Figures 3.6.3 and 3.6.4 show the thermal images of the same bridge deck over a period of one month. The differences in the thermal patterns of the two figures were due to the damage to the hot air delivery system caused by the excessive vibration of the deck section. Nevertheless it was established that such a procedure was capable of producing thermal patterns under field conditions. 


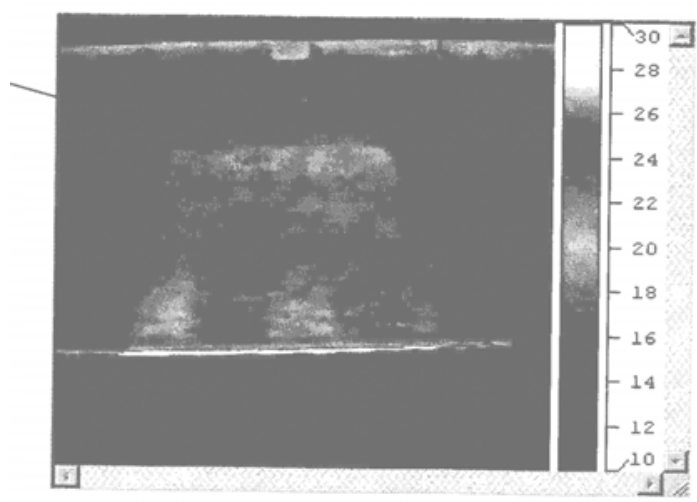

Figure 3.6.3. Thermal image of the bridge deck where hot air from space heater is channeled through polyvinyl chloride (PVC) piping and junctions into tubes 1 (leftmost tube) and 2,4 and 5 and 9 and 10. Because of space restrictions the hot air entered the tubes from the bottom side and the hot air impinges on the inside top surface of the tube (Miceli et al. 2001).

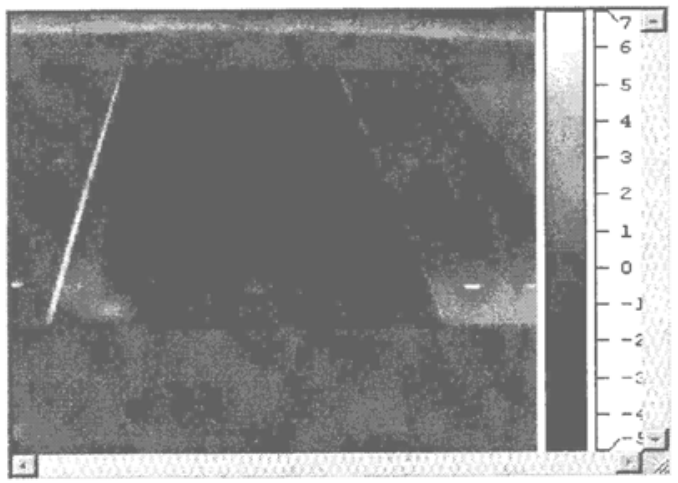

Figure 3.6.4. Thermal image of the bridge one month later. This examination was conducted at $4 \mathrm{AM}$ to avoid solar heating variations (Miceli et al. 2001).

Further efforts to define the sensitivity of the method to disbond type imperfections were pursued using model deck in the laboratory. The model deck was tested using forced hot air. Mathematical modeling of the heat conduction associated with the convective heat transfer was in close agreement with experimental observations.

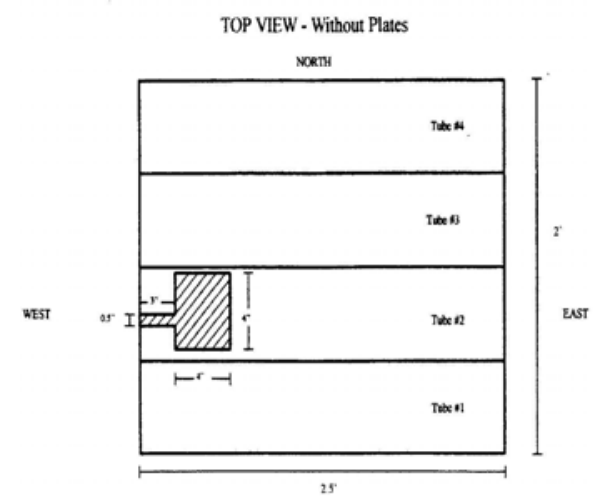

Figure 3.6.5. Schematic view of the deck model with a disbond created between the tubes and the plates. The shaded area is the disbond (Miceli et al. 2001).

The effect of moisture on the detectability of the disbond was tested by filling the disbond with water through the channel (shown in Figure 3.6.5). It could be concluded that 
the thermal conductivity of the water, being higher than that of air, did affect the thermal image (Figures 3.6.6 and 3.6.7).

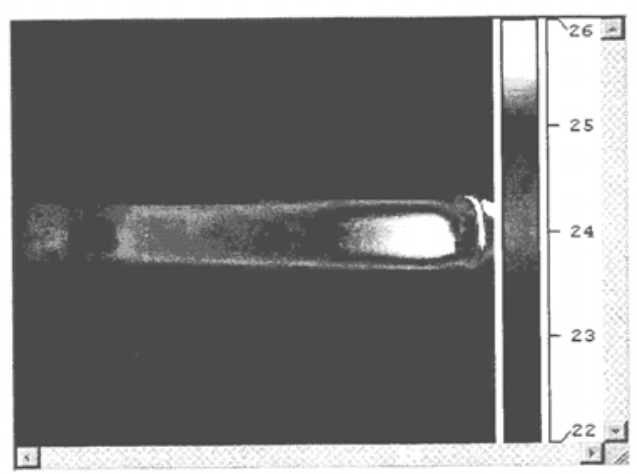

Figure 3.6.6. Thermal image of the deck model with hot air flowing through the tube directly beneath the disbond.

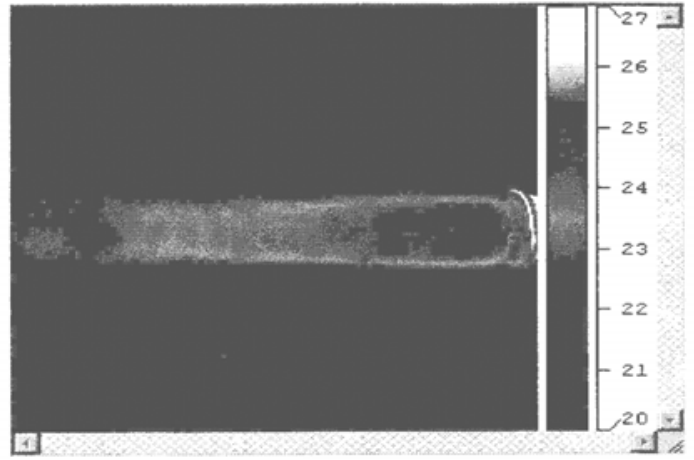

Figure 3.6.7. Thermal image of the disbond filled with water that by comparison with fig 3.6.6 has less distinct boundaries.

\subsubsection{Conclusions}

Infrared thermal imaging can be adopted for monitoring the health of FRP structures by detecting the possible presence of disbonds, etc. Surface anomalies such as staining and non-uniform wearing of the surface may complicate the interpretation of the thermal images. The presence of moisture in the disbond may cause the size of the disbond to be underestimated.

\subsection{Summary and Conclusions}

The literature review presented in this chapter has shown that infrared thermography can be used for qualitative as well as quantitative data analysis. The presence of defects can be seen in the thermographs. Analysis of digital thermographs using parameters such as contrast, break time, and other time parameters (e.g., peak slope, period of heat pulse) can enable the quantitative estimation of defect depth and profiling of the spatial extent of the defect. Also, the accuracy of the quantitative analysis may be improved by applying noise filtering techniques to the digitally acquired data before any analysis is conducted. 


\section{CHAPTER 4}

\section{LABORATORY EXPERIMENTS}

\subsection{Introduction}

Structural members made of Fiber Reinforced Polymer (FRP) composite materials are fast gaining popularity in civil engineering applications. They are being pultruded in different shapes and sizes for various applications. Apart from the strength tests (destructive tests) such as tension, compression, torsion and fatigue tests carried out on these materials, tests are also being conducted to detect the presence of delaminations, cracks, voids, etc. by nondestructive methods. These defects can develop during the manufacturing of these members (pultrusion process), during the construction, or during the service life of the structure when it is subjected to the loads.

The development of delaminations or cracks in a composite member may adversely affect the structure locally and globally. Since the durability aspects of the composite materials are not fully understood, it is very important to continuously monitor them until some standards are established. Infrared thermography has been identified as an effective nondestructive testing and evaluation method for testing of these members. Details of the experimental setup, thermal imaging equipment, specimens and data interpretation methodology are presented in this chapter.

\subsection{Experimental Set-up}

The experiments consisted of two steps. The first step was the creation of the delaminations of known shapes and sizes in the specimens and the second was to locate them using infrared thermography. Figure 4.2.1 shows the schematic view of the experimental set up of infrared thermography used in the laboratory. 


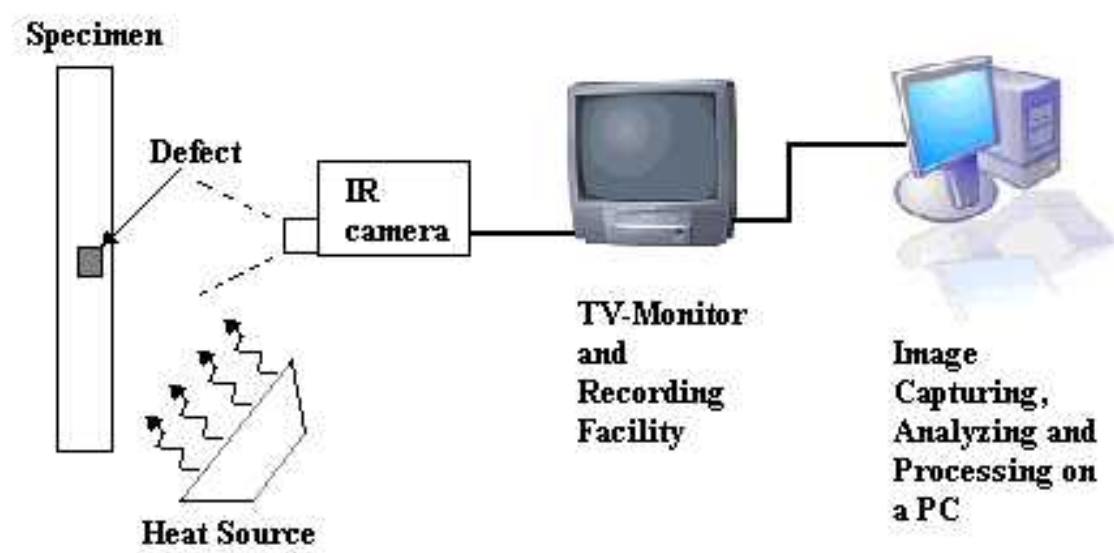

Figure 4.2.1. Schematic view of the infrared thermography set up in the laboratory.

\subsection{Infrared Camera}

The thermal images were recorded using FSI Prism SP (Single Point) infrared camera (Figure 4.3.1). The camera is capable of detecting the infrared radiation in the medium wavelength ( 3 to $5 \mu \mathrm{m})$ spectral region and displaying a real-time image showing relative intensity of the radiation (FSI FLIR SYSTEMS 1994). It is also possible to remotely measure the absolute temperature of a specific point on the target. The camera has a resolution of $0.2^{\circ} \mathrm{C}$. The detector type used in the camera is Platinum Silicide (PtSi) IR CCD array (324x244 pixels). The camera also has Level /Gain control (which work only in the manual mode). The Level control is used for positioning a selected span of temperatures relative to all the temperatures within the scene. The Gain control is used for setting the video sensitivity by limiting the span of temperatures to be displayed. The video output can be set to either Gray scale image mode or Color image mode with an image update rate of $60 \mathrm{~Hz}$ (in NTSC mode). The camera can be operated in 'White-hot' mode where the hotter regions appear as white or 'Black-hot' mode where they appear black. During laboratory experiments, it was set to White-hot mode. 


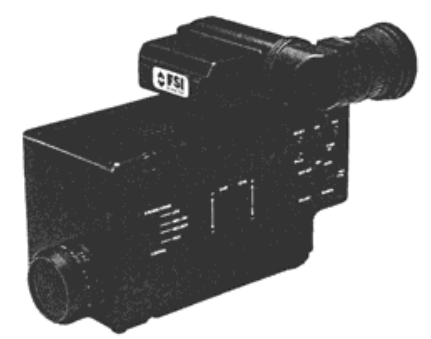

Figure 4.3.1. FSI Prism SP (Single Point) infrared camera (FSI FLIR SYSTEMS 1994).

A 9-inch TV monitor with built-in VCR was used to view and record the real time thermal images captured by the camera. The camera was mounted on a tripod in order maintain a constant distance between the specimen and the camera. This helps to record an unaltered sequence of images over a period, which are useful in image processing (such as image subtraction etc., explained later). The real time thermal images recorded on a VHS tape were transferred to a personal computer in the form of still images using special equipment (Snappy Video Snapshot).

\subsection{Heating Source}

The main heating source used in the laboratory was a quartz tower heater (Figure 4.4.1). This heater operated in two settings - 750 and 1500 Watts. To impart high energy in a short time the 1500 Watts setting was used during the experiments. It was found that heating the specimens by placing the heater at a distance from the specimen surface helped in achieving more uniform heating. It was also observed that studying the thermal images by heating the specimen for a small duration of time was much more effective than heating the specimen for a long duration and studying the images as the specimen cools down. The former method (also known as 'pulse heating' method) yielded better results as the variations in the temperatures occur at a faster rate. 


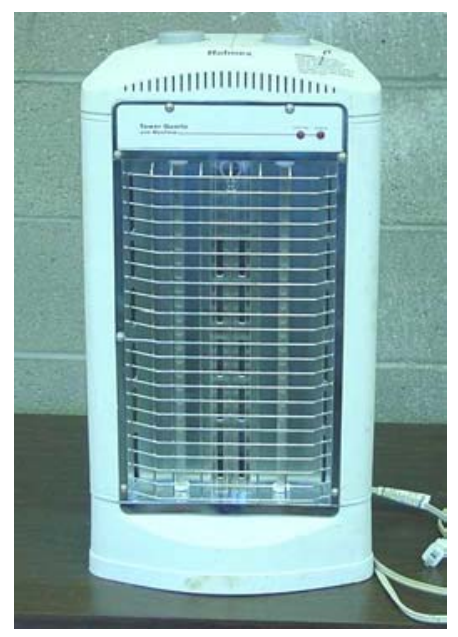

Figure 4.4.1. The quartz tower heater used for heating the specimens in the laboratory.

\subsection{Specimen Set-up}

Two types of glass fiber reinforced polymer (GFRP) composite sections were tested in the laboratory. They were, 2"x 5" box sections and bridge deck specimens. The delaminations of different dimensions were inserted in these box sections during the pultrusion process - the process by which the FRP sections are manufactured in the plant (Figure 4.5.1).

The delamination was made by joining two polypropylene sheets (the material used for making microwave safe containers) with an enclosed air pocket in between them. This material can withstand high temperatures of the pultrusion process $\left(\cong 190{ }^{\circ} \mathrm{C}\right)$. Figure 4.5.2 shows the raw materials used for making the delamination. The small strips were glued along the boundary as spacers in order to enclose an air pocket in between the two sheets. Additional strips were placed in the central region as stiffeners in case of larger delaminations. Finally, this delamination was sealed in between two latex sheets so that the air is fully trapped inside. The delaminations were then inserted at selected locations inside various FRP specimens during the pultrusion process. 


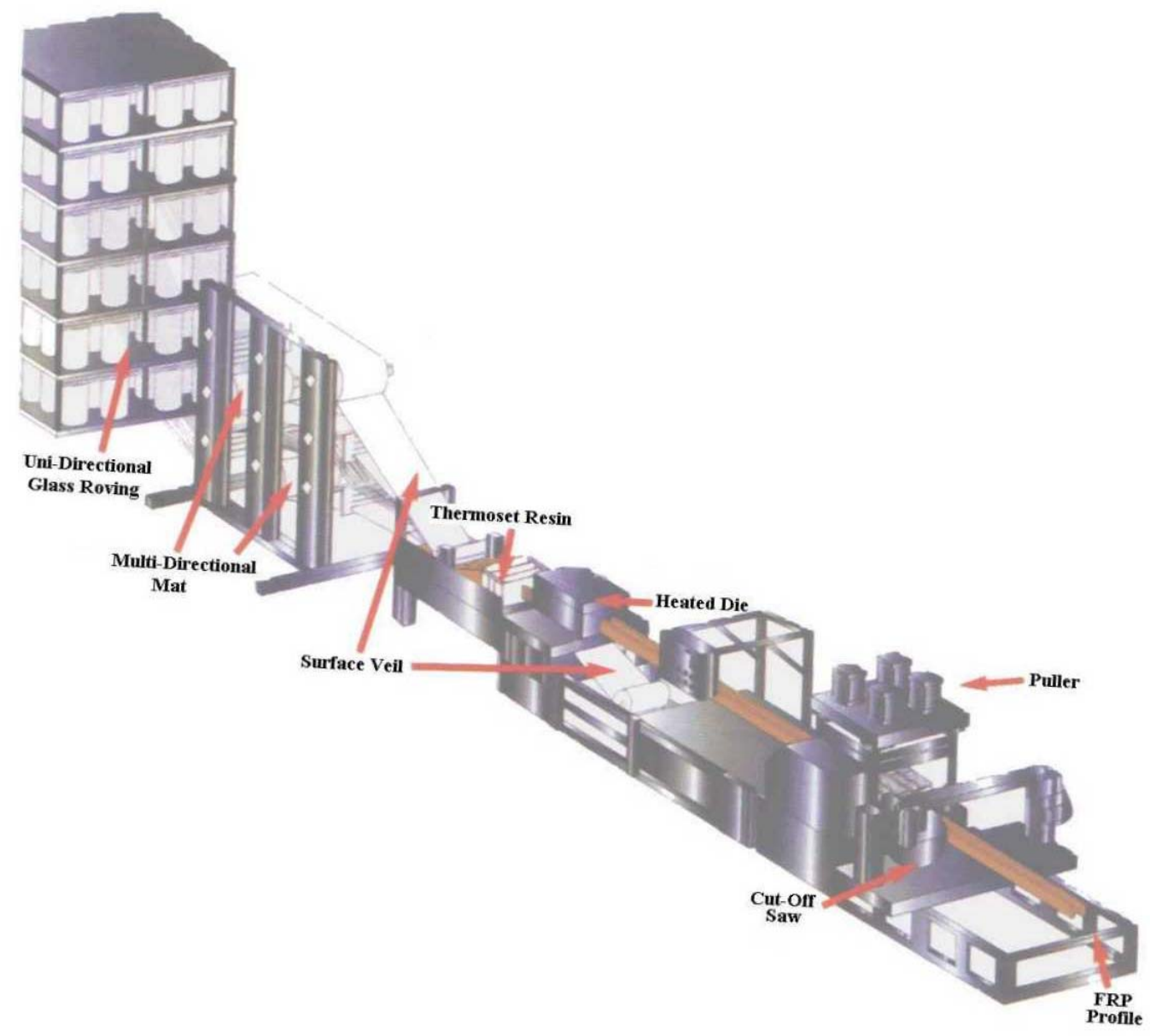

Figure 4.5.1. Schematic view of the pultrusion process (Bedford Reinforced Plastics, Inc. 2002).

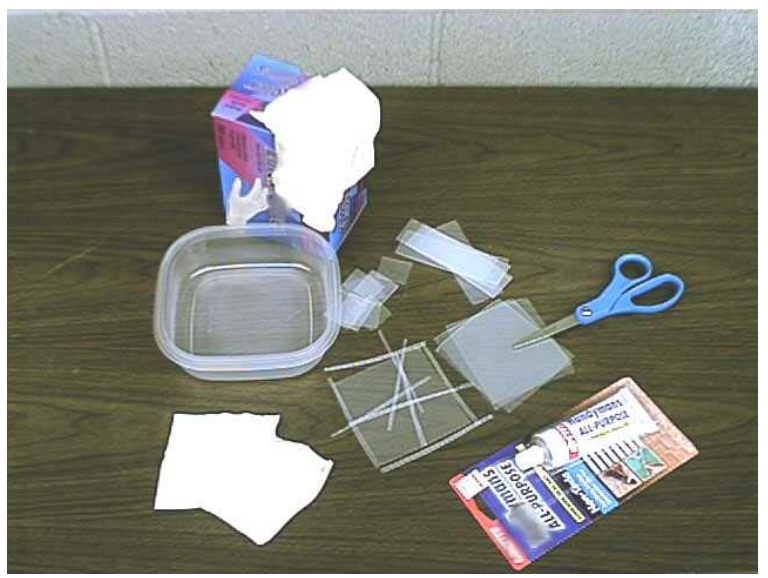

Figure 4.5.2. The delamination prepared by enclosing an air pocket between two polypropylene sheets. 


\subsubsection{Box Sections}

The GFRP box sections which were tested in the laboratory were of 2" x 5" overall dimensions and 3/16" thickness with the following specifications for glass fiber-resin combination.

The glass layout:

\begin{tabular}{|c|c|c|}
\hline per sq. yard & OC mat $14 "$ & $0.0728 \mathrm{lbs}$ \\
\hline per sq. yard & OC mat $44.25 "$ & $0.3496 \mathrm{lbs}$ \\
\hline 113 yield & roving $80 "$ & 0.4720 lbs. \\
\hline Total glass weight & & 0.8944 lbs. \\
\hline Polyester resin weight: & & $0.8630 \mathrm{lbs}$ \\
\hline
\end{tabular}

Four different types of box section specimens with embedded delaminations were pultruded at Bedford Reinforced Plastics, Inc., PA, and tested in the laboratory. The following sections describe those specimens.

\subsubsection{Specimen - Box1}

A 3"x3" delamination made by trapping air between two latex sheets (obtained by cutting disposable gloves) was inserted in the specimen (Figure 4.5.3). Since the latex sheets were very flexible, it was not possible to maintain a 3"x3" shape during the pultrusion process.

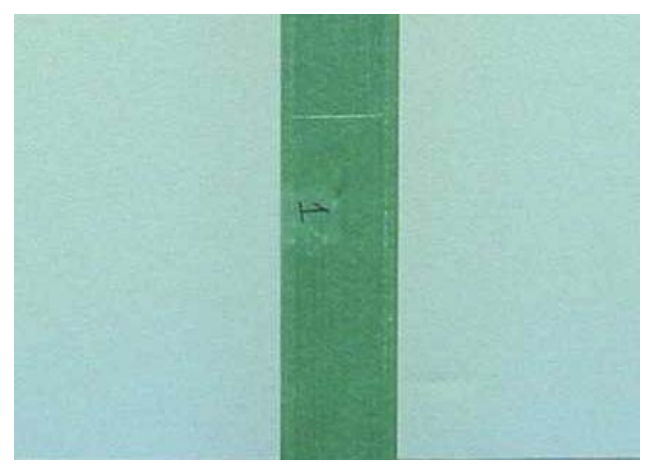

Figure 4.5.3. Box section specimen - Box1. 


\subsubsection{Specimen - Box2}

A 2"x2" delamination of $1 / 16 "$ thickness was made by trapping air between two polypropylene sheets as explained earlier, and was inserted in the specimen during the pultrusion process (Figure 4.5.4). Since the delamination is located very close to the surface, it is visible to the naked eyes (the difference in the colors of the box section material and the delamination material is also a reason).

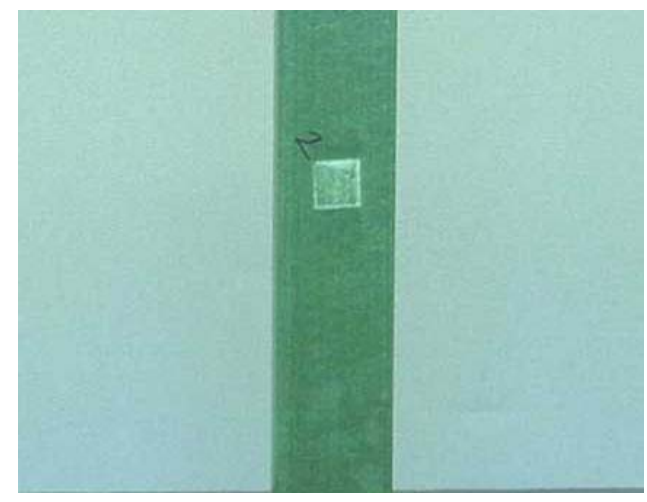

Figure 4.5.4. Box section specimen - Box2.

\subsubsection{Specimen - Box3}

This specimen was made by inserting a 3"x3" delamination of 1/16" thickness made from polypropylene sheets (Figure 4.5.5). Even in this specimen the delamination is visible to the naked eyes.

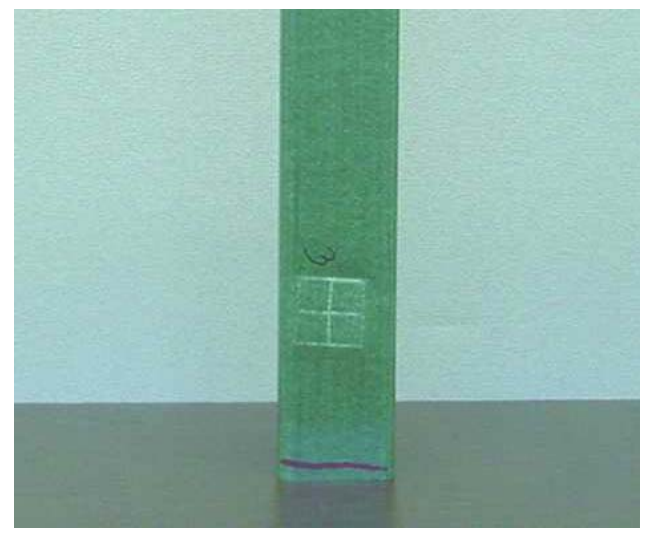

Figure 4.5.5. Box section specimen - Box3. 


\subsubsection{Specimen - Box4}

This specimen was made by inserting delaminations of two sizes - one 3"x3" size and the other of 2"x2" size (both with 1/16" thickness). Further, to conceal the delaminations a layer of paint was applied on the surface of the specimen (Figure 4.5.6). Hence, unlike specimens Box 2 and Box3, the location of the delaminations in specimen Box4 are not visible to the naked eye.

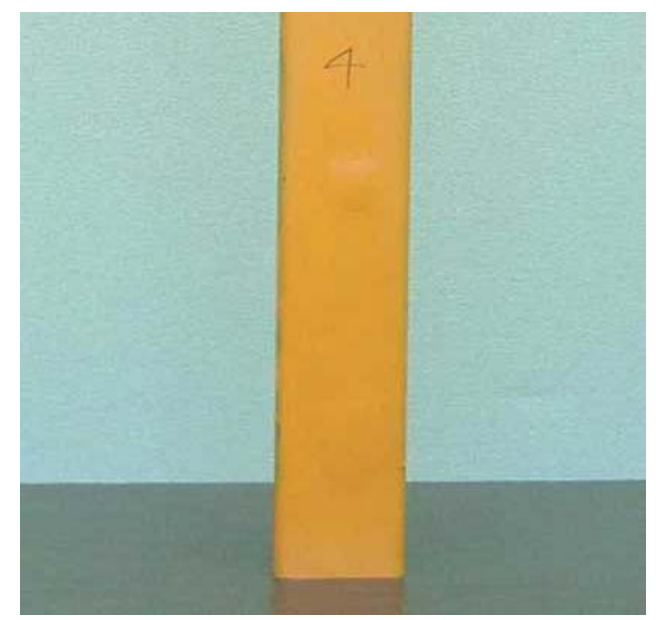

Figure 4.5.6. Box Section Specimen - Box4.

\subsubsection{Bridge Deck Specimens}

Figure 4.5.7 shows the cross-section of a FRP bridge deck module. Each module of the bridge deck is 24" wide, 8" deep and 12 feet long (pultruded at Bedford Reinforced Plastics Inc., PA.). Several such modules are attached together to form a bridge deck in actual field construction.

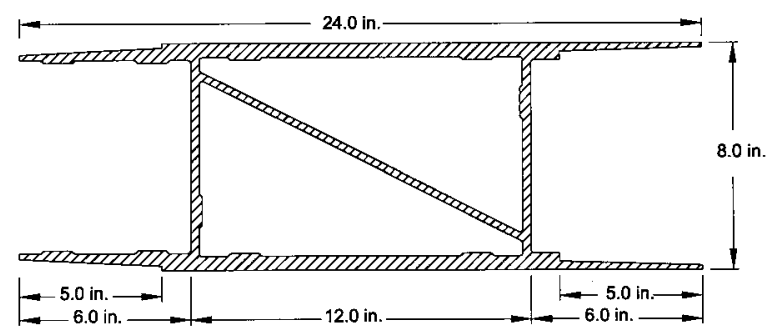

Figure 4.5.7. Bridge deck module - Cross-section. 
The bridge deck is composed of E-glass fibers and polyester resin combination. The glass fibers are continuous strand roving and triaxial fabrics. The fiber volume fraction is about $45 \%$.

There are many regions within a FRP deck where there is a possibility of occurrence of delaminations under service loads. Some of the possible regions where delaminations could occur are: within the flange of any given module, between the flange joints of two modules, and between the wearing surface and the deck. Taking the above factor into consideration, different specimens with various subsurface delamination configurations were made and tested using infrared thermography.

\subsubsection{Specimen - BD1}

This specimen was made by connecting two 12" long pieces (cut from a 12' long bridge-deck module). The pieces were connected to each other using a structural adhesive ("Pliogrip" manufactured by Ashland Specialty Chemical Company) in the same way as it is done at the construction site. Two delaminations of size 3"x3" and 2"x2" (both with 1/16" thickness), made using polypropylene sheets as explained earlier, were inserted within the joint between the two modules. The depth of the delaminations from the deck surface was about 5/16". Figure 4.5.8 shows the photographic view of the specimen and Figures 4.5.9 and 4.5.10 show the location of the delaminations.

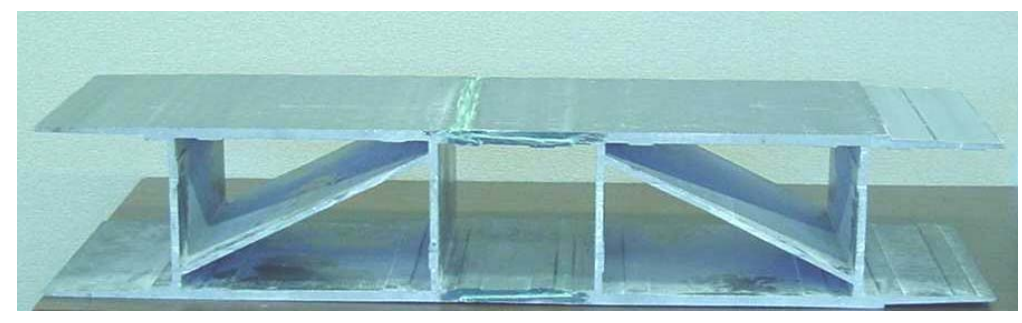

Figure 4.5.8 Bridge deck specimen - BD1. 


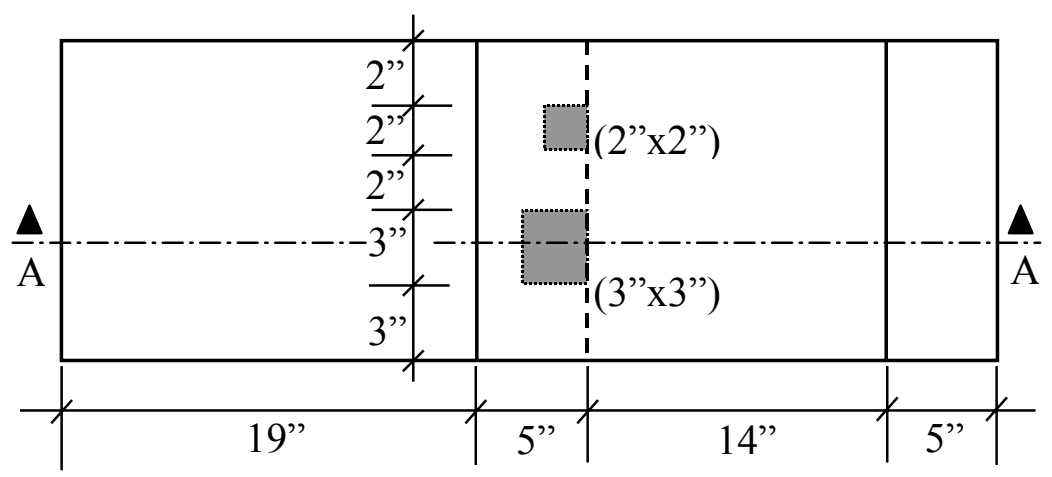

Figure 4.5.9. The delamination location in the bridge deck specimen - BD1.

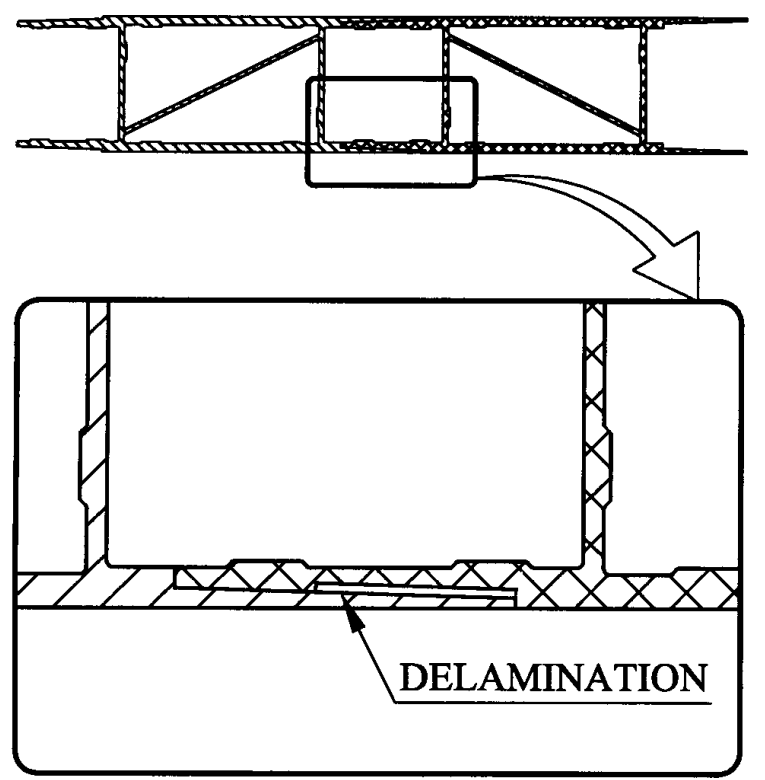

Figure 4.5.10. Section at A-A (in Figure 4.5.9) and the enlarged view of the delamination.

\subsubsection{Specimen - BD2}

In this specimen (which is a 12" long piece cut from a 12' long bridge deck module), the delaminations were inserted between the bridge deck and the $3 / 8$ " thick wearing surface. The wearing surface is a non-skid, flexible, hybridized, and copolymer overlay system, with a commercial name Mark-163 FLEXOGRID (manufactured by Poly-Carb, Inc., OH). It is made of a specially selected blend of aggregates (Glacial gravel - Basalt, Quartzite, Granite) used along with two-part liquid polymer system (mixed at the job site). Two delaminations of 
sizes 2"x2" and 3"x3" (both with thickness of 1/16") were placed on the surface of the FRP deck specimen. This was followed by the application of $3 / 8$ " thick wearing surface as per the directions given in the product technical data sheets provided by Poly-Carb, Inc. Figure 4.5.11 shows photographic view of the specimen BD2. Figures 4.5.12 and 4.5.13 show the locations of the delaminations.

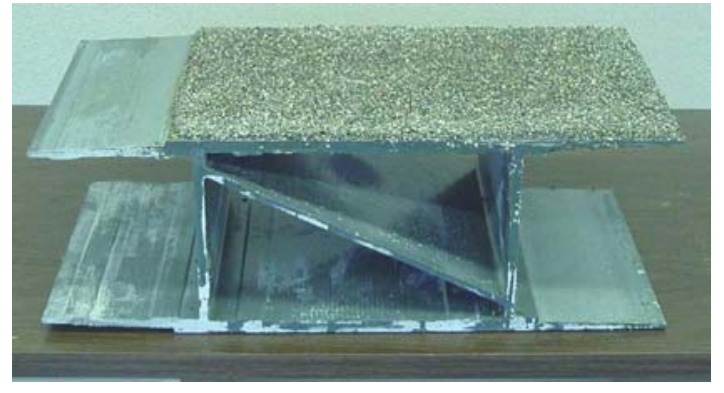

Figure 4.5.11. Bridge deck specimen - BD2.

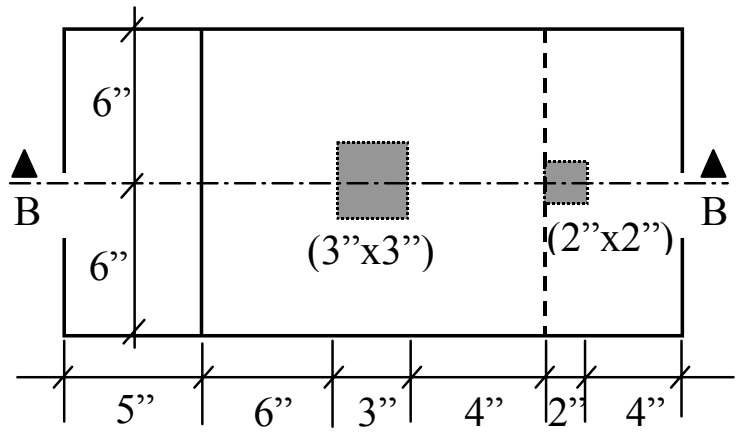

Figure 4.5.12 Location of delaminations in bridge deck specimen - BD2.

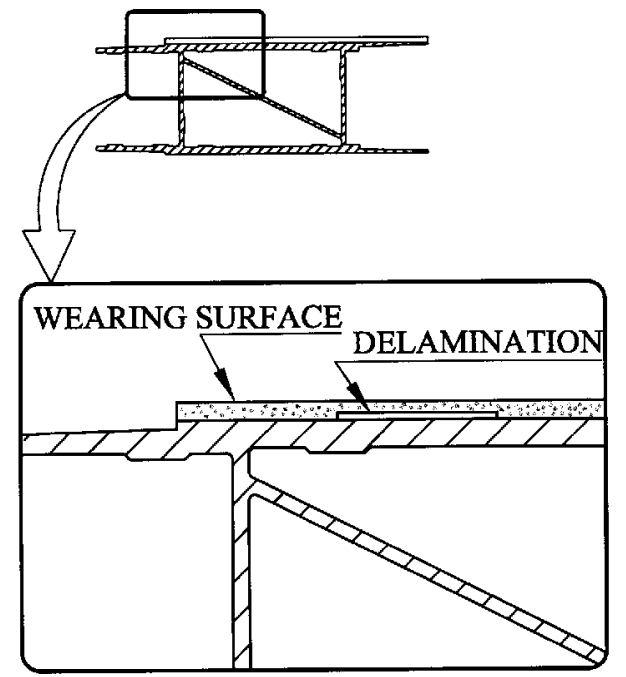

Figure 4.5.13. Section at B-B (in Figure 4.5.12) and the enlarged view of the delamination. 


\subsection{Infrared Testing and Results}

The specimens were heated by placing the quartz heater at a distance of 6-8 inches from the surface. The surface temperature profiles were observed using the infrared camera and were recorded on a VHS tape. Figure 4.6.1 shows the setup of the infrared thermography equipment in the laboratory. Since some thermographers feel that the images in gray scale gives better thermal contrasts than the color images, both color and gray scale images were recorded.

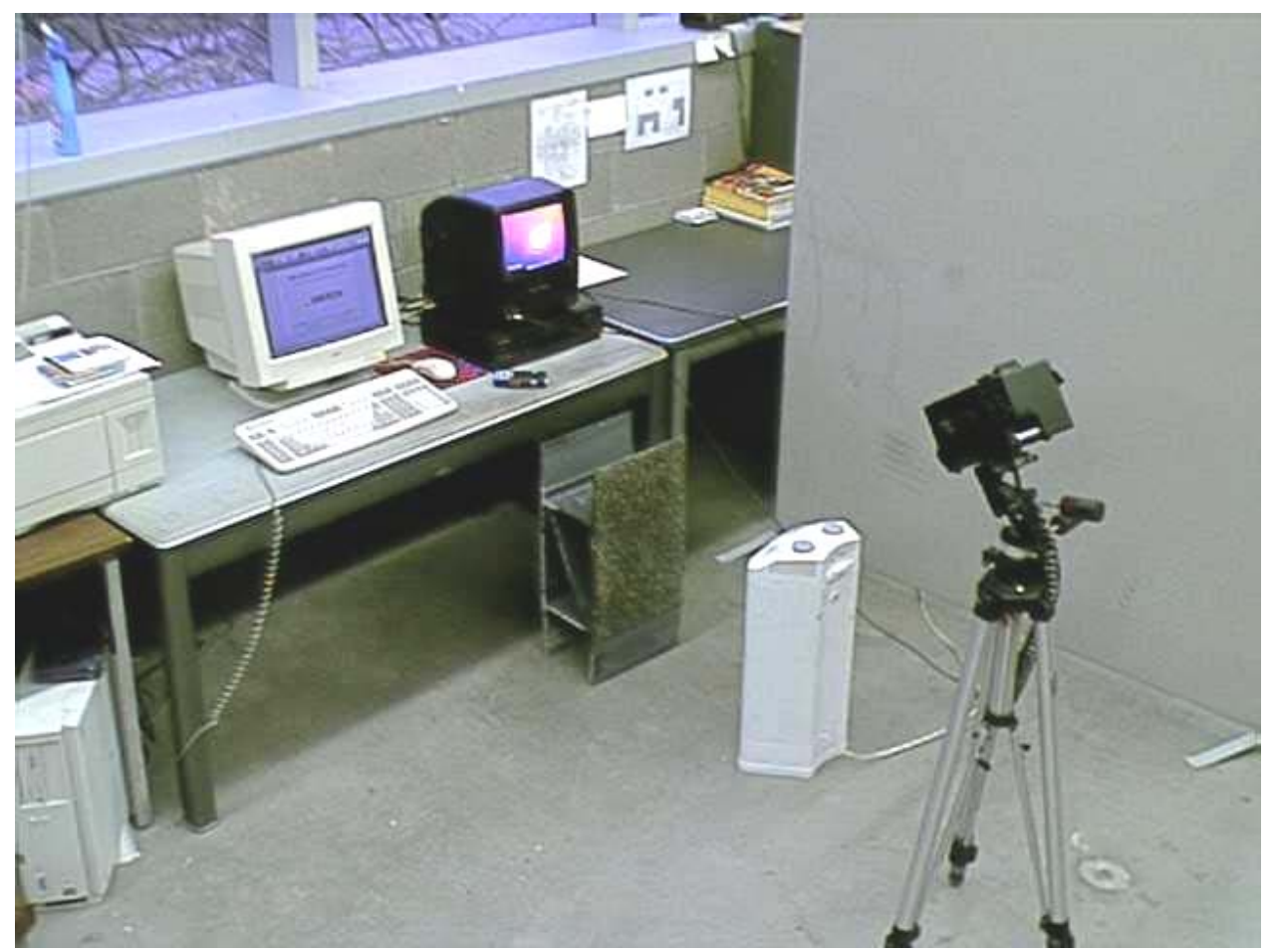

Figure 4.6.1. Infrared thermography experiment set up in the laboratory.

\subsubsection{Results for the Box Sections}

The following sections present the infrared testing results for different specimens.

\subsubsection{Specimen - Box1}

Figures 4.6.2.a and 4.6.2.b show the color and gray scale infrared images of the specimen Box1. As seen in the images the bright spot on the specimen indicates the 
delamination. Since the delamination was created using latex sheets for this specimen, the originally intended dimension of 3"x3" could not be obtained (as the latex is very flexible). The image clearly shows the delamination size being different (approximately 1.5"x3").
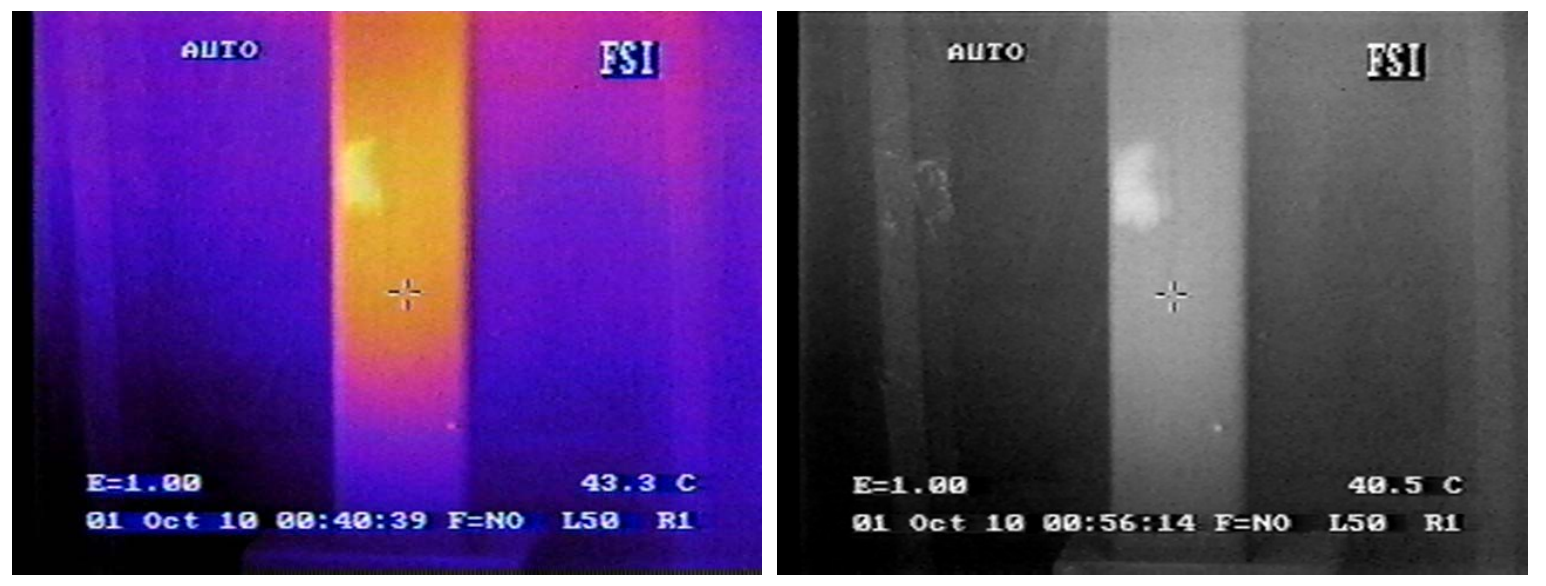

Figure 4.6.2. Specimen - Box1. (a) Color infrared image. (b) Gray scale infrared image.

\subsubsection{Specimen - Box2}

The 2"x2" delamination (1/16" thick) that was inserted in the specimen is clearly seen in both the color and gray scale infrared images (Figures 4.6.3.a and 4.6.3.b).
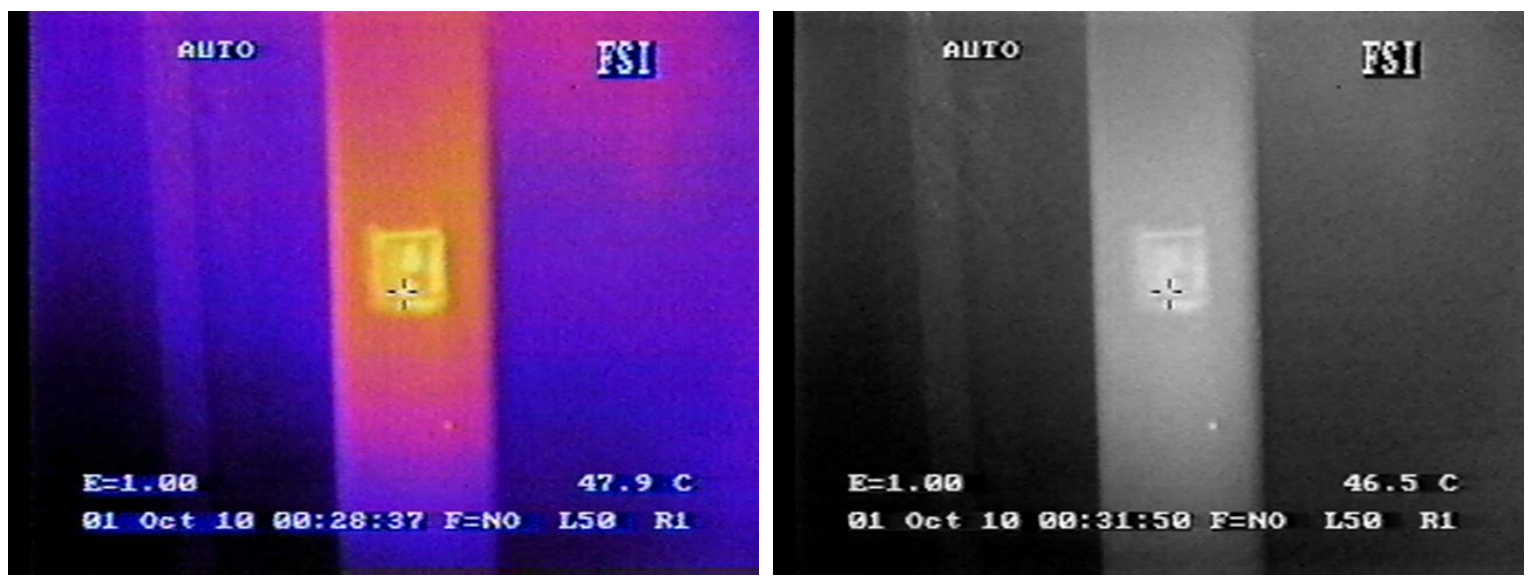

Figure 4.6.3. Specimen - Box2. (a) Color infrared image. (b) Gray scale infrared image. 


\subsubsection{Specimen - Box3}

The infrared images clearly show the delamination of size 3 "x3" in the specimen (Figures 4.6.4.a and 4.6.4.b).
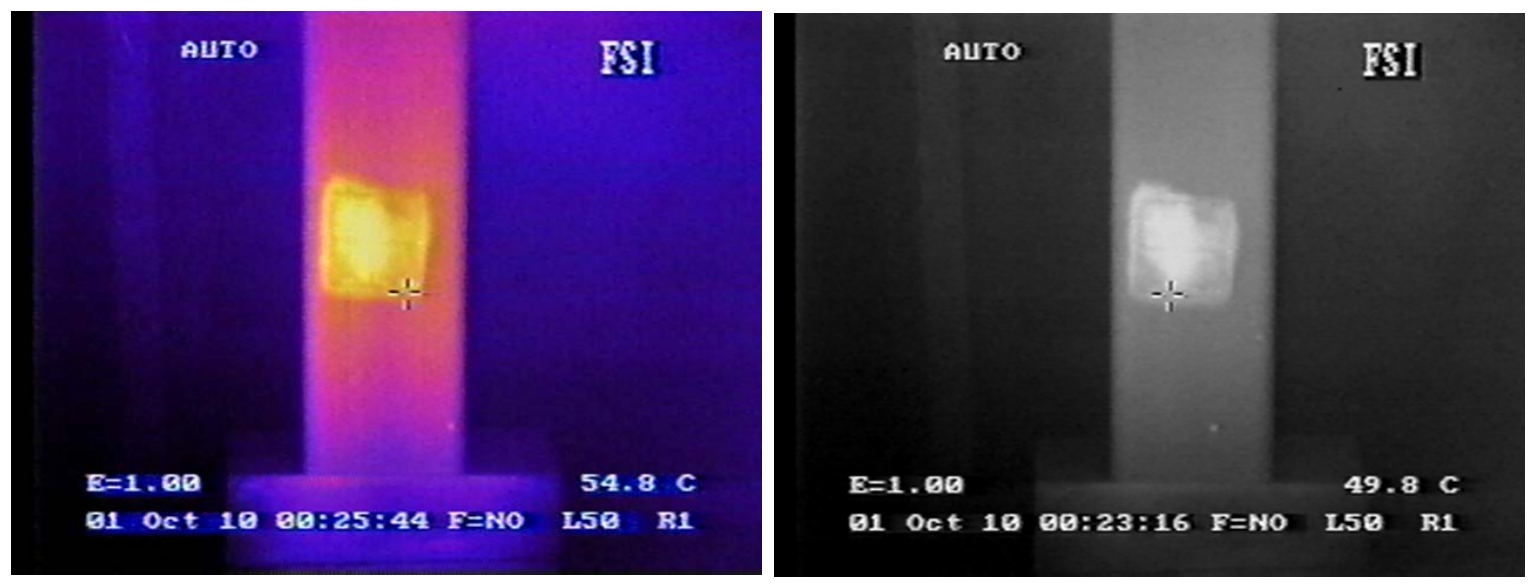

Figure 4.6.4. Specimen - Box3. (a) Color infrared image. (b) Gray scale infrared image.

\subsubsection{Specimen - Box4}

Though the specimen Box4 was painted and the delaminations were not visible from a distance, they could be located easily with infrared thermography. Figures 4.6.5.a and 4.6.5.b show the thermal infrared images of the specimen. Both the 2"x2" and 3"x3" delaminations are clearly visible.
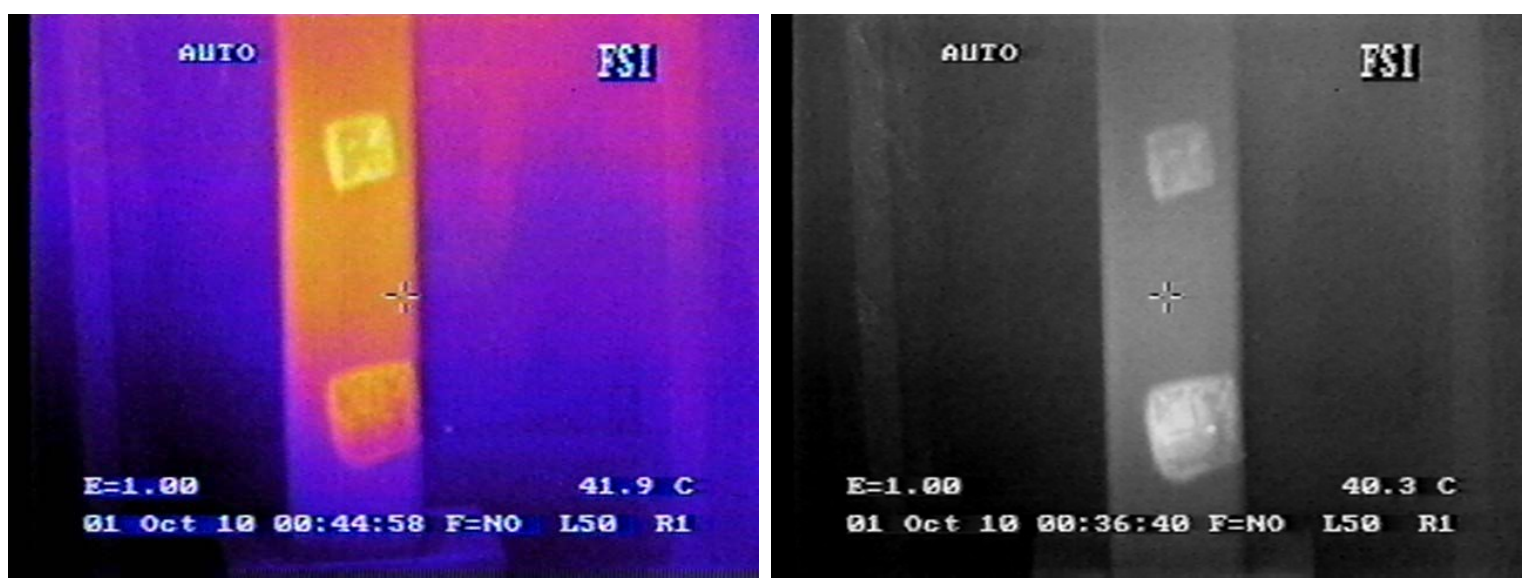

Figure 4.6.5. Specimen - Box4. (a) Color infrared image. (b) Gray scale infrared image. 


\subsubsection{Bridge Deck Specimens}

\subsubsection{Specimen - BD1}

Figure 4.6.6 shows the oblique and the front views of the bridge deck specimen BD1 tested in the laboratory. Figures 4.6.7.a and 4.6.7.b show the color and gray scale thermal images of the specimen, respectively. Though the images show some differential temperature zones, the shapes of the patches are different from what is expected and they can not be categorically judged as delaminations. It can be concluded that $1 / 16$ " thick delaminations at a depth of 5/16" from the surface in a GFRP deck are not distinctly visible using the current infrared thermography technique.
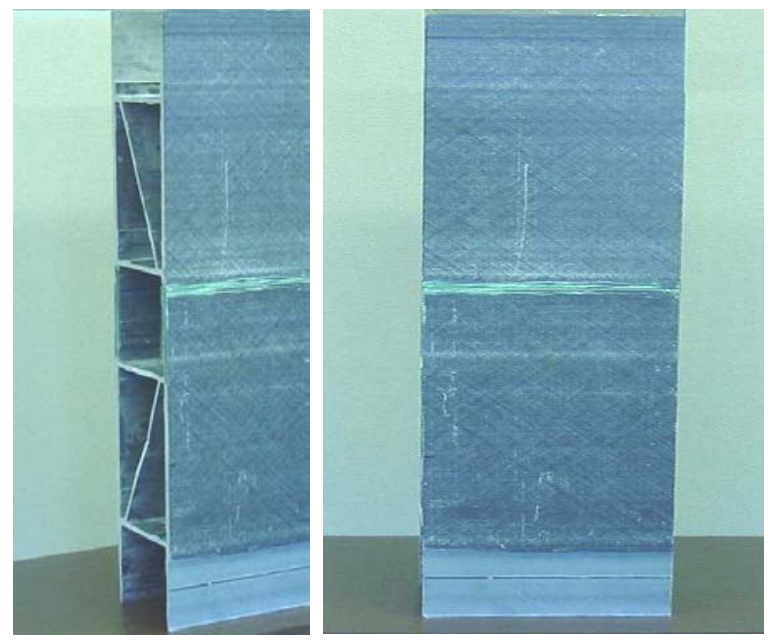

Figure 4.6.6. Oblique and the front views of the bridge deck specimen - BD1.
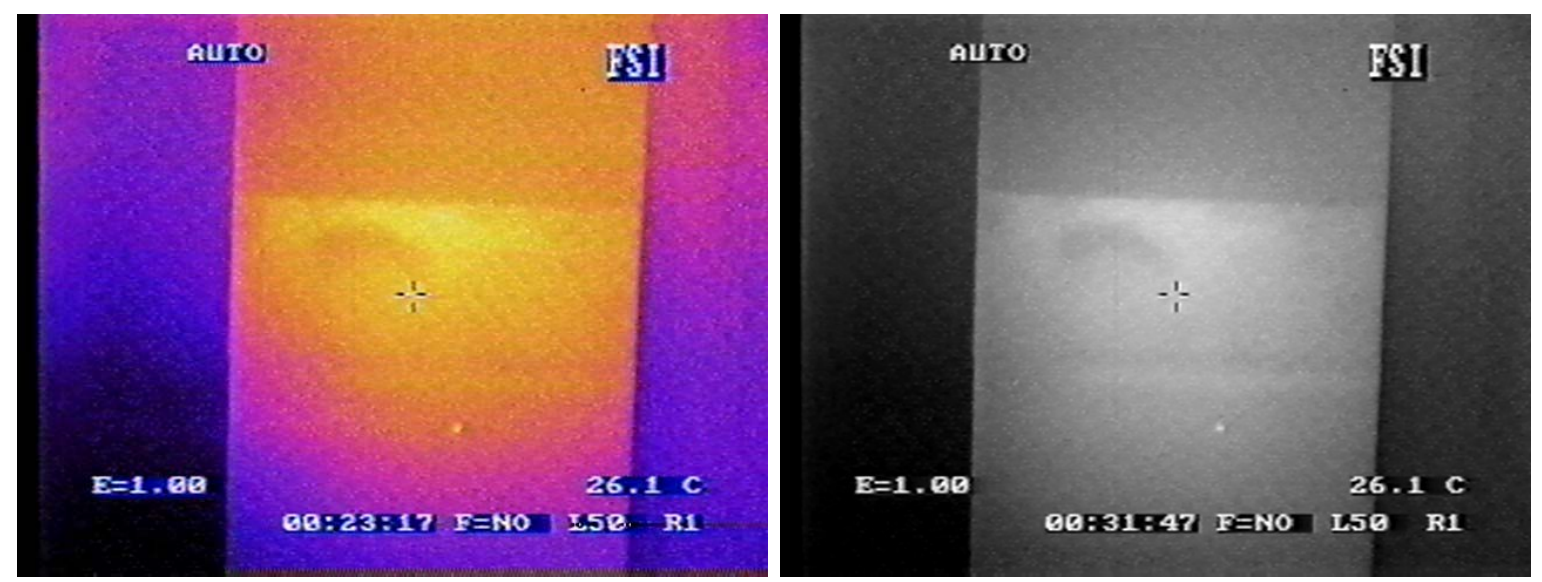

Figure 4.6.7. Bridge deck specimen - BD1. (a) Color infrared image. (b) Gray scale infrared image. 


\subsubsection{Specimen - BD2}

The photographic view of the bridge deck specimen BD2 is shown in Figure 4.6.8. The delaminations in this specimen are of 3"x3" and 2"x2" dimensions (with 1/16" thickness) and are present in between the $3 / 8^{\prime \prime}$ thick wearing surface and the deck surface. It is impossible to locate the presence of the delaminations by visual observation. However, by tapping the surface it is possible to locate the presence of delamination to some extent. Infrared thermography was very successful in predicting the locations as well as the shapes and relative sizes of the two delaminations as can be seen from the color and gray scale infrared images from this specimen (Figures 4.6.9.a and 4.6.9.b).
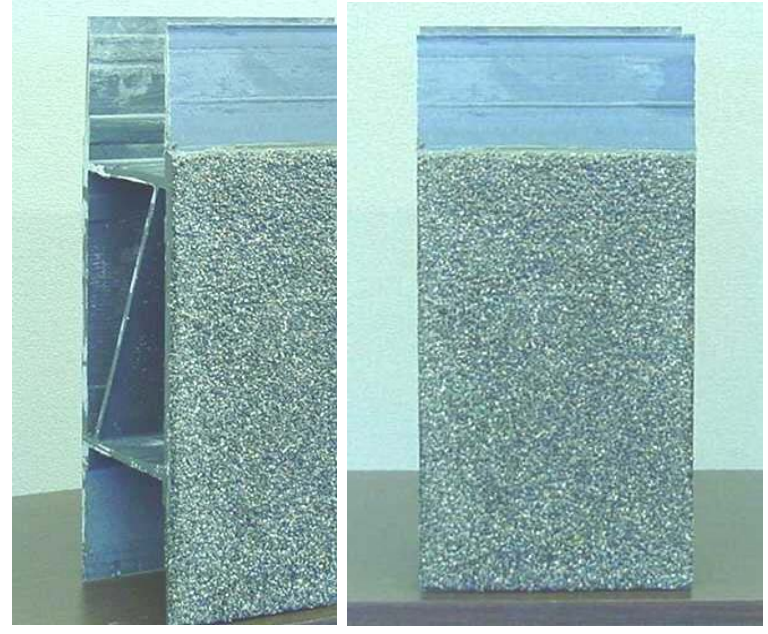

Figure 4.6.8. Oblique and the front views of the bridge deck specimen - BD2.
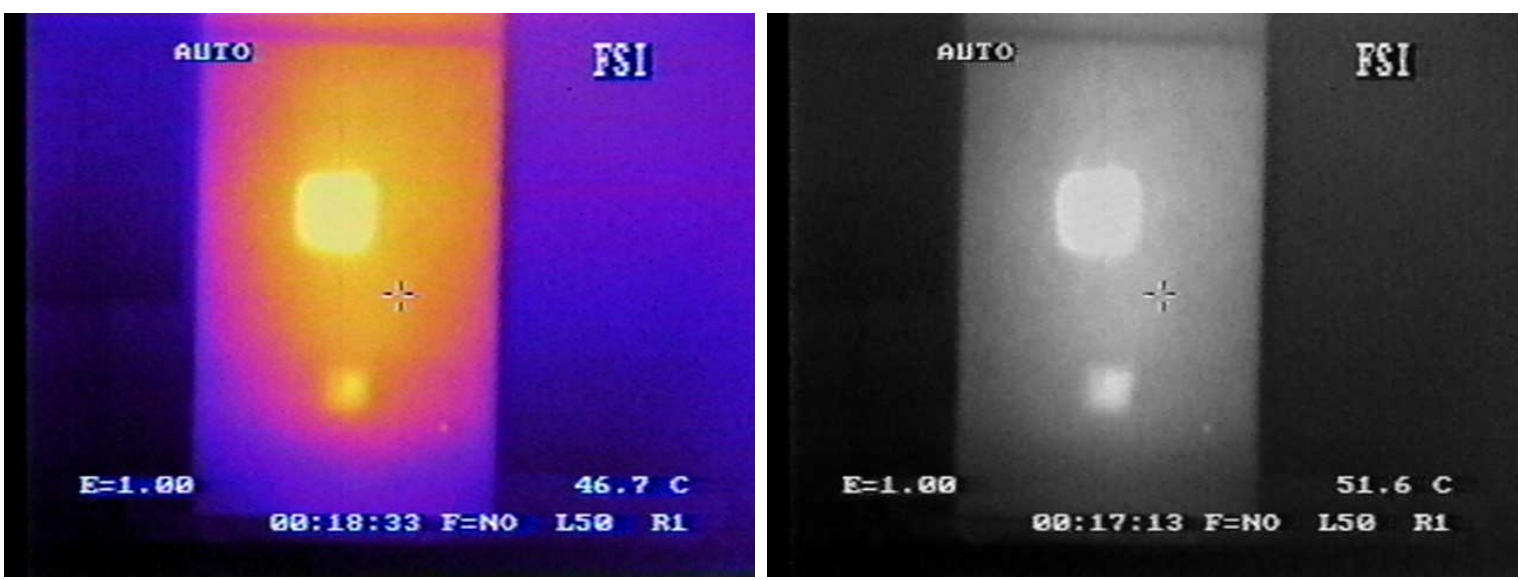

Figure 4.6.9. Bridge deck specimen - BD2. (a) Color infrared image. (b) Gray scale infrared image. 


\subsection{Conclusions}

Based on the wide range of tests conducted in the laboratory, it can be concluded that infrared thermography can be used as an effective tool for detecting subsurface delaminations in members built with FRP materials.

The delaminations in the box sections were easily located. This may be due to the delamination being very close to the surface. Even though the specimen Box 4 was covered with a thick coating of paint that made the delaminations invisible to the naked eye, they could be detected very easily using infrared thermography.

The delaminations present between the flanges of two adjacent sections in the bridge deck specimen BD1 could not be located with the current infrared technique. However, in specimen BD2, the delaminations between the wearing surface and the bridge deck surface could be easily detected. This is because of higher thermal conductivity of the wearing surface material (thermal conductivity of gravels $\approx 1 \mathrm{~W} / \mathrm{m} / \mathrm{C}$ ) compared to the composite deck (thermal conductivity $\approx 0.3$ to $0.38 \mathrm{~W} / \mathrm{m} / \mathrm{C}$ ), as indicated in Table 2.1 . 


\section{CHAPTER 5}

\section{FIELD TESTS}

\subsection{Introduction}

This chapter presents the field tests conducted on the wrapped columns of the Pond Creek bridge. The columns of this bridge are made of reinforced cement concrete (RC). The columns on the south side of the bridge were rehabilitated with FRP wraps in October 1997. These wraps are being monitored periodically for the development of any subsurface delaminations or voids that may adversely affect the structure.

\subsection{Description of the Bridge and Background}

The Pond Creek bridge is located on Interstate Highway I-77 to the south of Parkersburg, (West Virginia) at 158.4 milestone (Figure 5.2.1). The bridge deck is of composite construction, with RC slab on steel stringers. The decking system is supported on the RC columns. The columns are about 30 " in diameter. The six columns on the south side of the bridge are wrapped with the adhesively bonded glass fiber reinforced plastic material. Three of the columns were wrapped by hand lay-up method and the remaining three using pre-cured shells (Figure 5.2.2).

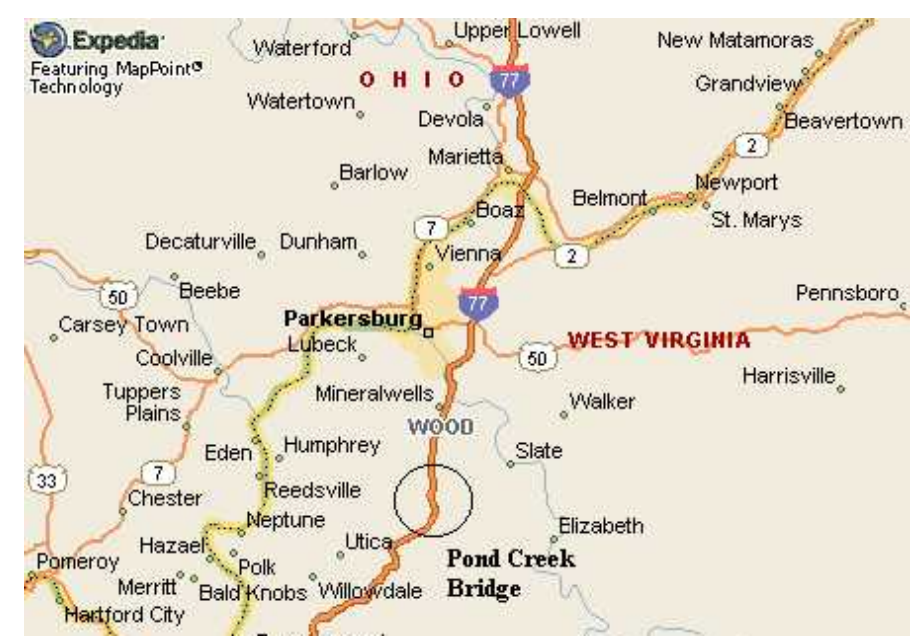

Figure 5.2.1. Map showing the location of Pond Creek bridge. 


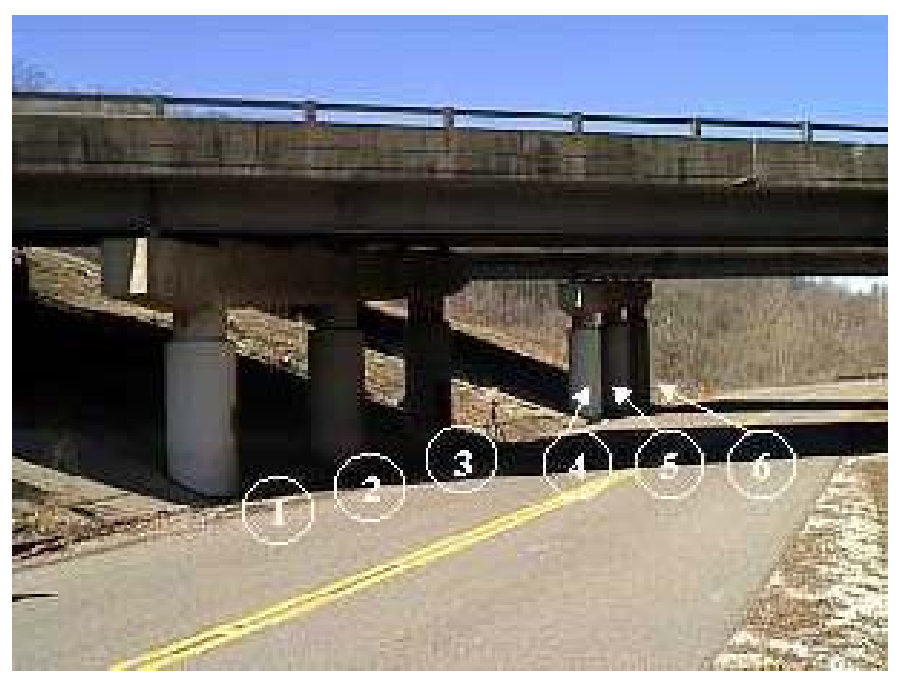

Figure 5.2.2. Photographic view of the Pond Creek bridge. The columns marked 1, 2 and 3 are wrapped by hand lay-up method and those marked 4,5 and 6 are wrapped with pre-cured shells.

In hand lay-up method, the composite fabric dipped in resin is manually placed on the structure and is then allowed to cure (Johnson et al. 1999). The dry fabric, which is available in wide rolls, is cut to suitable lengths and is then saturated by dipping in liquid resin bath typically located at the bottom of the structure. The fiber material used was hybrid of E-glass and polyaramid called SHE-51 (Knytex). Alternatively, an all E-glass fabric could also have been used. The fiber reinforcement was mainly placed around the column in the hoop direction. The resin material was a two part epoxy called Tyfo S. The fiber-resin ratio was approximately $0.81 \mathrm{~b}$ of epoxy to $11 \mathrm{~b}$ of fiber. After surface preparation, the resin is applied on the column surface (Figure 5.2.3). The tacky and possibly dripping fabric is then spread on the structure manually and any trapped air is squeezed out. In another variation, a layer of resin is coated on the surface. The fabric which comes in rolls with paper backing, is placed on the resin coat with the paper facing outside and the surface is smoothened. The paper is removed and another coating of resin is applied and the wrap is allowed to cure. This is done so as to wet the fabric fully from both sides. 


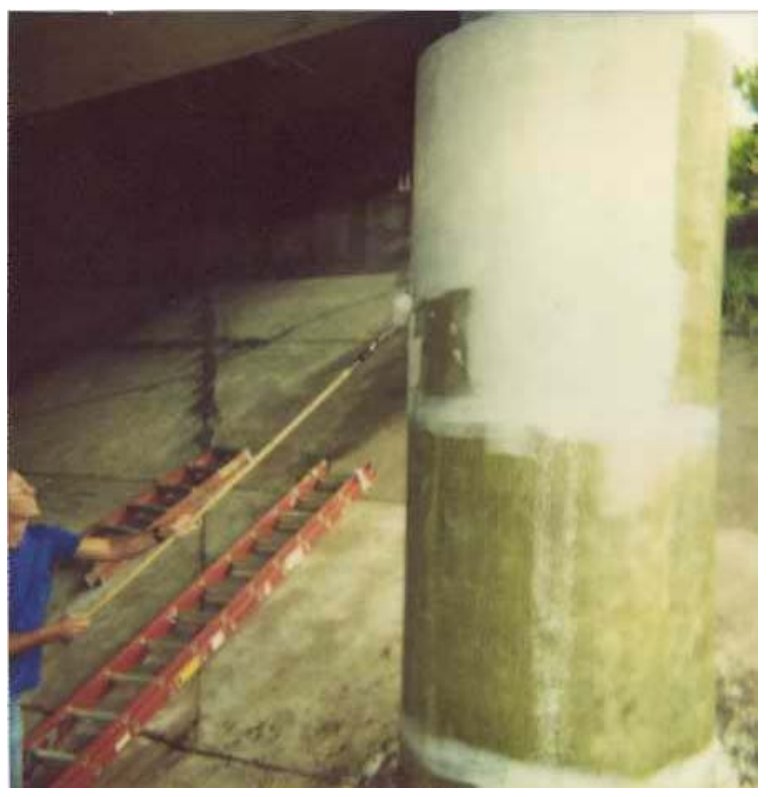

Figure 5.2.3. Resin is being applied on the column.

In fiber composite prefabricated jacket system, the shells were prefabricated using high strength fabric encapsulated in corrosion resistant matrix. Multi-axial non-woven Eglass fabric was used. The fiber direction is predominantly in the hoop direction. The resin material of the jacket was isophthalic polyester. The fabric is saturated with resin and molded to the shape and size of the column to which it needs to be wrapped and cured to form a shell. The shells are split longitudinally and are trucked to the job site. The columns are cleaned, prepared and sprayed with adhesive. The shells are opened along the slit (manually or by using supports) and positioned around the column and released. The shell snaps onto the column. Additional shells are applied one over the other until the required thickness is achieved. A uniform layer of urethane adhesive was applied to bond the adjacent sleeves. Figure 5.2.4 shows the pre-cured shells in the job site ready for application. 


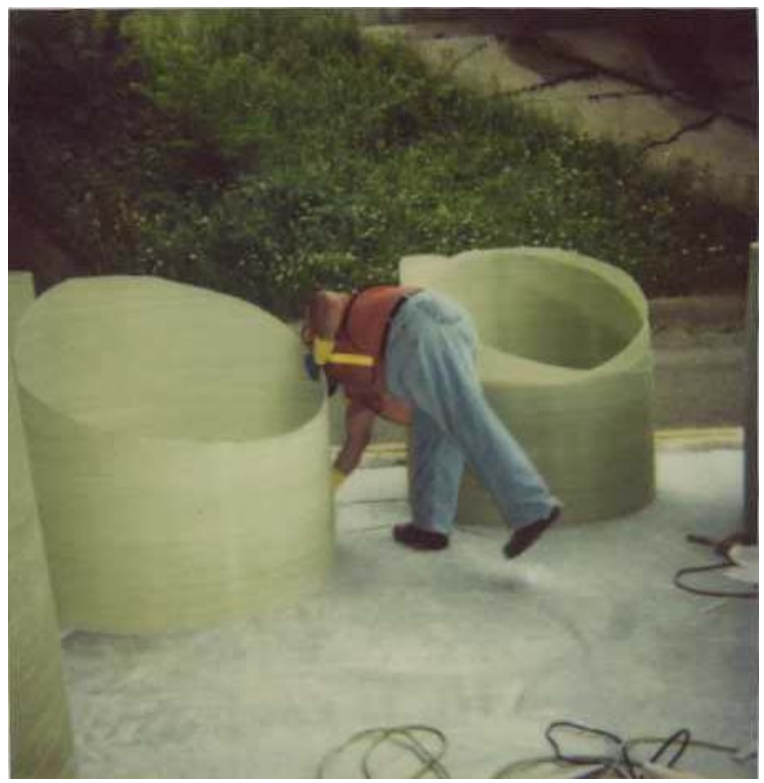

Figure 5.2.4. The pre-cured shells are ready for application.

\subsection{Infrared thermography}

The infrared camera used for testing was same as the one used in the laboratory testing -FLIR's FSI Prism SP (Single Point) which can detect the radiation in the medium wavelength ( 3 to $5 \mu$ ) spectral-range. The heating source used was 1500-Watt capacity quartz tower heater, operated by a portable generator. Heating was done for a period of 20 seconds by keeping the heater at a distance of 4 inches from the surface. Since the columns were not exposed to the sun at the time of recording the thermal images, it could not be utilized as a heat source. The infrared images were continuously recorded on videotape. Later in the laboratory, the still images were captured on to a personal computer (from the videotape) for analysis.

\section{$5.4 \quad$ Observations and Results}

By visual inspection of the columns it could be noticed that the wraps are performing well in the field. There were no visible patches or discoloration on the surface indicating the 
absence of any moisture ingression. The columns were also tested by tapping them with a rod and the locations having delaminations were marked by a chalk and spray paint.

Figures 5.4.1.a and 5.4.1.b show the photographic view and the corresponding thermal image of one of the locations on column 3 respectively. The thermal image shows a bright spot clearly indicating a temperature differential on the surface. This location was also tested by tapping with a rod and the presence of delamination was confirmed.

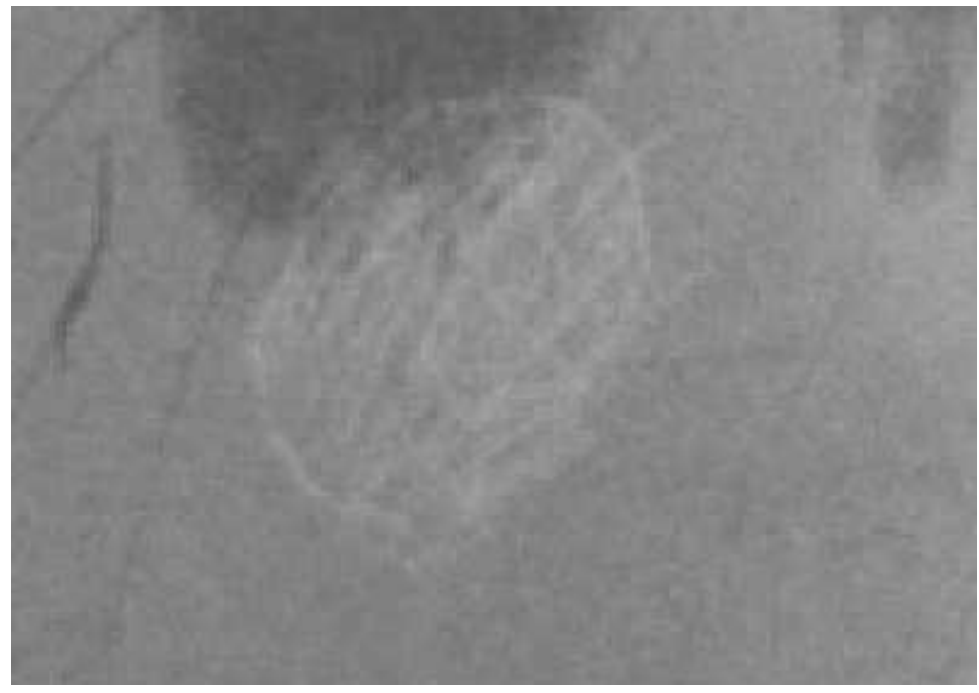

Figure 5.4.1.a. Photographic view of one of the locations on column 3.

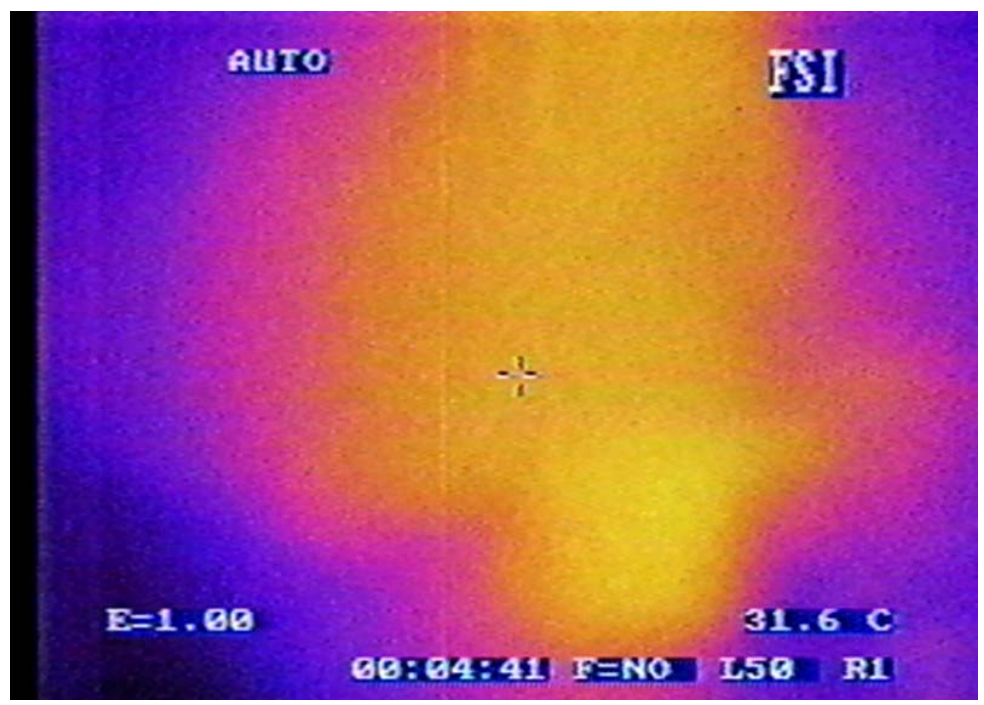

Figure 5.4.1.b. Thermal image showing a bright spot indicating the presence of delamination. 
Similarly Figures 5.4.2.a and 5.4.2.b show the photographic view and the corresponding thermal image of another location near one of the seams (where two sheets are joined together). The thermal image shows a bright spot clearly indicating a temperature differential on the surface. However, the tap testing of this location did not indicate the presence of any delamination. The bright spots are possibly because of the presence of extra resin in that region. The dry resin patch, which has a different thermal conductivity than the overall wrap, shows up as a bright spot.

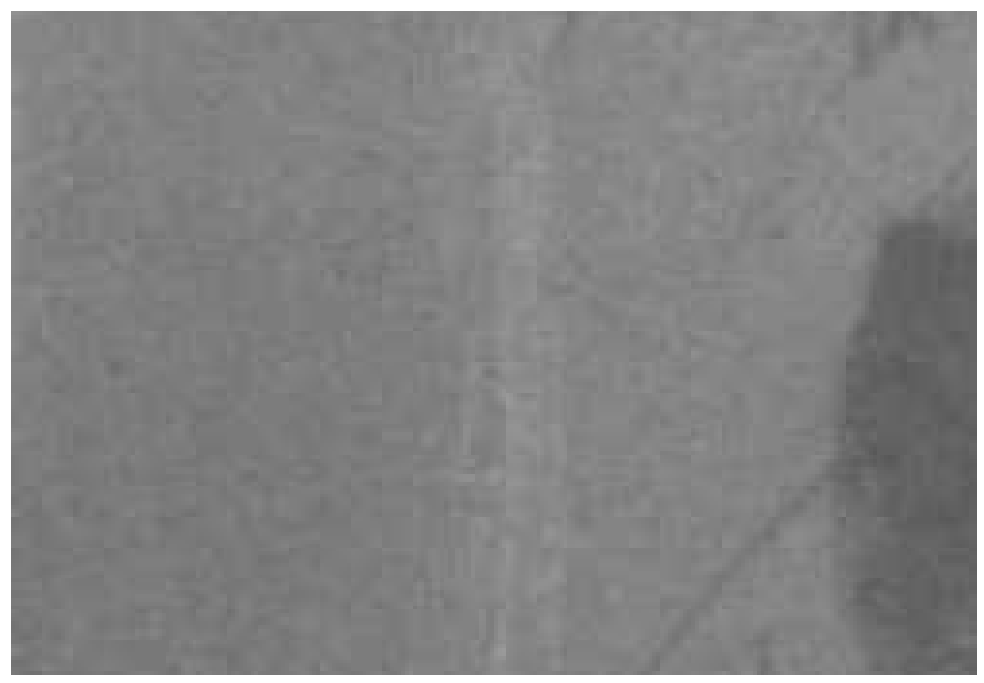

Figure 5.4.2.a. Photographic view of a seam on column 3.

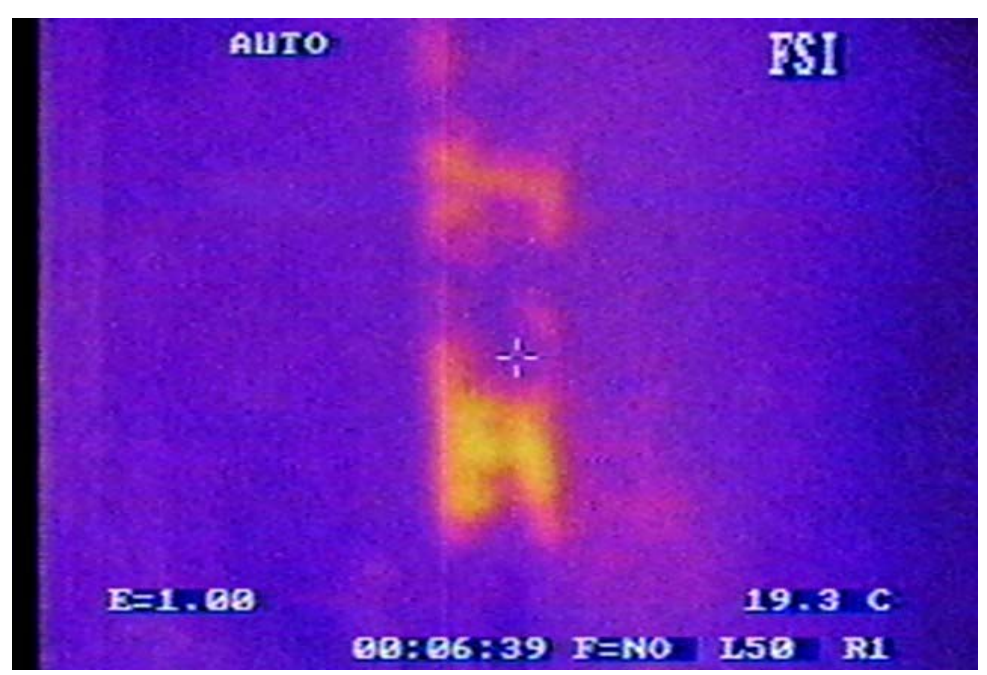

Figure 5.4.2.b. Thermal image of the seam showing bright spots. 
Figure 5.4.3 shows the photographic view of the three columns (4, 5 and 6) wrapped with pre-cured shells. These columns were tap tested and the delaminations that were detected were marked with spray paint.

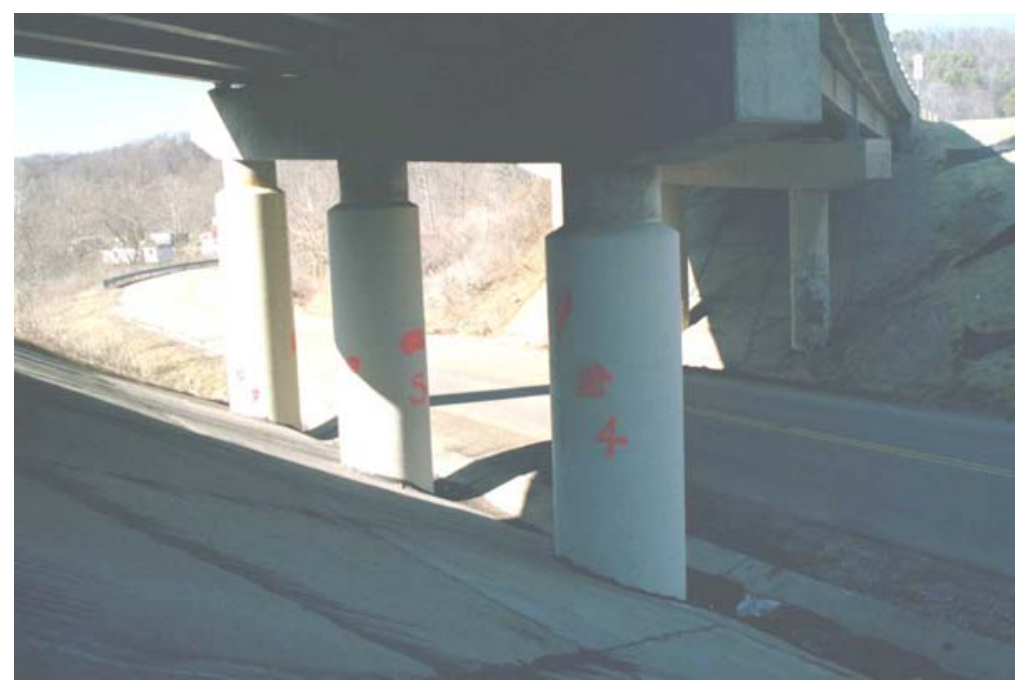

Figure 5.4.3. Delaminations found by tap testing of three pre-cured shell wrapped columns.

\subsection{Conclusions}

From the field tests it could be concluded that the composite wraps on the columns are serving the intended purpose well. There were no damp spots or discoloration anywhere on the surface of the wraps. However a few delaminations were detected at some locations by infrared thermography and by tap testing using a rod. The delaminations could be identified at many locations on the columns wrapped with pre-cured shells and only at one location on the columns wrapped with hand lay-up method. Special care has to be exercised while analyzing the thermal images in the vicinity of the seams because they can be easily mistaken for delaminations. 


\section{CHAPTER 6}

\section{CONCLUSIONS AND RECOMMENDATIONS}

\subsection{Conclusions}

\section{Literature review:}

As per the literature review in Chapter 3, the following observations were made:

- In the laboratory tests conducted on the FRP bridge deck specimens (Sec. 3.1.1), the presence of an extraneous material (duct tape) between the wearing surface and the bridge deck surface could not be detected using infrared thermography. A probable reason for this could be the absence of notable differences in the thermal properties of the materials (duct tape, wearing surface and the FRP deck). A delamination of 0.05 " thick under a wearing surface of $3 / 8$ " thick is detectable by infrared thermography. From the field tests conducted on two FRP bridge decks (Sec. 3.1.2), it was concluded that while there were many locations in the deck with thermal contrasts, such contrasts could also result from surface anomalies, shadows and oil spills. Hence, care must be exercised while interpreting the results.

- The delaminations underneath the composite wraps used for the seismic retrofitting of bridge columns (Sec. 3.2) were successfully detected using infrared thermography. The main advantage of this technique is that large areas can be inspected in a short time.

- The presence of defects can be identified and defect signature can be defined without human intervention (Sec. 3.3) by using parameters such as lateral heat flow, non-uniform temperature distribution and characteristics of onset time (Sec. 3.3.4).

- It is possible to determine the defect depth from the surface of the structure using its thermal response (contrast of the thermal image) and data inversion procedure (using a 
polynomial equation). This was demonstrated for a thick, composite aircraft component (Sec 3.4).

- It is possible to enhance the resolution of the thermographic images by using FFT and inverse-filter, and other image enhancement techniques (Sec. 3.5).

- The presence of moisture in the disbond may cause the size of the disbond to be underestimated (Sec. 3.6).

\section{Laboratory experiments:}

After conducting infrared thermography tests in the laboratory on four FRP box specimens and two FRP bridge deck specimens, the following conclusions were drawn.

- In the box-section specimens, the subsurface delaminations were clearly visible in the thermal images (Sec. 4.6.1). This is probably due to the presence of delamination very close to the surface. The presence of a thick coating of paint on specimen Box 4 made the delaminations invisible to the naked eye, though it could be easily detected using infrared thermography (Sec. 4.6.1.4).

- The delamination of $1 / 16$ " thickness inserted at the flange-to-flange junction in between two bridge deck modules (specimen BD1), at a depth of about 5/16" from the surface, was not detectable using the current infrared thermography technique (Sec. 4.6.2.1).

- The delaminations of $1 / 16$ " thickness between the $3 / 8$ " thick wearing surface and the bridge deck surface were easily detectable using infrared thermography (Sec. 4.6.2.2). This is because of higher thermal conductivity of the wearing surface material (thermal conductivity of gravels $\approx 1 \mathrm{~W} / \mathrm{m} / \mathrm{C}$ ) compared to the composite deck (thermal conductivity $\approx 0.3$ to $0.38 \mathrm{~W} / \mathrm{m} / \mathrm{C}$ ), as indicated in Table 2.1 . 


\section{Field evaluation:}

The following conclusions were drawn after conducting field investigation of FRP wrapped reinforced concrete columns in a bridge.

- Infrared thermography can be successfully employed in the field for determining the location of debonds between the wrap and the concrete surface.

- Care must be exercised while examining the thermal images near the seams (where the wraps meet) as they can be mistaken for debonds. Since near the seams usually there is extra resin, which have different thermal properties compared to those of the wrap, the surface temperature differentials are created. Hence it is better to confirm the presence of debonds by tapping the location.

- The columns wrapped with precured shells have debonds at more locations than the columns wrapped with hand lay-up method. This is because the precured shells are cast in the factory to a particular shape and size, and the minor irregularities on the column surface result in trapping of voids (delaminations) between the column surface and the precured shells.

- The infrared images can be used to estimate the spatial extent of the subsurface defects (e.g., air voids or delaminations), which is an important parameter in making rehabilitation decisions as per ACI 440F (2000). For example, Section 6.2.3 of ACI 440F states that delaminations less than $2 \mathrm{in}^{2}\left(1300 \mathrm{~mm}^{2}\right)$ are permissible as long as the delaminated area is less than $5 \%$ of the total laminate area and there are no more than 10 such delaminations per $10 \mathrm{ft}^{2}\left(1 \mathrm{~m}^{2}\right)$. On the other hand, larger delaminations need to be repaired in accordance with Section 6.2.3 of ACI 440F (2000). 


\subsection{Advantages and Disadvantages of Using Infrared Thermography}

Following are the advantages of using infrared thermography:

- The technique is fast. It is possible to inspect large areas in a short period.

- The interpretation of results is easy - that is, not much calculations and post processing of the acquired data is required. However, care must be exercised while interpreting the infrared images as the thermal gradients due to shadows, oil spills, etc. can be mistaken for defects. The thermographer needs to consider these factors.

- It is relatively easy to set up the apparatus and record the data. Thus, infrared thermography is well suited for field testing.

- The cost of infrared cameras is reducing over time resulting in reduced overall testing expenses. With the increased use of infrared thermography in various applications, the prices of the cameras are coming down. Also, the new models of infrared cameras provide better features such as recording of complete digital images, better gain and temperature range controls, and improved image processing software.

The following are the disadvantages of using infrared thermography:

- Thermal images can be easily misread. The interpreter of the results must be fully aware of the field conditions during the recording of the thermal images.

- Passive thermography, where the ambient temperature of the structures is utilized for thermal imaging, is not always possible. Therefore, external heating source is often required to heat the specimen (active thermography) before the surface temperature differentials are recorded.

- Non-uniform heating of the surface from an external source may result in erroneous interpretation of the results. 


\subsection{Recommendations for Future Research}

As can be inferred from the above sections, infrared thermography has a great potential for use as an effective NDT\&E technique for the assessment of structures built with FRP materials. However, the technique can be further improved to enhance its effectiveness. Some areas where the improvements can be made are:

- Use of a better heating source. The main problem of active thermography is non-uniform heating of the surface. Uneven heating leads to differential temperature zones on the surface, which can be mistaken for defects. The use of a heating blanket can provide uniform heating of the surface. Also, with a good insulation on the blanket, the heat loss can be minimized and the required heating can be achieved at a faster rate.

- Use of a digital infrared camera. Such cameras can be connected directly to a personal computer for acquiring digital images with the corresponding temperature values of each pixel in the image. This data can be used in conjunction with 2D FFT - inverse FFT routines for spatial filtering or instrumental noise resulting from the internal components of the camera or from non-uniform heating of the specimen. Also, subtraction of a uniform temperature field from a sequence of digitally acquired images can enhance the contrast due to defects, and plots of the contrast versus time can be used to conduct quantitative analysis to predict the depth and spatial extent of the subsurface defect(s). The accuracy and reliability of the quantitative analysis can be further enhanced by using more robust definitions for the contrast parameter (Sec. 3.4.4).

- Use of a camera operable in dual band (3-5 $\mu$ and 8-14 $\mu$ ranges), which can help in reducing negative environmental effects. 
- Use infrared thermography in conjunction with other techniques such as fiber optics and ground penetrating radar to improve the likelihood of detecting subsurface defects. The conclusions drawn from one technique serves as a confirmation of the results from the other. Also, different NDT techniques are affected in different ways by environmental parameters (e.g., moisture), hence use of multiple NDT techniques can greatly enhance the accuracy and reliability of field evaluation.

- Conduct additional laboratory experiments to investigate the effect of oil spills and other surface irregularities on the infrared images and to differentiate the effect of these features from those due to subsurface defects.

- The actual infrared thermography test results can be compared with those from analytical methods such as finite element modeling, which can lead to quantitative prediction of the size and depth of the detected delaminations. The finite element modeling can also be a useful tool in establishing the minimum detectable defect sizes under a given set of conditions (e.g., temperature and duration of the applied heat source). 


\section{REFERENCES}

ACI 440F (2000). Guide for the Design and Construction of Externally Bonded FRP Systems for Strengthening Concrete Structures, American Concrete Institute, Farmington Hills, MI, May 24, (Revised Draft).

Almond, Hamzah, Delpesh, Wen, Behesty and Saintey (1996). "Experimental investigations of defect sizing by transient thermography." Proc. Eurotherm Seminar \#50 on Quantitative IR thermography QIRT'96, Sept. 2-5, Stuttgart, Germany, p. 233-238.

Alqennah, H. (2000). "Detection of subsurface anomalies in composite bridge decks using infrared thermography." MS Thesis, Department of Civil and Environmental Engineering, West Virginia University, Morgantown, West Virginia.

Bedford Reinforced Plastics, Inc., PA (2002). http://www.bedfordplastics.com/.

Favro, L. D., Xiaoyan, H., Kuo, P. K., and Thomas, R. L. (1996). Proc. SPIE Thermosense XVIII, Vol. 2766, D.D. Burleigh, J. W. M. Spicer eds., SPIE, Bellingham, p. 236.

FSI FLIR SYSTEMS (1994). Prism Single Point INFRARED CAMERA OPERATOR'S MANUAL, Revision 0, Release Date: May 5.

Gonzalez, R., and Wood, R. (1992). Digital Image Processing, Addison Wesley, p. 261-289.

Halabe, U. B., and Maser, K. R. (1986). "Thermal modelling of a leaky roof." MIT CCRETechnical Note 86-4, Center for Construction Research and Education, Department of Civil and Environmental Engineering, Massachusetts Institute of Technology, Cambridge, MA.

Han, Favro, Ahmed, Wang, and Thomas (1998). Review of Progress in Quantitative NDE, Vol. 18A, Snowbird, UT, July, p. 593-596. 
Johnson, E. C., Nokes, J. P., and Hawkins, G. F. (1999). "NDE of composite seismic retrofits to bridges." Nondestructive Characterization of Materials IX, AIP conference proceedings 497, Sydney, Australia, p. 367-372.

Kaplan, H. (1999). Practical Applications of Infrared Thermal Sensors and Imaging Equipment, SPIE -The International Society for Optical Engineering, Bellingham, Washington, USA.

Karpez, J.-C., Balages, D., Doem, A., and Lepoutre, F. (1994). Advances in Signal Processing for NDE of Materials, X. Maldague ed., NATO ASI Series, Series E, p. 303.

Kreith, F., and Bohn, M. S. (1993). Principles of Heat Transfer, $5^{\text {th }}$ Edition, International Thomson Publishing / PWS Publishing Company, Boston, MA, p. 558-560.

Lhota, J. R., Shepard, S. M., Bruce, A., Rubaduex, and Ahmed, T. (2000). "Enhanced spatial and depth resolution of pulsed thermographic images." Review of Progress in Quantitative Nondestructive Evaluation, Volume 20A, AIP Conference Proceedings 557, Amens, Iowa, p. 492-498.

Maldague, X. (1993). Nondestructive Evaluation of Materials by Infrared Thermography, Springer-Verlag, London.

Maldague, X., and Marinetti S. (1996). "Pulse phase infrared thermography." Journal of Applied Physics, 79[5], March 1, p. 2694-2698 (paper available at http://www.ndt.net/v06n04.htm and http://www.gel.ulaval.ca/ maldagx/malda_pu.html). 
Maldague, X. (2000). "Applications of infrared thermography in nondestructive evaluation." Trends in Optical Nondestructive Testing (invited chapter), Pramod Rastogi ed., p. 591- 609. (paper also available at http://www.ndt.net/v06n04.htm).

Malloy, J.F. (1969). Thermal Insulation. Reinhold Book Corporation, New York, NY.

Miceli, M., Horne, M. R., and Duke, J. C. (2001). "Health monitoring of FRP bridge decks." Advanced Nondestructive Evaluation for Structural and Biological Health Monitoring, Proc. SPIE - Volume 4335, Tribikram Kundu ed., March, p. 100-105.

National Bridge Inventory (2002). www.nationalbridgeinventory.com.

Neville, A.M. (1973). Properties of Concrete. John Wiley \& Sons, Inc., New York, NY.

Plotnikov, Y.A., and Winfree, W.P. (1999). "Visualization of subsurface defects in composites using a focal plane infrared camera." Proc. SPIE Thermosense XXI, Vol. 3700, D.H. LeMieux, J. R. Snell eds., SPIE, Bellingham, April, p. 26-31.

Plotnikov, Y.A., and Winfree, W.P. (1999). "Temporal treatment of thermal response for defect depth estimation." Review of Progress in Quantitative Nondestructive Evaluation, Volume 19A, AIP Conference Proceedings 509, Montréal, Canada, p. 587-594.

Reynolds, W.N., and Wells, G.M. (1984). Video-compatible thermography. British Journal of NDT, January, p. 40-44.

Ringermacher, Pandey and Howard (1998). "Thermal depth resolution exceeding conventional IR imaging limits." presented at Twenty-Fifth Annual Review of Progress in QNDE, Snowbird, Utah, July 19-24. 
Shepard, S. M., Rubadeux, B. A., and Ahmed, T. (1999). "Automated thermographic defect recognition and measurement." Nondestructive Characterization of Materials $I X$, AIP Conference Proceedings 497, Sydney, Australia, p. 373-378.

Shepard, S.M., Ahmed, T., and Chaudhry, B.C. (1998). Review of Progress in Quantitative Nondestructive Evaluation, Volume 18, AIP Conference Proceedings XXX, Plenum, New York, p. 605.

Threlkeld, J.L. (1970). Thermal Environmental Engineering. Second edition, Prentice-Hall, Inc., Englewood Cliffs, New Jersey, NJ.

Touloukian, Y. S., and DeWitt, D. P. (1970). Thermal Radiative Properties. Thermophysical Properties of Matter, vol. 7, IFI/Plenum, New York, Washington.

Tretout, H. (1987). “Applications industrielle de la thermographie infrarouge au controle non destructif de pieces en materiaux composites." Rev. Gen. Therm. Fr., vol. 301, p. 4753 (in French).

Vavilov (1980). "Infra-red non-destructive testing of bonded structures: aspects of theory and practice.” British Journal of NDT, July, p. 175-183.

Vavilov (1994). "Infrared techniques for material analysis and nondestructive testing." Infrared Methodology and Technology, Monograph Series International Advances in NDT, X. Maldague ed., Gordon and Breach, U.S.A., p. 230-309.

Vavilov, V. P. (1996). Proc. SPIE Thermosense XVIII, vol. 2766, D.D. Burleigh and J.W.M. Spacier eds., SPIE, Bellingham, p. 276.

Vanzetti, R. (1972). Practical Applications of Infrared Techniques. John Wiley \& Sons, Inc., New York, NY. 